\title{
Les tuiles et les briques au Moyen Âge en Pays de la Loire : un état de la question
}

The current status of medieval tiles and bricks in the Pays de la Loire Die Ziegel und Backsteine des Mittelalters in der Region Pays de la Loire : Bemerkungen zum aktuellen Forschungsstand

Jean-François Nauleau

\section{(2) OpenEdition}

\section{Journals}

Édition électronique

URL : http://journals.openedition.org/rao/3510

DOI : $10.4000 /$ rao.3510

ISSN : $1775-3732$

Éditeur

Presses universitaires de Rennes

\section{Édition imprimée}

Date de publication : 31 décembre 2016

Pagination : $277-310$

ISBN : 978-2-7535-5683-6

ISSN : 0767-709X

\section{Référence électronique}

Jean-François Nauleau, « Les tuiles et les briques au Moyen Âge en Pays de la Loire : un état de la question», Revue archéologique de l'Ouest [En ligne], 33 | 2016, mis en ligne le 31 juillet 2019, consulté le 02 mars 2021. URL : http://journals.openedition.org/rao/3510; DOl : https://doi.org/10.4000/rao 3510

@ Presses universitaires de Rennes 


\title{
Les tuiles et les briques au Moyen Âge en Pays de la Loire : un état de la question

\author{
The Current Status of Medieval Tiles and Bricks \\ in the Pays de la Loire
}

\author{
Jean-François NAUlEaU ${ }^{a}$
}

\begin{abstract}
Résumé : Les matériaux de construction en terre cuite sont bien présents en Pays de la Loire durant le Moyen Âge et l'Époque moderne. Qu'il s'agisse de tuiles, de briques, de carreaux de sol ou d'autres éléments spécifiques, le recours à la terre cuite, surtout à partir des XII ${ }^{\mathrm{e}}$-XIII ${ }^{\mathrm{e}}$ siècles, est important.

Étudier ces matériaux permet de les identifier et de mieux comprendre leur place et la nature de leur mise en œuvre dans le bâtiment. Pour certains d'entre eux, une évolution morphologique autorise la réalisation d'une typo-chronologie, précieuse pour l'archéologue. Pour tous, l'étude sur le temps long révèle des temps de présence forte et d'autres de repli, qu'il est intéressant de décrypter et de comprendre.

Plus globalement, s'intéresser à tous les facteurs naturels, économiques, sociaux et culturels qui sont en jeu dans l'histoire de ces matériaux, permet de mieux comprendre la question du choix de la terre cuite dans l'économie du bâtiment en dépit de l'abondance régionale d'autres matériaux, tels que le granite, le tuffeau et l'ardoise.
\end{abstract}

\begin{abstract}
Terra cotta construction materials were used in the Pays de la Loire during the Middle Ages and the Modern period. Be it tiles, bricks, floor tiles or other more specific elements, the use of terra cotta is widespread especially from the $12^{\text {th }}-13^{\text {th }}$ century onwards.

The study of these materials leads to their identification and a greater understanding of their use in building. For certain types, the morphological evolution can form the basis of a chrono-typology which is an important tool in archaeology. For all, their study over a long period of time reveals when one material is more favoured that others and vise-versa, which is interesting to decipher and to understand.

Overall, to be aware of natural, economic, social and cultural factors that all play a role in the history of these materials leads to a greater understanding of the choice to use terra cotta in construction despite the local abundance of other materials such as granite, tuffeau stone and slate.
\end{abstract}

Mots clés : Moyen Âge, matériaux de construction, architecture, tuile, brique, géologie, argile, climat.

Keywords: Middle Ages, construction materials, architecture, , tile, brick, geology, clay, climate.

Sans être une terre de brique à l'égal des Flandres ou du Midi toulousain, la région des Pays de la Loire est un territoire dans lequel ce matériau est bien présent. Pourtant la pierre à bâtir y est abondante et adaptée à de nombreux usages. La brique n'y est donc pas un matériau de substitution utilisé par défaut. Les tuiles, sous diverses formes, sont également bien présentes malgré la présence forte des gisements d'ardoise. Si les matériaux en terre cuite ont été utilisés, c'est donc bien par la volonté des commanditaires et des bâtisseurs.

Ces matériaux ont souffert d'un désintérêt auprès de la communauté archéologique, avec comme présupposé qu'ils n'étaient pas porteurs d'informations susceptibles d'intéresser l'archéologue. Cependant, depuis une dizaine d'années,

a Archéologue Inrap - Centre archéologique de Carquefou, 4 rue du Tertre, 44470 CARQUEFOU. 
ces matériaux ont été réévalués et les études les concernant sont de plus en plus nombreuses ${ }^{1}$ (Chapelot et al., 2009 par exemple et Hunot, Guérin, 2007 pour la région)

Le travail présenté ici est le résultat d'une collecte de données recueillies ces dernières années dans le cadre de l'archéologie préventive sur des sites médiévaux et modernes. Le recensement exhaustif de l'ensemble des données disponibles dans la région n'a pas été possible; un tel travail aurait dépassé largement les moyens et le cadre de cette étude.

L'aire d'étude retenue n'a pas d'homogénéité historique et culturelle, puisqu'elle regroupe au Moyen Âge le comté du Maine, le duché d'Anjou et le Poitou. Elle ne correspond pas non plus à une entité géographique ou géologique déterminée. Mais elle regroupe précisément un ensemble de territoires variés dans lesquels se rencontrent des matériaux divers : tenter d'en comprendre les raisons sera un des objectifs de cette étude.

Traditionnellement, ces matériaux nommés terres cuites architecturales sont classés dans la rubrique " mobilier " au même titre que la céramique. Pourtant, ceux-ci sont à l'évidence intimement liés à des ensembles immobiliers : c'est pourquoi le terme de matériaux de construction en terre cuite semble plus approprié. Cette question n'est pas sans importance. Il est en effet nécessaire de comprendre leur cadre technique de mise en œuvre et de les restituer dans leur contexte architectural pour mieux les appréhender. C'est cette approche qui a été privilégiée ici.

L'éventail des matériaux rencontrés est assez large, même si, d'un point de vue quantitatif, en dehors des matériaux de couverture courants, des briques et des carreaux de sol, les autres types (briques décoratives, modillons, antéfixes, tuyaux de canalisation, etc.) sont plus anecdotiques.

Tous ces matériaux, bien qu'appartenant à des catégories diverses, ont une histoire commune : ils décroissent tous simultanément dès l'Antiquité tardive et réapparaissent ensemble dans la région pendant le second Moyen Âge; ils semblent donc intimement liés, ce qui justifie de les rassembler dans une même étude.

Globalement, au sein de cette longue période qu'est le Moyen Âge, deux ensembles typologiques se distinguent : un premier alto-médiéval, appartient encore à une tradition technique antique, tandis qu'un second qui se développe vers les $\mathrm{XII}^{\mathrm{e}}$-XIII ${ }^{\mathrm{e}}$ siècles peut être regardé comme résolument médiéval.

1. Depuis début 2014, un « réseau TCA », interinstitutionnel, rassemble les chercheurs travaillant autour de la question des matériaux en terre cuite depuis l'Antiquité jusqu’à nos jours (reseautca.hypotheses.org).

\section{LES TUILES}

\section{Toitures de tradition romaine : tegulae et imbrices}

La tegula, héritage de la culture technique grecque, est une tuile plate rectangulaire ou trapézoïdale munie d'un rebord sur ses grands côtés. Elle est pourvue d'encoches d'emboîtement en parties haute et basse qui permettent à la tuile aval de bloquer la tuile amont, tout en assurant un recouvrement nécessaire à l'étanchéité (fig. 1).

L'imbrex est une tuile identique aux tuiles canal telles que nous les connaissons actuellement. La différence de largeur entre parties amont et aval est moindre que sur les matériaux contemporains, mais la différence majeure concerne leur épaisseur qui atteint pour les imbrices romaines des valeurs très élevées, en moyenne une vingtaine de millimètres.

Les tegulae sont posées en files bord à bord, les imbrices assurant l'étanchéité entre les différentes files.

La pente des toitures «à la romaine " est comprise entre 17 et 23 degrés, soit entre 30 et $43 \%$ environ (Demandrille, Cambou, 2008, p. 4-5). Il est en effet impossible que ces tuiles supportent sans glissement une pente supérieure à 25 degrés, sauf avec système d'accroche. Or ces tuiles ne sont munies morphologiquement d'aucun système de ce type en face inférieure tandis que les perforations de fixation restent très rares.

Compte tenu de cette valeur de pente, la longueur du recouvrement constaté (entre 90 et $125 \mathrm{~mm}$ ) est faible et ne semble pas en mesure d'assurer une bonne étanchéité 2 . On peut donc raisonnablement se poser la question de l'adéquation réelle de ces couvertures aux climats atlantiques de la région d'étude. Elles conviennent davantage aux climats de la Provence et du Languedoc (Lebouteux, 2001, p. 147).

Le poids moyen constaté de ces toitures varie pendant la période romaine de 70 à $95 \mathrm{~kg} / \mathrm{m}^{2}$ dans la région (Nauleau, 2013a), les plus lourdes étant rencontrées à l'époque augustéenne, au moment de l'apparition de ce nouveau matériau. Leur poids décroît ensuite rapidement pour aboutir à une valeur plancher vers le milieu du II ${ }^{\mathrm{e}}$ siècle autour de $70 \mathrm{~kg} / \mathrm{m}^{2}$.

\section{Les données régionales pour le haut Moyen Âge}

L'utilisation de la tegula au cours du haut Moyen Âge est un sujet très peu documenté dans la région. Si ailleurs, en Languedoc, en Limousin, dans l'Orléanais ou dans le sud (Chapelot, 2004; Jesset, 2014), la production en contexte alto-médiéval est avérée, il n'en est rien en Pays de la Loire.

2. Pour des pentes inférieures à 25 degrés, l'usage de la tuile est de nos jours proscrit. Pour des pentes de 25 degrés, les recouvrements recommandés sont compris entre 140 et $170 \mathrm{~mm}$ suivant les types de climat. Les faibles pentes de ce type ne supportent pas la conjugaison de la pluie et du vent qui cause des problèmes d'infiltration. 


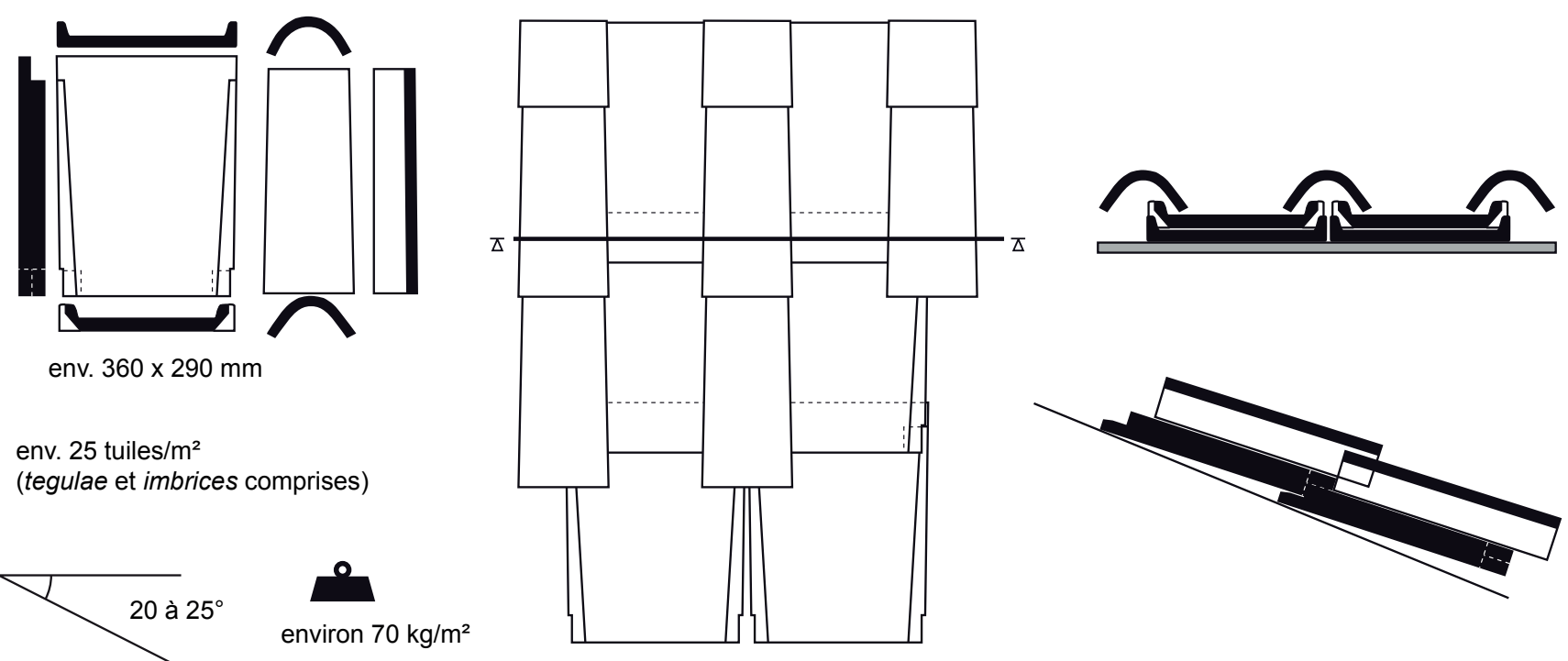

Figure 1 : Toiture "à la romaine » associant tegulae et imbrices : restitution et caractéristiques techniques (J.-F. Nauleau, Inrap). Figure 1: Roof "Roman style" associating tegulae and imbrice: restitution and technical characteristics (J.-F. Nauleau, Inrap).

Seul le site de la basilique paléochrétienne des ChampsSaint-Martin à Rezé (Loire-Atlantique) a livré en quantité importante des tegulae, très probablement produites au début du VI ${ }^{e}$ siècle (Pirault, 2002; fig. 2). En dehors de ce contexte, on ne recense qu'une seule tegula issue des fouilles de l'église Saint-Similien à Nantes ${ }^{3}$. Notons enfin un lot très fragmenté en provenance du site de la HauteForêt II à Carquefou (Loire-Atlantique; Nauleau, 2012), mais sans certitude quant au contexte chronologique de sa production et celui, encore plus modeste, découvert à Ancenis (Loire-Atlantique) sur le site du Pâtis 1 (Nauleau, 2015).

L'important corpus de sites réunis au sein du Projet Collectif de Recherche dirigé par A. Valais sur l'habitat rural médiéval dans le Nord-Ouest de la France (Valais, 2012) nous donne une vision plus représentative de la place des toitures "à la romaine " durant le haut Moyen Âge : sur la vingtaine de sites concernés, aucun n'a livré le moindre fragment de ces matériaux. En milieu rural, y compris sur des sites au statut privilégié incontestable comme par exemple aux Murailles à Distré (Maine-et-Loire, Valais, 2012, Tome 2, p. 127), la tuile est absente.

Le format de ces rares tuiles alto-médiévales est variable : l'exemplaire de Saint-Similien à Nantes est petit (343 mm de longueur) tandis que les quelques tuiles archéologiquement complètes de Rezé s’échelonnent entre 380 et $405 \mathrm{~mm}$. Dans l'ensemble, malgré la faiblesse numérique du lot recensé, elles semblent de petit gabarit comparées aux

3. Collections du musée Dobrée (Inv. 56 6572). tuiles romaines étudiées dans la région dont les plus grandes tegulae observées mesurent $525 \mathrm{~mm}$ (Nauleau, 2013a).

Les tuiles présentent un gabarit trapézoïdal contrairement aux tegulae romaines du Haut-Empire qui elles, sont le plus souvent parfaitement rectangulaires. L'exemplaire de SaintSimilien mesure ainsi $305 \mathrm{~mm}$ en partie haute et $30 \mathrm{~mm}$ de moins en partie basse.

Les observations faites sur les tuiles de Rezé et d'Ancenis concordent sur bien des points. Les encoches d'embồtement, très variables d'un individu à l'autre, sont le plus souvent réduites en longueur et en profondeur, jusqu'à devenir inopérantes sur certains individus. Dans ce cas, c'est le format trapézoïdal des tuiles qui permet le blocage de la tuile amont par le rebord de la tuile aval. C'est d'ailleurs encore le principe des tegulae utilisées de nos jours en Italie (Campanie, Latium, Toscane; fig. 3).

Globalement le façonnage est peu soigné et les rebords présentent des sections très irrégulières. Dans les trois cas évoqués, le type de pâte est identique : il s'agit d'une pâte beige à brune, bien cuite, dont l'importante fraction non plastique est composée d'inclusions siliceuses (quartz et feldspath). Ces pâtes differrent clairement de celles rencontrées régionalement pour les matériaux romains (les observations faites ici s'appuient sur des études de pâtes menées sur une trentaine de sites environ répartis dans les différents départements de la région). Ces pâtes sont très majoritairement fines (à faible proportion d'inclusions), orange à ocre et surtout caractérisées par la présence de nodules d'argilite rouge à ocre (fig. 4). La question de la nature de ces nodules n'a pour le moment pas été approfondie. Ils sont 


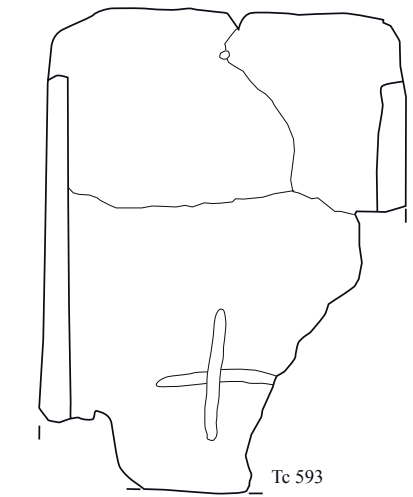

Rezé (Loire-Atlantique), "Basilique des Champs-Saint-Martin"
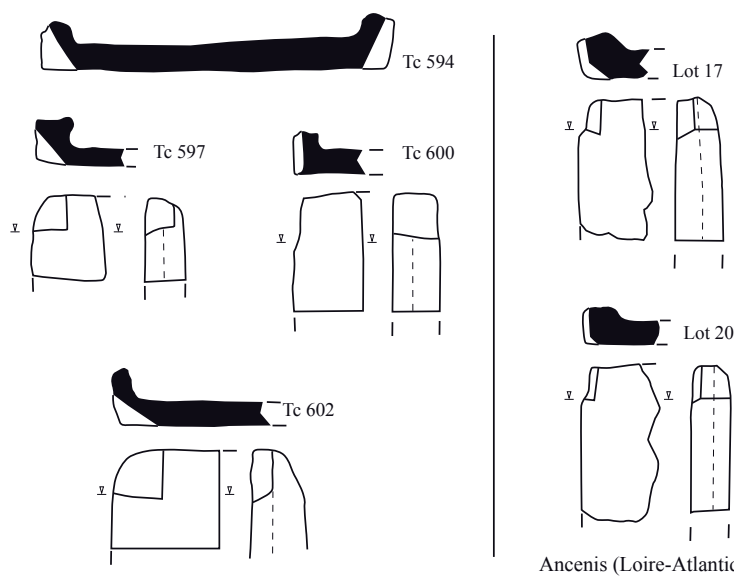

Ancenis (Loire-Atlantique), "Le Pâtis 1"

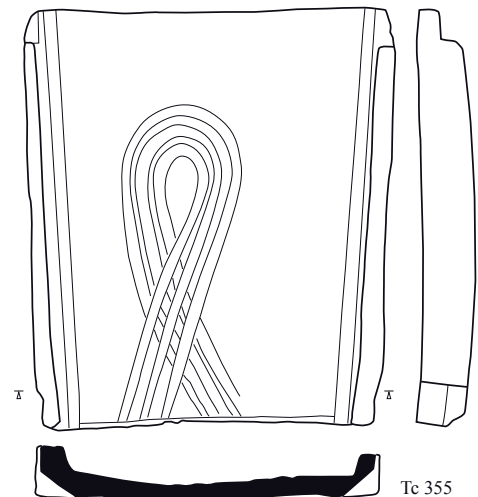

Nantes (Loire-Atlantique), "Eglise Saint-Similien"

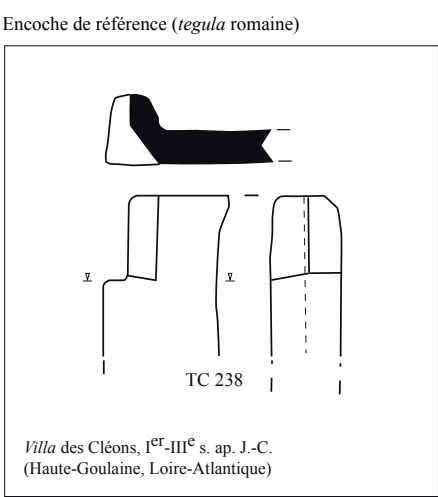

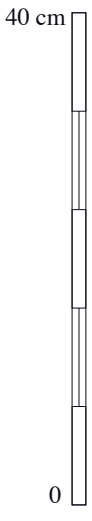

Figure 2 : Les quelques tegulae alto-médiévales recensées en Pays de la Loire (J.-F. Nauleau, Inrap).

Figure 2: The few Early medieval tegulae inventoried in the Pays de Loire (J.-F. Nauleau, Inrap).
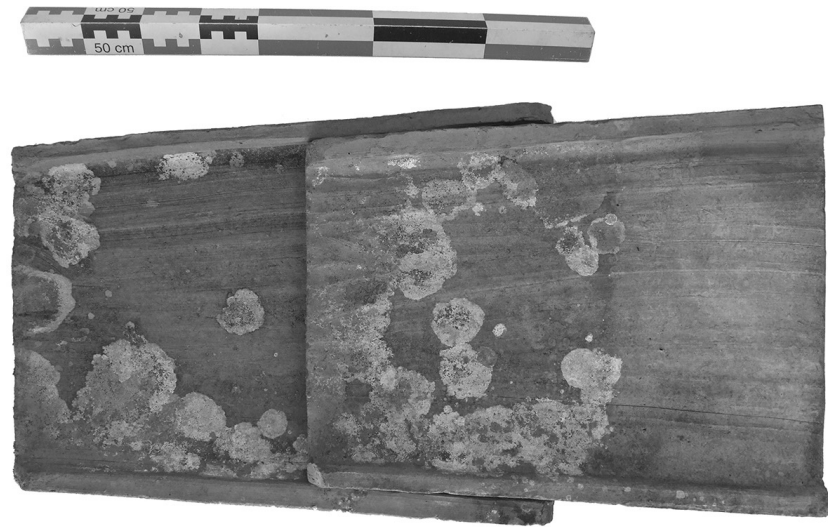

Figure 3 : (Voir planche couleur XXVIII) Tegulae toscanes (fin du $\mathrm{XIX}^{\mathrm{e}}$ siècle environ). Le recouvrement d'environ $200 \mathrm{~mm}$ est nettement supérieur à celui des tegulae antiques (Cliché J.-F. Nauleau, Inrap).

Figure 3: (Voir planche couleur XXVIII) Tuscan tegulae (about the end of the $19^{\text {th }}$ century). The $200 \mathrm{~mm}$ covering is much better than for Roman tegulae (Photo J.-F. Nauleau, Inrap). fréquemment décrits comme chamotte mais dans le cas des matériaux de construction et dans une région ou les argiles altéritiques sont riches en " dégraissants " siliceux, il paraît peu probable que le recours à la terre cuite pilée ait été nécessaire. Une autre hypothèse qui tiendrait plutôt au processus de préparation de l'argile (broyage à sec par exemple) devrait être considérée : pour répondre à cette question, le recours à l'expérimentation et à des analyses pétrographiques paraît indispensable.

Des études ultérieures permettront peut-être de déterminer si ces caractéristiques sont généralisables à la région. Elles pourraient dès lors constituer un critère d'identification pour les productions alto-médiévales.

Notons également des marques digitées singulières qui diffèrent de celles observées sur les tegulae romaines : dans le cas de l'exemplaire de Saint-Similien, c'est une boucle de grande taille (plus des deux tiers de la hauteur de la tuile) réalisée à trois doigts qui a été dessinée (fig. 2). À Rezé, sur le site de la basilique paléochrétienne, il s'agit d'une marque cruciforme. Ce motif n'apparaît semble-t-il sur aucune tuile romaine dans la région. Concernant ces marques digitées, l'hypothèse fréquemment retenue est celle d'un marquage 


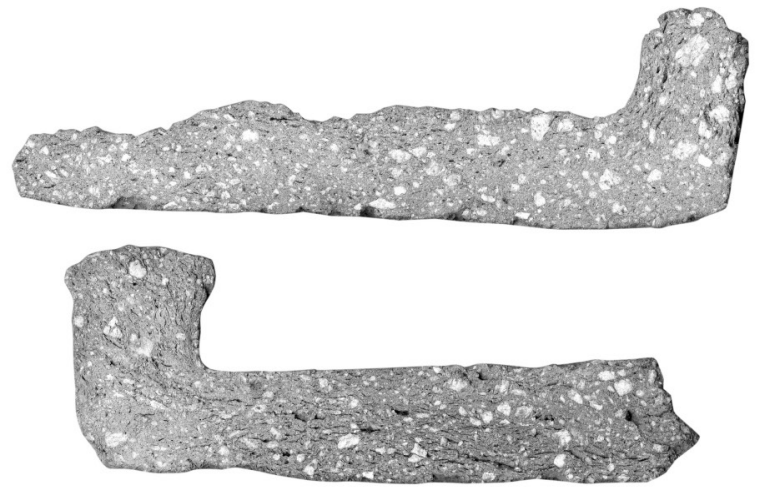

Tegulae du $\mathrm{VI}^{\mathrm{e}}$ siècle (Rezé 'Basilique des Champs-Saint-Martin')
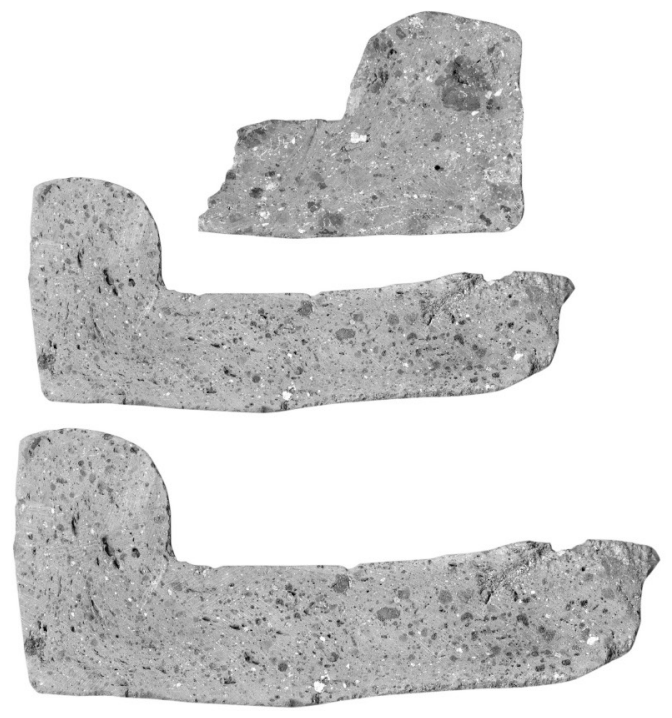

Tegulae des I $\mathrm{e}^{\mathrm{e}}-\mathrm{II}^{\mathrm{e}}$ siècles

(Nantes 'Plateau du Bouffay' et 'Zac Erdre-Porterie')

Figure 4 : (Voir planche couleur XXVIII) Abondance comparative de la fraction siliceuse entre tegulae alto-médiévales (haut) et romaines (bas) (J.-F. Nauleau, Inrap).

Figure 4: (Voir planche couleur XXVIII) The comparative abundance of the silica fraction between Early Medival (top) and Roman tegulae (bottom), (J.-F. Nauleau, Inrap).

réalisé par le mouleur à des fins de décompte de sa production, et n'affecterait qu'une fraction des tegulae (1 sur 10 ou 1 sur 50 par exemple). Cependant, la question est complexe et on a pu montrer récemment en étudiant des lots considérables de tegulae provenant de la villa des Cléons à Haute-Goulaine (Loire-Atlantique) et du site de la Clinique Saint-Louis à Angers (Maine-et-Loire, Nauleau, 2014a) que certaines familles de tegulae comportent systématiquement de telles marques tandis que d'autres en sont totalement dépourvues.

\section{Une tegula médiévale de type inédit}

Un site de production de matériaux de construction en terre cuite (La Tufferie), daté de la fin du XII ${ }^{e}$-début $\mathrm{XIII}^{\mathrm{e}}$ siècle $^{4} \mathrm{a}$ été découvert sur la commune de Beaupréau (Maine-et-Loire), dans les Mauges (Nauleau, 2013b). Parmi les productions du site (tuiles canal avec et sans crochet, briques, tuyaux de canalisation) a été découvert un type de tuile inédit dans la région (fig. 5). Il s'agit d'une tuile plate, légèrement trapézoïdale, longue de $440 \mathrm{~mm}$, large de $175 \mathrm{~mm}$ à l'aval et de $190 \mathrm{~mm}$ à l'amont. Elle est munie d'un petit rebord légèrement décalé vers l'intérieur et comporte un dispositif d'emboîtement caractérisé à l'aval par une petite découpe latérale oblique. À l'amont, toute la partie centrale de la tuile est amincie, formant ainsi une réserve profonde de $15 \mathrm{~mm}$ et longue d'environ $60 \mathrm{~mm}$.

Les caractéristiques de cette tuile sont surprenantes : elles sont identiques à celles d'une tegula romaine, avec néanmoins des modifications morphologiques importantes, à savoir un format nettement rectangulaire, un gabarit trapézoïdal facilitant l'emboîtement, un rebord ramené légèrement vers l'intérieur et un système d'emboîtement encastré limitant l'effet de la surépaisseur.

Plusieurs éléments amènent à se poser la question de sa production. Jusqu'à présent, ce type de tuile n’a jamais été découvert dans la région sur des sites de consommation 5 . Par ailleurs, son façonnage même est singulier. L'ensemble de l'objet est en effet modelé et réalisé sans moule, contrairement à ce qui a toujours été constaté pour les tegulae antiques. Enfin, le type d'emboîtement imaginé pour cette tuile semble peu opérant : l'encastrement diminuant d'autant les performances en matière d'étanchéité de la tuile, déjà médiocres pour une tegula classique.

En définitive, cette tuile découverte à La Tufferie évoque davantage un prototype qui auraient été élaboré dans l'atelier mais jamais réellement mis en production ni encore moins diffusé. En tout état de cause, au-delà du problème que soulèvent sa production réelle et sa représentativité, cet objet est important pour un autre aspect : la morphologie générale de cette tuile est en effet celle d'une tegula romaine, même si des modifications y ont été apportées. Et si le renouveau de la culture constructive antique est bien attesté à l'époque

4. Datation 14C : 1160-1220 à 1 sigma, 1050-1090, 1120-1140, 1150-1220 à 2 sigma (Beta Analytic Radiocarbon Dating Laboratory; Beta360232).

5. D'autres types singuliers et peu diffusés ont été décrits : à Metz (Moselle), dans les reins de voûte de l'église Saint-Vincent ont été trouvés des fragments de tegulae et d'imbrices contemporains de la construction $\mathrm{du} \mathrm{XIII}^{\mathrm{e}}$ siècle. Les tegulae reprennent la morphologie antique mais l'emboîtement est différent. Les encoches sont abandonnées au profit d'une partie basse en forme de col de bouteille. En face inférieure, ces tuiles sont munies d'un tenon permettant l'accroche sur un liteau. Les imbrices sont, quant à elles munies d'un ergot bloquant la tuile amont (Goutal, 1996). 


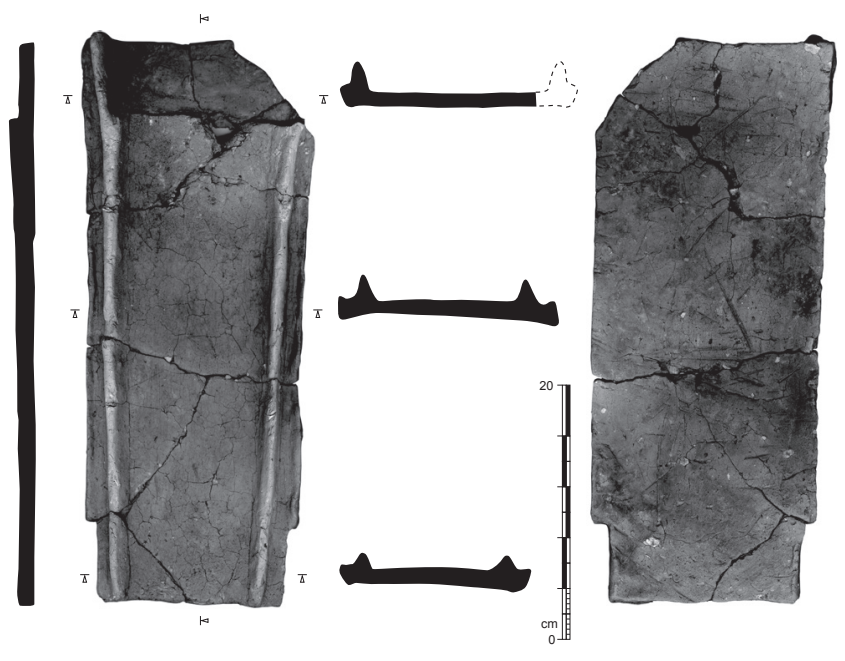

Figure 5 : (Voir planche couleur XXIX) Tegula médiévale (fin XII ${ }^{\mathrm{e}}$ début XIII ${ }^{e}$ siècle), site de production de Beaupréau "La Tufferie " (Maine-et-Loire) (J.-F. Nauleau, Inrap).

Figure 5: (Voir planche couleur XXIX) Medieval Tegula (end $12^{\text {th }}$ beginning $13^{\text {th }}$ century), production site at Beaupréau "La Tufferie " (Maine-et-Loire) (J.-F. Nauleau, Inrap).

carolingienne, même s'il reste modeste régionalement, il est plus surprenant d'en établir le constat pour cette époque plus tardive (fin du XII ${ }^{\mathrm{e}}$-début XIII ${ }^{\mathrm{e}}$ siècle).

\section{Discussion}

En l'état actuel de nos connaissances, on peut estimer que, régionalement, la production de tegulae et d'imbrices est quasi nulle pendant le haut Moyen Âge. Il ne s'agit plus alors que d'une production très spécifique, qui semble ne plus concerner que de très rares édifices et notamment les premiers édifices chrétiens.

Par ailleurs, si le principe global de la toiture antique est conservé, des nuances montrent que la technique a évolué. Le système d'emboîtement romain par encoches ne semble plus réellement fonctionnel. C'est la forme trapézoïdale des tuiles qui permet dorénavant l'assemblage sur la toiture. Les pâtes elles-mêmes ne sont plus préparées selon le même processus : des pâtes romaines fines à nodules d'argilite, on passe à des pâtes à inclusions siliceuses plus abondantes.

Le retour à des toitures végétales s'est entretemps généralisé pour devenir quasi-exclusif (on signale malgré tout des tegulae sur un édifice carolingien à Louresse-Rochemenier (Maine-et-Loire), Hunot, 2011). L'ardoise, même si de très rares occurrences carolingiennes sont mentionnées ${ }^{6}$, ne se développe ensuite que vers le XII ${ }^{e}$ siècle (Hunot, 2011).

6. Des fragments d'ardoises de couverture ont été découverts en position secondaire dans des niveaux du viII ${ }^{\mathrm{e}}$ siècle fouillés au château d'Angers (Brodeur et al., 1997, vol. 2, p. 121 et pl. 165).

\section{Les tuiles canal du second Moyen Âge}

Elles sont emblématiques du renouveau des toitures en terre cuite dans le sud de la zone d'étude pendant le second Moyen Âge. Indifféremment appelées tuiles canal ou tuiles creuses; en Vendée et dans le sud du Maine-et-Loire, elles sont dénommées "tiges de botte".

Morphologiquement, les tuiles canal sont proches des imbrices romaines, mais leur forme tronconique est plus accentuée et leur épaisseur est moindre, elles ont perdu au minimum $50 \%$ de leur poids par rapport à l'époque romaine.

Deux types de tuiles canal se rencontrent : des tuiles munies de crochet permettant leur fixation sur la charpente, et d'autres qui en sont dépourvues. Elles seront mises en œuvre sur des architectures de comble différentes.

\section{Tuiles canal à crochet}

Les sites

Quatre sites principaux ont fourni des individus complets sur lesquels ont été menées des études détaillées. En Sarthe, au Mans, la fouille de la place du Jet-d'eau dans le quartier canonial (Nauleau, 2016) a fourni un lot majeur en lien avec des habitats antérieurs à 13547. À Précigné, le site du manoir du Plessis-Roland (Nauleau, 2009) a livré un lot important issu de niveaux de démolition datés du XIV $v^{e}$ siècle et correspondant à un état ancien du manoir actuel. À Juigné-sur-Sarthe, un autre lot important a été découvert sur le site rural des Touches (Nauleau, 2013c) : il provient d'un bâtiment non maçonné situé au cœur d'un enclos fossoyé de faible envergure. En Maine-et-Loire, sur le site de la Foresterie à Saint-Jean-de-Linières, la cave maçonnée d'un manoir était comblée par un niveau de démolition associant tuiles, ardoises et mobilier domestique datés du $\mathrm{XIV}^{\mathrm{e}}$ au XVI $\mathrm{X}^{\mathrm{e}}$ siècle (Pirault, 2004). D'autres sites ont fourni des lots plus fragmentés : Saint-Fulgent, La petite Valinière (Vendée, Guérin, 2001); Beaupreau, La Tufferie (Maineet-Loire) ; Coulans-sur-Gée, Les Nouis (Sarthe, Nauleau, 2014b); Courgains, La Colinière (Sarthe, Valais, 2006); Baugé, Golf de Baugé (Maine-et-Loire, Viau, 2006).

Signalons encore des observations faites en Sarthe ${ }^{8}$ qui attestent la présence de ce type de tuiles : à l'abbaye de l'Épaud, des fragments ont été trouvés dans des contextes du Xv ${ }^{e}$ siècle (Meunier, 2014); à Saint-Rémy-du-Val, la tour maîtresse du château, construite au début du XIII ${ }^{\mathrm{e}}$ siècle et détruite en 1441 a livré également des tuiles canal ${ }^{9}$; enfin, à

7. Le fossé lié à la fortification médiévale, creusé en 1354, a détruit les faubourgs préexistants.

8. Elles ont été réalisées par Hugo Meunier, archéologue au Capra (Sarthe).

9. Communication orale, H. Meunier (Capra). 
Dissay-sous-le-Lude, des fragments de tuiles accompagnaient du mobilier du XIII'-XIV ${ }^{\mathrm{e}}$ siècle dans un remblai de carrière ${ }^{10}$. À Laval, le site de production céramique de La Hardelière qui a notamment produit le type à " œil de perdrix ", a aussi fourni quelques fragments de tuiles (Naveau, 1984). À Entrammes, leur présence est aussi mentionnée dans les thermes (Bauchet, Naveau, 1991), tandis qu’à Brée, d'autres tuiles ont été rencontrées au sein du château de la Grande Courbe ${ }^{11}$.

Dans leur travail sur les couvertures et charpentes médiévales en Anjou, J.-Y. Hunot et J. Guérin (Hunot, Guérin, 2007) ont étudié deux églises du Maine-et-Loire et de la Sarthe, dans lesquelles des restes des couvertures initiales en tuiles ont été préservés à la faveur d'un rehaussement des combles réalisé à l'Époque moderne. Sont encore visibles les extrados des voûtes sur lesquelles figurent les empreintes des tuiles noyées dans un bain de mortier. Une datation renvoyant à la seconde moitié du XII ${ }^{\mathrm{e}}$ siècle a été proposée par les auteurs qui signalent par ailleurs de nombreuses autres occurrences, principalement en Sarthe et dans le nord-est du Maine-et-Loire.

En Vendée, le monastère Grand-Montain de ChassayGrammont a livré sur des têtes de mur des restes de couverture en tuiles antérieurs au XIV siècle (Delaval, 2011). Des matériaux de même époque sont aussi signalés au château de La Garnache (Chauveau et al., 2012) ainsi qu'aux Epesses (Lévesque, 1995).

Enfin, dans le sud du département de la Loire-Atlantique, un programme de prospection pédestre a permis d'identifier des matériaux de même nature sur de nombreux sites, au sein d'une large zone localisée autour de la commune de Machecoul (Forré, Jolin, 2006).

\section{La morphologie}

La morphologie des tuiles courantes (tuiles évacuant l'eau) et des tuiles couvrantes (tuiles d'étanchéité à la jonction des files de tuiles courantes) est différente et permet de les distinguer aisément (fig. 6 et 7).

Les premières se présentent sous la forme de tuiles canal dont la concavité est peu marquée. En face inférieure, c'està-dire du côté convexe, elles sont munies d'un ergot situé à l'extrémité supérieure de la tuile. Ce dispositif permet l'accroche de la tuile sur le réseau de liteau fixé sur le chevronnage. Les longueurs des éléments complets s'échelonnent entre 362 à 384 mm à Précigné, 353 et 375 mm au Mans, tandis que le seul élément complet de Juigné-sur-Sarthe mesure $385 \mathrm{~mm}$. Les largeurs varient de 165 à $200 \mathrm{~mm}$ en partie haute et de 148 à $175 \mathrm{~mm}$ en partie basse. Le crochet

10. Communication orale, H. Meunier (Capra).

11. Communication orale, A. Valais (Inrap). lui-même de forme très homogène, est large de $50 \mathrm{~mm}$ et haut de 15 à $25 \mathrm{~mm}$ en moyenne (hauteur du crochet seul).

Toutes les tuiles décrites au sein de ce corpus sont d'un format similaire, à l'exception de celles du site de Saint-Jeande-Linières qui se distinguent par leur grande longueur (les deux tuiles courantes mesurant 417 et $423 \mathrm{~mm}$ ), et leur grande largeur ( 251 et $212 \mathrm{~mm}$ en partie haute et basse). Les hauteurs de crochet variant entre 45 et $50 \mathrm{~mm}$.

Les tuiles couvrantes présentent une concavité plus marquée permettant de faire l'étanchéité entre les files de tuiles courantes. En face supérieure, c'est-à-dire du côté convexe, elles sont munies d'un crochet situé en partie haute de la tuile, à quelques centimètres de l'extrémité. Ce système permet de retenir la tuile immédiatement en amont. Les longueurs relevées à Precigné s'échelonnent entre 310 et $346 \mathrm{~mm}$, contre 300 à 305 mm à Brée et 305 à 316 au Mans, soit des valeurs sensiblement inférieures à celles des tuiles courantes associées. Les largeurs en partie haute varient de 108 à $130 \mathrm{~mm}$ et de 120 à $140 \mathrm{~mm}$ en partie basse. Le crochet est large de 40 à $50 \mathrm{~mm}$ et haut de 25 à $30 \mathrm{~mm}$ en moyenne (hauteur du crochet seul). Il est distant de l'extrémité haute de la tuile d'environ 45 à $70 \mathrm{~mm}$ selon les cas.

Ici encore, le site de Saint-Jean-de-Linières se démarque $\mathrm{du}$ reste du corpus, la tuile couvrante mesurant $434 \mathrm{~mm}$ et les crochets étant dans l'ensemble, nettement plus gros.

Les dimensions des tuiles observées in situ sur les églises médiévales du Loir sont similaires à celles de Juigné-surLoire. À Huillé, elles s'échelonnent entre 385 et $425 \mathrm{~mm}$ et autour de $360 \mathrm{~mm}$ à Bazouges-sur-le-Loir.

Globalement, aussi bien pour les tuiles courantes que couvrantes, l'épaisseur est faible. Elle se situe entre 9 et $11 \mathrm{~mm}$.

\section{Les couvertures de tuiles canal à crochet}

Les caractéristiques des tuiles à crochet permettent de reconstituer l'aspect d'une toiture mettant en ouvre ce type de matériau (fig. 8 et 9).

L'écartement des liteaux sur la charpente peut être déduit de la longueur des tuiles courantes combinée à la dimension $\mathrm{du}$ recouvrement. Les traces de recouvrement sont parfaitement visibles sur des tuiles provenant du site de Précigné, la longueur de la zone "protégée » variant entre 85 et $90 \mathrm{~mm}$. On aboutit ainsi à une surface de tuile visible (le pureau) d'environ $290 \mathrm{~mm}^{12}$. Cette valeur correspondra également à la distance entre axe des liteaux fixés sur les chevrons. Quant à la largeur des tuiles courantes, en supposant que les files de tuiles soient posées au contact les unes des autres, elle induit également la distance entre axe des rangs de tuiles, cette valeur étant d'environ $190 \mathrm{~mm}$.

12. À Huillé, cette même valeur est de seulement $250 \mathrm{~mm}$ contre 309 mm à Bazouges-sur-le-Loir. 

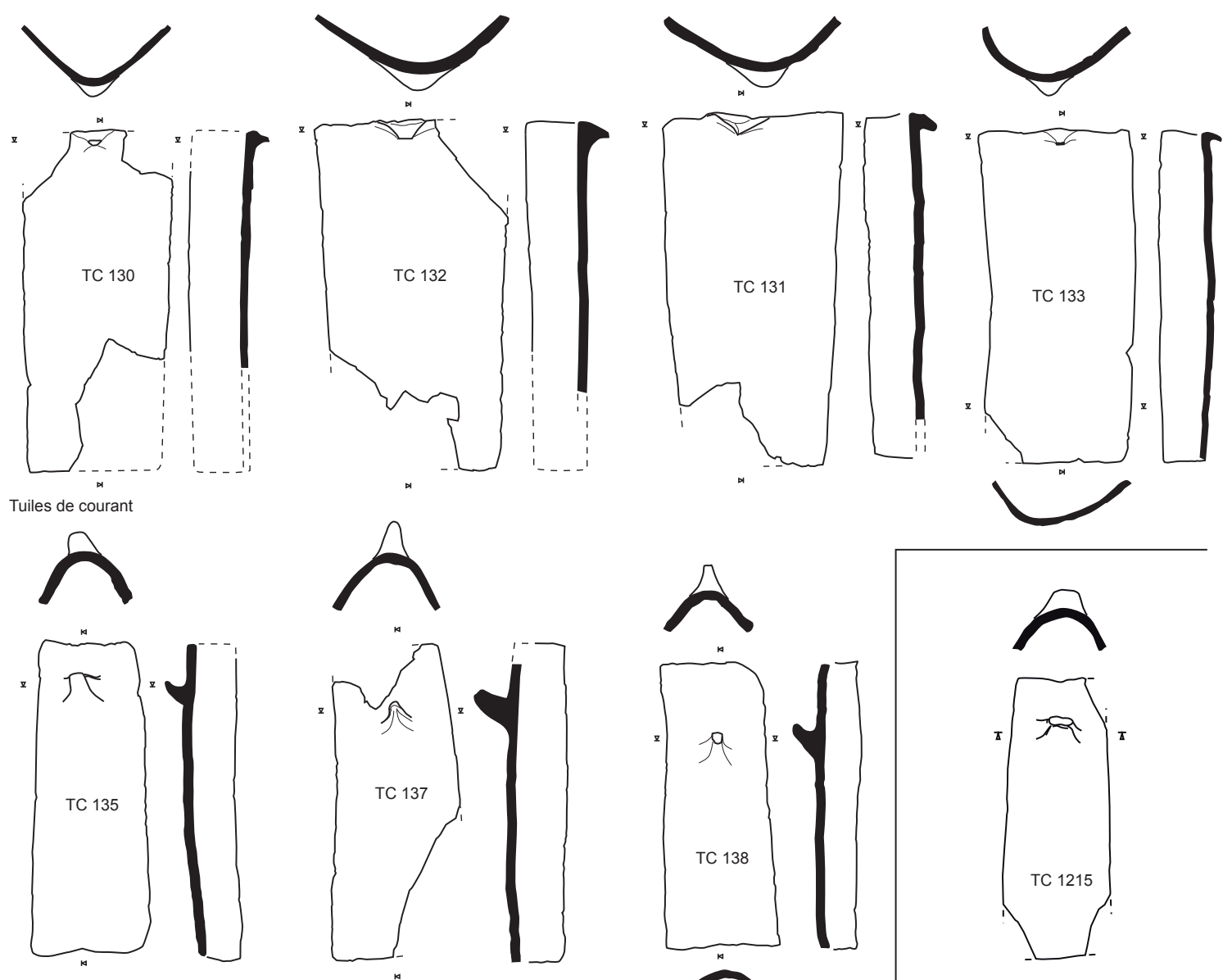

Tuiles de couvrant

Précigné (Sarthe), "Manoir du Plessis-Roland"
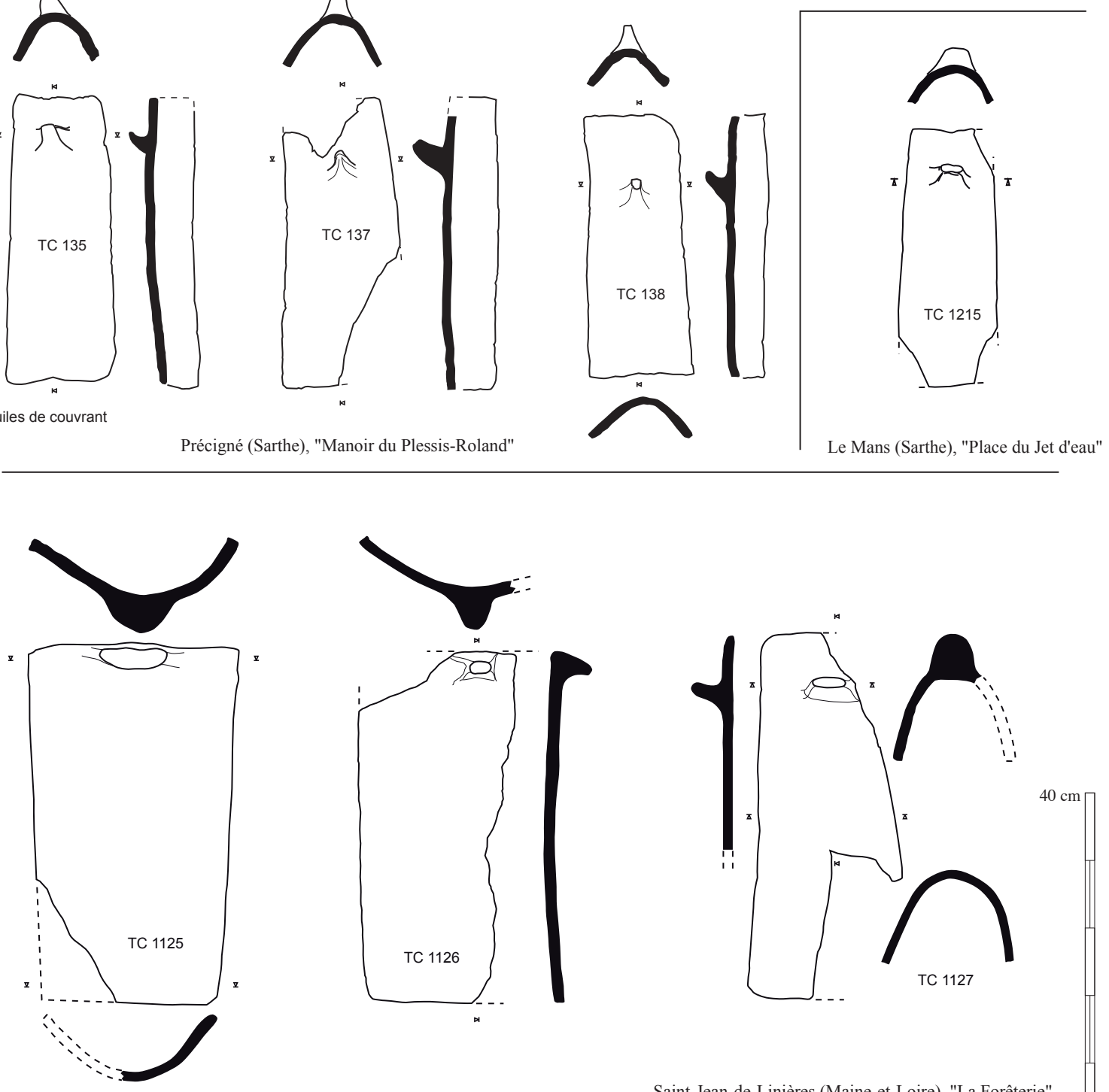

Saint-Jean-de-Linières (Maine-et-Loire), "La Forêterie"

Figure 6: Corpus de tuiles canal à crochet du second Moyen Âge (J.-F. Nauleau, Inrap).

Figure 6: Corpus of canal tiles with hook from the Late Medieval period (J.-F. Nauleau, Inrap). 


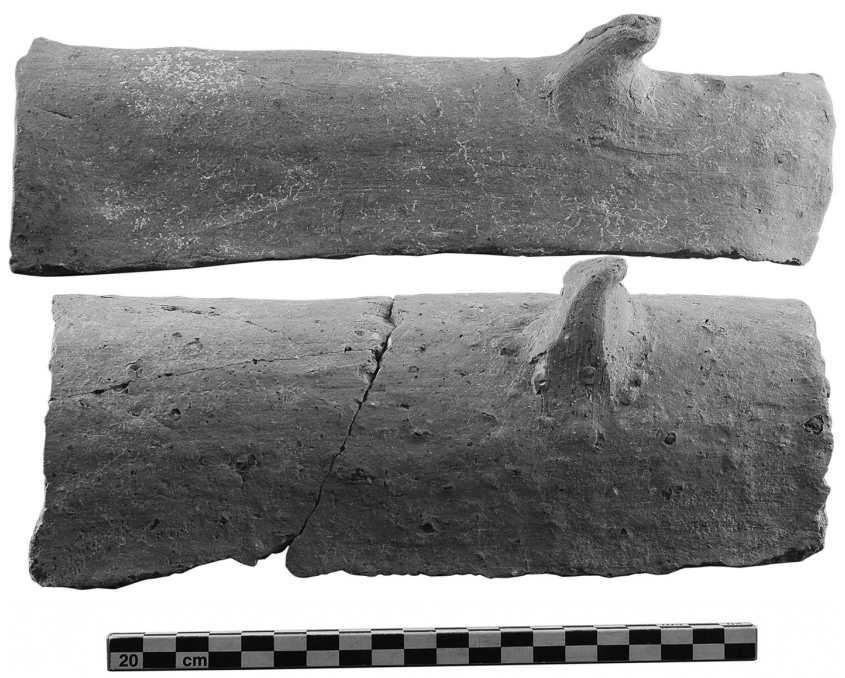

Figure 7 : (Voir planche couleur XXIX) Tuiles canal couvrantes à crochet provenant du site de Précigné "Le Plessis-Roland " (Sarthe) (Cliché H. Paitier, Inrap).

Figure 7: (Voir planche couleur XXIX) Covered canal tiles with hook from Précigné "Le Plessis-Roland" (Sarthe) (Photo H. Paitier, Inrap).
Le pureau des tuiles couvrantes est calculé à partir de la longueur moyenne des individus diminuée du recouvrement, qui correspond à la distance entre le crochet et l'extrémité haute de la tuile. Cette valeur est située aux alentours de $55 \mathrm{~mm}^{13}$. Le pureau obtenu est donc d'environ $290 \mathrm{~mm}$, ce qui correspond à celui calculé pour les tuiles courantes.

La pente estimée pour ce type de toiture est au minimum de 45 degrés (Jeannin, Bonvalot, 2009) et permet de former des combles volumineux ${ }^{14}$.

Il est aisé ensuite de calculer le nombre de tuiles par mètre carré. On obtient une valeur de 36 à 38 tuiles à Juignésur-Sarthe et Précigné, mais seulement 22 à Saint-Jean-deLinières. En se reportant au poids de chacune de ces tuiles, le poids moyen au mètre carré pour une toiture de ce type est d'environ $45 \mathrm{~kg} / \mathrm{m}^{2}$ dans le premier cas et $50 \mathrm{~kg} / \mathrm{m}^{2}$ à Saint-Jean-de-Linières ${ }^{15}$.

De ce point de vue, on peut noter une amélioration substantielle par rapport aux toitures «à la romaine " (avec tegulae et imbrices) nettement plus lourdes, autour de 70 à $75 \mathrm{~kg} / \mathrm{m}^{2}$ durant le haut Moyen Âge. Par ailleurs, la pente requise pour ce type de matériau est la même que pour les couvertures végétales (seigle, roseau, etc.) et le poids induit n'est que légèrement supérieur; l'introduction de ce maté-

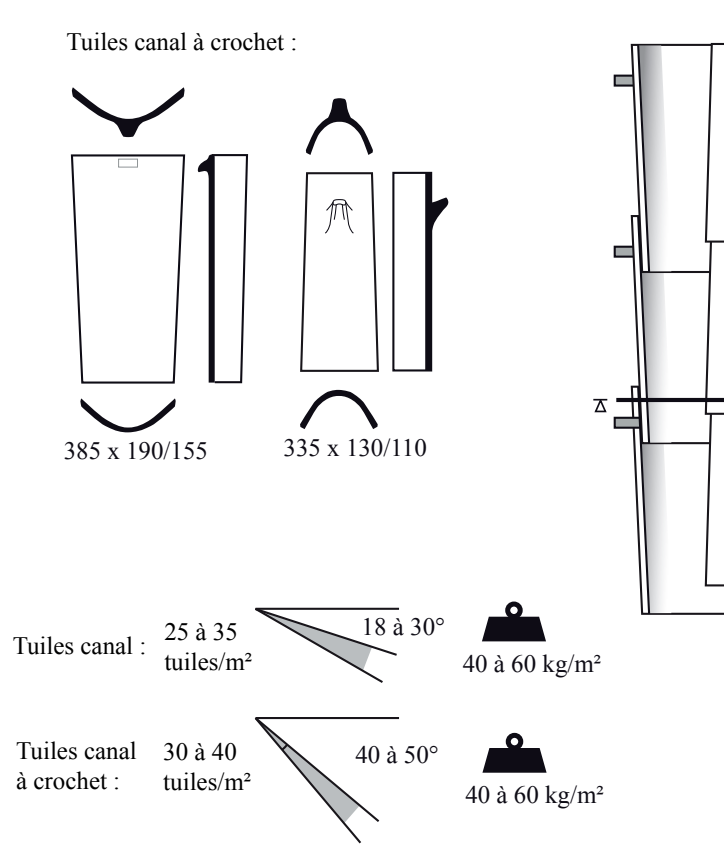

Figures 8 : Restitution et caractéristiques techniques des tuiles canal à crochet (J.-F. Nauleau, Inrap).

Figure 8: Restitution and technical characteristics of canal tiles with hook (J.-F. Nauleau, Inrap).
13. Le recouvrement des tuiles couvrantes est donc largement inférieur à celui des tuiles courantes : cette constatation, déjà faite pour les toitures "à la romaine " (tegulae et imbrices), s'explique par le fait que les tuiles couvrantes n'ont pas à gérer les eaux " amont".

14. Ce n'est pas le cas sur les églises du Loir où on relève environ 30 degrés à Huillé et 40 degrés à Bazouges-sur-le-Loir, mais dans les deux cas, la pose est réalisée sur une voûte avec pose à bain de mortier.

15. L'épaisseur des tuiles n'est que légèrement plus forte, et ce surpoids est en partie compensé par la plus faible surface cumulée de recouvrement. 


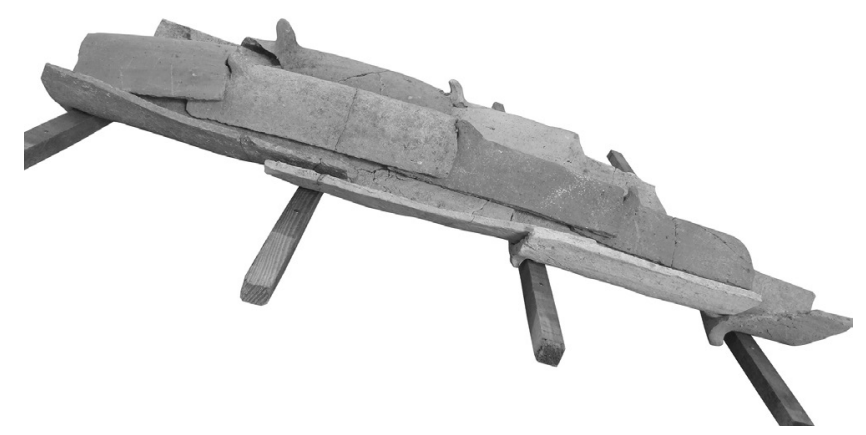

Figures 9: (Voir planche couleur XXX) Mise en œuvre des tuiles canal à crochet. Reconstitution à partir du lot découvert sur le site du « Plessis-Roland " à Précigné (Sarthe) (Cliché J.-F. Nauleau, Inrap).

Figure 9: (Voir planche couleur XXX) Using canal tiles with hooks. Reconstitution from a lot discovered at "Plessis-Roland" at Précigné (Sarthe) (Cliché J.-F. Nauleau, Inrap). riau n'a donc pas bouleversé la morphologie et la structure des charpentes.

Ces tuiles sont systématiquement façonnées du côté de la face portant le crochet; cette face seule est lissée tandis que l'autre porte l'empreinte du support de façonnage. Il en résulte que pour les tuiles courantes, la face d'écoulement de l'eau n'est pas la face lisse mais la face brute. Cette surface irrégulière favorise l'implantation de mousse, la rétention de déchets végétaux, ce qui augmente la porosité du matériau et constitue un terrain idéal pour la dégradation par le gel, dont les stigmates sont effectivement présents sur certains individus (desquamation en écailles).

\section{Cartographie des sites d'utilisation}

La carte de répartition des sites recensés reflète dans une certaine mesure l'état de la recherche sur les différents terri-

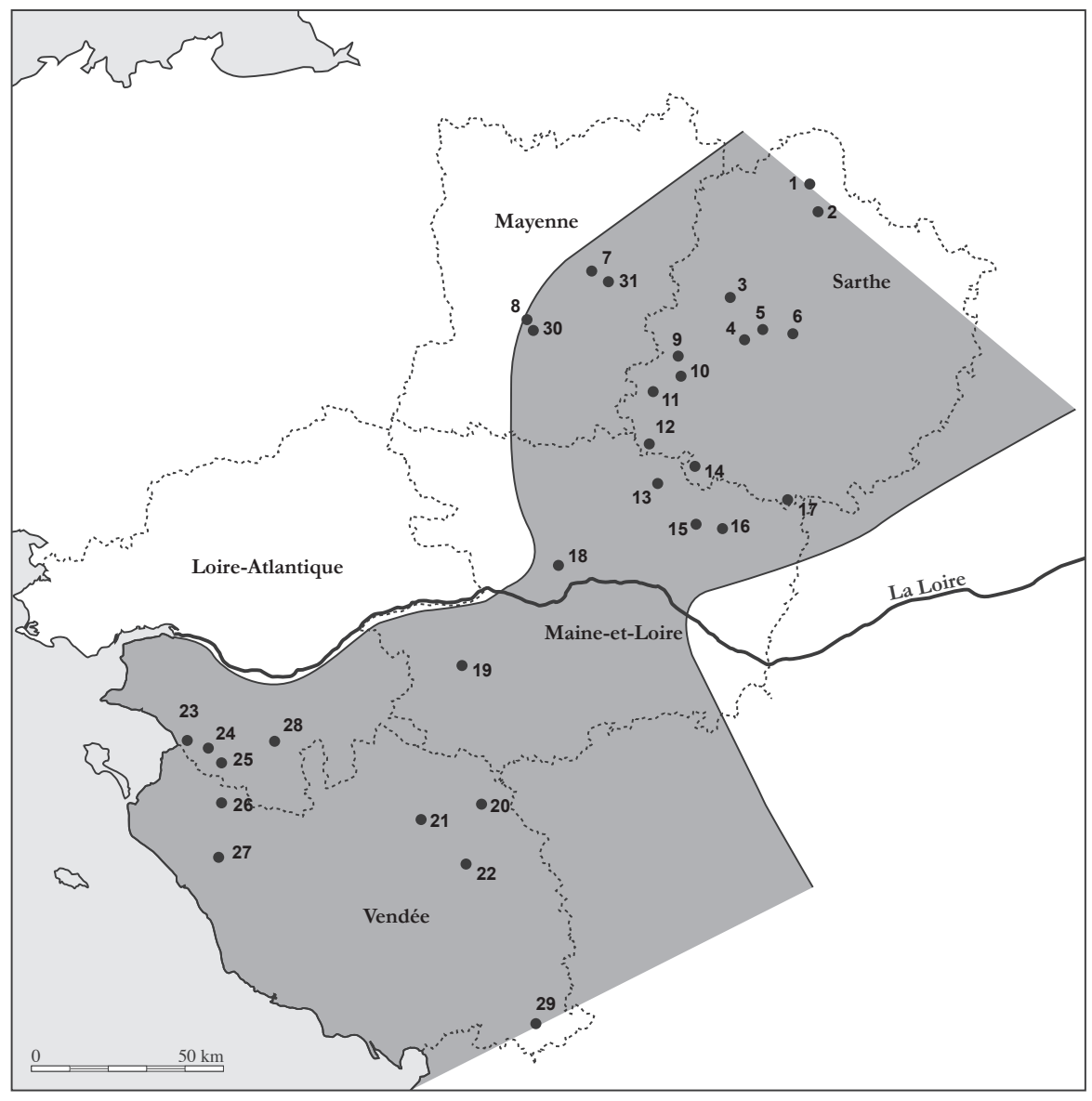

Aire de diffusion estimée de la tuile 'canal' à crochet.

1 : Saint-Rémy-du-Val ; 2 : Courgains ; 3 : Neuvy-en-Champagne ; 4 : Coulans-sur-Gée ; 5 : Fay ; 6 : Le Mans ;

7 : Brée ; 8 : Laval ; 9 : Chévillé ; 10 : Fontenay-sur-Vègres ; 11 : Juigné-sur-Sarthe ; 12 : Précigné ; 13 : Huillé ;

14 : Bazouges-sur-le-Loir ; 15 : Echémiré ; 16 : Beaugé : 17 : Dissé-sous-le-Lude ; 18 : Saint-Jean-de-Linières ;

19 : Beaupréau ; 20 : Les Epesses ; 21 : Saint-Fulgent ; 22 : Saint-Prouant ; 23 : Bourgneuf-en-Retz ;

24 : Fresnay-en-Retz ; 25 : Machecoul ; 26 : La Garnache ; 27 : Commequiers ; 28 : Saint-Philbert-de-Grand-Lieu

29 : Maillezais ; 30 : Entrammes ; 31 : Saint-Christophe-du-Luat.

Figure 10 : Localisation des sites ayant livré des tuiles canal à crochet (J.-F. Nauleau, Inrap).

Figure 10: Location of sites on which canal tiles were found (J.-F. Nauleau, Inrap). 
toires, mais on peut estimer que globalement, les tendances esquissées sont bien représentatives de la réalité (fig. 10).

Un premier ensemble de sites, centré principalement sur le département de la Sarthe, l'est de la Mayenne et l'extrémité nord-est du Maine-et-Loire se dessine clairement. Une seconde entité concerne la Vendée, le pays de Retz et les Mauges. Seul le site de Saint-Jean-de-Linières est localisé à la jonction de ces deux entités. Il faut rappeler qu'il a livré, en association avec le lot de tuiles, de nombreuses ardoises de couverture et ce dans les mêmes niveaux, laissant ainsi supposer que des couvertures tuiles et ardoises ont coexisté. Dans le secteur du Maine-et-Loire, la diffusion de la tuile a été largement contrariée par la concurrence des schistes ardoisiers.

Sur cette carte ne figurent pas les sites où la tuile est manifestement absente, mais ceux-ci ont contribué à définir les limites de l'aire de diffusion de ce matériau. On peut citer les deux sites majeurs localisés en Loire-Atlantique : le château des ducs de Bretagne à Nantes et celui de Châteaubriant. Les différentes fouilles menées ces dernières années (Pascal et al., 2007 pour Nantes et Martineau et al., 2007 pour Châteaubriant), n'ont jamais livré de matériaux de couverture en terre cuite, tandis que les ardoises de couverture y sont très nombreuses.

\section{Les données chronologiques}

Deux sites fournissent des données concernant l'apparition de ces tuiles à crochet. Celui de l'atelier de Beaupréau, qui a livré quelques fragments de crochets, donne une fourchette ${ }^{14} \mathrm{C}$ 1160-1220 (1 sigma). Les couvertures des églises du Loir sont quant à elles datées de la seconde moitié $\mathrm{du} \mathrm{XII}{ }^{\mathrm{e}}$ siècle sur des critères architecturaux. Une peinture murale de la chapelle Saint-Jean-Baptiste de ChâteauGontier (Mayenne), datée du XI ${ }^{\mathrm{e}}$ siècle, représentant une toiture de tuiles creuses, serait le premier témoignage connu à ce jour concernant ce matériau (Davy, 1995; Hunot, Guérin, 2007).

La plupart des autres sites sarthois et vendéens, montrent une diffusion au cours des XIII ${ }^{\mathrm{e}}$ et XIV ${ }^{\mathrm{e}}$ siècles. Au Mans (Sarthe), des bâtiments antérieurs à 1354 en étaient couverts, tandis que l'occupation de Juigné-sur-Sarthe (Sarthe), est datée de la fin du XIII ${ }^{\mathrm{e}}$ jusqu'à la seconde moitié du XIV $^{e}$ siècle. À Brée (Mayenne), la grande salle du manoir de la Grande Combe portait ces matériaux dans la seconde moitié du XIII e siècle. En Vendée, les sites de La Garnache, Machecoul, Saint-Fulgent, Les Épesses, et Saint-Prouant s'inscrivent dans ce même contexte chronologique, avec au plus tôt, une apparition dans le courant du XIII ${ }^{\mathrm{e}}$ siècle.

En ce qui concerne le repli et la disparition de ce matériau, les données concernant la fin du Moyen Âge sont plus rares. Cependant, aucun site ne fournit de datations postérieures au XVI ${ }^{\mathrm{e}}$ siècle. En l'état actuel de nos connaissances, c'est cette période qui est retenue pour la disparition de la tuile à crochet.

\section{Tuiles canal simples}

Les lots de tuiles étudiés en région sont rares. Citons celui découvert à Carquefou (Loire-Atlantique, Nauleau, 2012) dans des contextes chronologiques de la toute fin du Moyen Âge. Une tuile intacte est longue de $358 \mathrm{~mm}$ et large de 143 et $168 \mathrm{~mm}$ en parties haute et basse, son épaisseur étant très faible, de 9 à $9,5 \mathrm{~mm}$. Un autre lot a été mis au jour à Saint-Viaud (Loire-Atlantique, Nauleau, 2013d, p. 53), au sein d'un habitat moderne et contemporain. Les longueurs des tuiles s'échelonnent de 340 à $354 \mathrm{~mm}$ pour des largeurs de 125 à $160 \mathrm{~mm}$, les épaisseurs étant comprises entre 9 et $10 \mathrm{~mm}$. Dans l'atelier de production de Beaupréau, les rares tuiles intactes sont longues d'environ $370 \mathrm{~mm}$. Certaines sont épaisses de $15 \mathrm{~mm}$ tandis que d'autres ne dépassent pas les $9 \mathrm{~mm}$.

On constate donc que la plupart des observations faites au sujet des tuiles canal à crochet valent pour celles sans crochet. Les épaisseurs sont faibles, les matériaux sont bien cuits et se distinguent aisément des imbrices romaines plus épaisses, aux pâtes orange-ocre à nodules d'argilite.

L'étude de la localisation des occurrences souffre du peu d'intérêt porté à ces matériaux sur les sites du second Moyen Âge et de l'Époque moderne. Néanmoins, il apparaît clairement que ces tuiles canal sont relativement abondantes en Vendée, dans le pays de Retz et dans les Mauges. En revanche, le Maine est dépourvu de ce type de matériau.

Sur le plan chronologique, elles sont attestées à la fin du $\mathrm{XVI}^{\mathrm{e}}$ siècle et se développent surtout à partir du XVII ${ }^{\mathrm{e}}$ siècle en Vendée (Lévesque, 1995). Dès lors, ce matériau devient incontournable dans toute cette aire et prend le pas sur les matériaux périssables ${ }^{16}$.

Cependant, ce schéma d'ensemble souffre de quelques exceptions notables. Ainsi l'atelier de production de Beaupréau (Nauleau, à paraître) a livré de nombreuses tuiles canal dépourvues de crochet. Citons encore les tuiles découvertes à Fontevraud qui auraient été mises en œuvre sur une toiture du XII ${ }^{\mathrm{e}}$ siècle (Hunot et Guérin, 2007).

\section{Les tuiles plates (avec ou sans perforation)}

Aucun matériau de ce type ou même morphologiquement approchant n'est connu pour l'époque romaine ${ }^{17}$. Ces tuiles figurent parmi les nouveaux matériaux apparaissant au cours du second Moyen Âge.

16. Le département de la Vendée compte déjà 120 tuileries en 1809 (Jean, 1981, p. 32), c'est-à-dire bien avant l'essor des tuileries-briqueteries à partir du milieu du XIX ${ }^{e}$ siècle.

17. À l'exception des rarissimes tuiles en écailles. 


\begin{tabular}{|c|c|c|c|c|c|c|c|c|}
\hline Site & $\mathrm{N}^{\circ}$ individu & Type & $\begin{array}{l}\text { Longueur } \\
\text { (mm) }\end{array}$ & $\begin{array}{c}\text { Largeur } \\
\text { haute }(\mathrm{mm})\end{array}$ & $\begin{array}{l}\text { Largeur } \\
\text { médiane } \\
(\mathrm{mm})\end{array}$ & $\begin{array}{c}\text { Largeur } \\
\text { basse }(\mathrm{mm})\end{array}$ & $\begin{array}{c}\text { Epaisseur (en } \\
\text { mm) }\end{array}$ & $\begin{array}{c}\text { Distance / rebord } \\
\text { tuile }(\mathbf{m m})\end{array}$ \\
\hline \multirow{18}{*}{$\begin{array}{l}\text { Précigné } \\
\text { (Sarthe) } \\
\text { «Le Plessis- } \\
\text { Rolland » }\end{array}$} & Tc 130 & courante & 370 & 161 & 156 & & $7,5 / 9$ & \\
\hline & Tc 131 & courante & 383 & 195 & 182 & 148 & $9,5 / 11$ & \\
\hline & Tc 132 & courante & 384 & 200 & 190 & 170 & $10 / 11$ & \\
\hline & Tc 133 & courante & 362 & 165 & 157 & 158 & $7 / 9$ & \\
\hline & Tc 134 & courante & 380 & & & & $9 / 11$ & \\
\hline & Tc 139 & courante & & 190 & 177 & 170 & $10 / 11$ & \\
\hline & Tc 140 & courante & & 180 & 173 & & $10,5 / 11$ & \\
\hline & Tc 141 & courante & & 177 & 170 & & $10 / 12$ & \\
\hline & Tc 142 & courante & & 190 & & & $11,5 / 12$ & \\
\hline & Tc 143 & courante & & 168 & 158 & & $10,5 / 11$ & \\
\hline & Tc 146 & courante & & 190 & & & 10 & \\
\hline & Tc 135 & couvrante & 343 & 110 & 120 & 130 & $10,5 / 11$ & 46 \\
\hline & Tc 136 & couvrante & & 111 & \multicolumn{2}{|c|}{120 à 131} & $11 / 11,5$ & 65 \\
\hline & Tc 137 & couvrante & 346 & 120 & 133 & 140 & $9 / 10,5$ & 60 \\
\hline & Tc 138 & couvrante & 310 & 110 & 115 & 120 & $9 / 10,5$ & 73 \\
\hline & Tc 144 & couvrante & & 120 & & & $9,5 / 10,5$ & 70 \\
\hline & Tc 145 & couvrante & & 130 & & & $11 / 11,5$ & 41 \\
\hline & Tc 154 & couvrante & & 128 & & & $10 / 11$ & 51 \\
\hline \multirow{7}{*}{$\begin{array}{c}\text { Le Mans } \\
\text { (Sarthe) } \\
\text { « Place du Jet } \\
\text { d'eau » }\end{array}$} & Tc 1212 & courante & 353 & 165 & & 155 & $10 / 14$ & \\
\hline & Tc 1213 & courante & 375 & 185 & & 175 & $11 / 13$ & \\
\hline & Tc 1214 & couvrante & 310 & 110 & & 125 & $11 / 12$ & 44 \\
\hline & Tc 1215 & couvrante & 305 & 100 & & 120 & $9 / 11$ & 45 \\
\hline & Tc 1216 & couvrante & 310 & & & & $10 / 12$ & 46 \\
\hline & Tc 1217 & couvrante & 310 & 105 & & 125 & $9 / 12$ & 48 \\
\hline & Tc 1218 & couvrante & 316 & & & & $10 / 11$ & 56 \\
\hline $\begin{array}{c}\text { Le Mans } \\
\text { (Sarthe) « Ecole } \\
\text { Claude Chappe » }\end{array}$ & & couvrante & 300 & 120 & & 133 & $9 / 10$ & 48 \\
\hline \multirow{6}{*}{$\begin{array}{c}\text { Juigné-sur-Sarthe } \\
\text { (Sarthe) } \\
\text { « Les Touches » }\end{array}$} & Tc 1172 & courante & 385 & 190 & & 157 & $9 / 11$ & \\
\hline & Tc 1152 & courante & & & & 150 & $9 / 11$ & \\
\hline & Tc 1150 & couvrante & & 108 & & & 11 & \\
\hline & Tc 1151 & couvrante & & & & 130 & 12 & \\
\hline & Tc 1153 & couvrante & & 110 & & & $9 / 10$ & 55 \\
\hline & Tc 1154 & couvrante & & 112 & & & $9 / 10$ & 48 \\
\hline \multirow{3}{*}{$\begin{array}{c}\text { Brée (Mayenne) } \\
\text { « Manoir de la } \\
\text { Grande Courbe » }\end{array}$} & Tc 1266 & courante & 357 & 175 & & 165 & $10 / 12$ & \\
\hline & Tc 1267 & couvrante & 302 & 106 & & 132 & 10 & 40 \\
\hline & Tc 1268 & couvrante & $302 / 305$ & 98 & & 118 & 10 & 40 \\
\hline \multirow{4}{*}{$\begin{array}{c}\text { Saint-Jean-de- } \\
\text { Linières (Maine-et- } \\
\text { Loire) } \\
\text { « La Forêterie » }\end{array}$} & Tc 1125 & courante & 423 & 251 & & 212 & $9 / 10$ & \\
\hline & Tc 1126 & courante & 417 & & & & 12 & \\
\hline & Tc 1127 & couvrante & 434 & $120 ?$ & 168 & & $10 / 11$ & 60 \\
\hline & Tc 1128 & couvrante & $380 / 390$ & & 162 & & $14 / 15$ & \\
\hline
\end{tabular}

Tableau 1 : Format des tuiles canal à crochet composant le lot étudié.

Table 1: Format of canal tiles with hook from the studied lot. 


\section{Les sites}

Un seul site localisé dans le département de la Sarthe, à Saint-Corneille (Nauleau, 2013e) a fourni un lot important de matériaux de cette nature. Les vestiges sont caractérisés par un enclos fossoyé ovoïde d'environ vingt-cinq mètres de diamètre au sein duquel un bâtiment sur poteau est implanté. L'ensemble est daté du XIII ${ }^{\mathrm{e}}$ et du début du XIV siècle.

Quatre autres sites ont livré des lots plus modestes. Le premier est situé à La Milesse (Sarthe, Nauleau, 2013f). Il s'agit d'un manoir de la fin du Moyen Âge et de l'Époque moderne. Le second est localisé à Coulans-sur-Gée, Les Nouis (cf. supra). Le troisième correspond au site urbain de la Place du Jet d'eau au Mans (cf. supra). Enfin, le dernier, toujours en Sarthe, a déjà été évoqué pour les tuiles canal. Il s'agit du site du manoir du Plessis-Roland (cf. supra). Des informations ont par ailleurs pu être tirées de la documentation de la fouille de l'école Claude Chappe réalisée en 1980 au Mans ${ }^{18}$.

\section{La morphologie}

Il s'agit de tuiles planes de forme rectangulaire, munies en partie haute d'un crochet en face inférieure et dans la plupart des cas, de deux perforations, le tout permettant l'accroche sur les liteaux fixés sur la charpente (fig. 11 et 12).

La surface supérieure présente un aspect brut, ce qui n'est pas le cas de la surface inférieure (surface de pose) soignée et lisse. De toute évidence, la tuile est moulée du côté sousface sur un lit de sable fin ou de cendre. C'est la nécessité de façonner le crochet sur la face inférieure qui conditionne cette technique de réalisation. On observe fréquemment, à la base du crochet, une marque transversale d'environ $100 \mathrm{~mm}$ de long, qui témoigne de l'emploi d'une pièce de bois servant de soutien pendant la réalisation du crochet. Les perforations sont tronconiques et réalisées depuis la face inférieure après le moulage. Leur diamètre moyen, légèrement supérieur à $3 \mathrm{~mm}$, est faible.

Seules trois tuiles en provenance du site de Saint-Corneille fournissent une longueur complète de 318, 329 et $339 \mathrm{~mm}$ (fig. 11). On possède davantage de données sur les largeurs, une douzaine sur ce même site, aux alentours de 190 mm. L'épaisseur moyenne calculée à partir de quarante individus est de $14 \mathrm{~mm}$. Toutes les tuiles intactes en partie haute sont munies de deux perforations, généralement situées de part et d'autre du crochet axial, légèrement en aval de celui-ci. En moyenne, les perforations sont positionnées à une distance de 30 à $35 \mathrm{~mm}$ du bord latéral de la tuile (40 mesures) et de 45 à $55 \mathrm{~mm}$ de son extrémité haute (39 mesures).

18. Communication orale H. Meunier.
À La Milesse, les éléments les plus anciens ( $\mathrm{XvI}^{\mathrm{e}}$ $\mathrm{XVII}^{\mathrm{e}}$ siècles) sont des tuiles de faible largeur (145 et $155 \mathrm{~mm}$ ), d'épaisseur variable (de 10 à $18 \mathrm{~mm}$ ), avec crochet axial mais sans perforation. Pour les phases plus récentes, le lot est plus restreint; l'élément le plus complet est une tuile de $161 \mathrm{~mm}$ de large. Le crochet est ici accompagné de deux perforations latérales.

À Précigné, quelques tuiles plates de $175 \mathrm{~mm}$ de large ont été trouvées dans des contextes des $\mathrm{XVI}^{\mathrm{e}}$ et $\mathrm{XVII}^{\mathrm{e}}$ siècles.

Deux tuiles singulières sont à signaler. Il s'agit de deux demi-tuiles scindées dans leur longueur avec une trace de découpe nette qui affecte aussi le crochet, clairement réalisée avant cuisson. Il est probable que ces tuiles étaient destinées à être posées en rive après avoir été sectionnées dans le sens de la longueur à la largeur voulue. Le type de pose au tiers à joints alternés implique en effet l'emploi de demi-tuiles en rive avec une fréquence d'un rang sur deux (fig. 13).

À Saint-Corneille, les individus Tc 1002 et Tc 1015 sont pourvus d'une perforation axiale située sous le crochet. Dans le cas de Tc 1002, une des perforations latérales est absente. Il s'agissait, selon toute vraisemblance, de tuiles destinées à être sectionnées.

\section{Les couvertures de tuiles plates}

Pour ce type de matériau, la pose au tiers à joints alternés est la seule possible (fig. 13). Dans cette configuration, chaque tuile recouvre la tuile aval aux deux tiers, ce qui occasionne un pureau approximativement égal à un tiers de la longueur de la tuile. C'est la disposition et l'écartement du lattis sur lequel vont être accrochées les tuiles qui vont permettre de réaliser une telle pose. Pour les tuiles de Saint-Corneille par exemple, un espacement de $110 \mathrm{~mm}$ est nécessaire entre les lattes. D'un rang sur l'autre, les tuiles sont décalées transversalement d'une demi-largeur.

Le mode de recouvrement de ces tuiles plates implique une pente de toit assez forte, estimée aux alentours de 45 degrés, mais la fourchette d'utilisation de ces tuiles est comprise entre 40 et 60 degrés (Lebouteux, 2001; Demandrille, Cambou, 2008).

Il est avéré que, dans certains cas, les perforations n'ont jamais été utilisées pour la fixation des tuiles sur la toiture. En effet, quelques amorces de perforations ont été observées. Par ailleurs, les diamètres constatés sont souvent trop faibles pour le passage d'un clou de fixation. Il faut donc envisager dans ce cas, une fixation au moyen du seul crochet.

À Saint-Corneille, on a procédé au calcul du poids au mètre carré d'une toiture mettant en œuvre ces matériaux. Le nombre de tuiles au mètre carré est de quarante-huit; à partir de cette valeur et compte tenu du poids moyen d'une tuile qui est ici d'environ $1500 \mathrm{~g}$ (moyenne de 3 valeurs), la valeur finale obtenue est proche de $72 \mathrm{~kg} / \mathrm{m}^{2}$. 

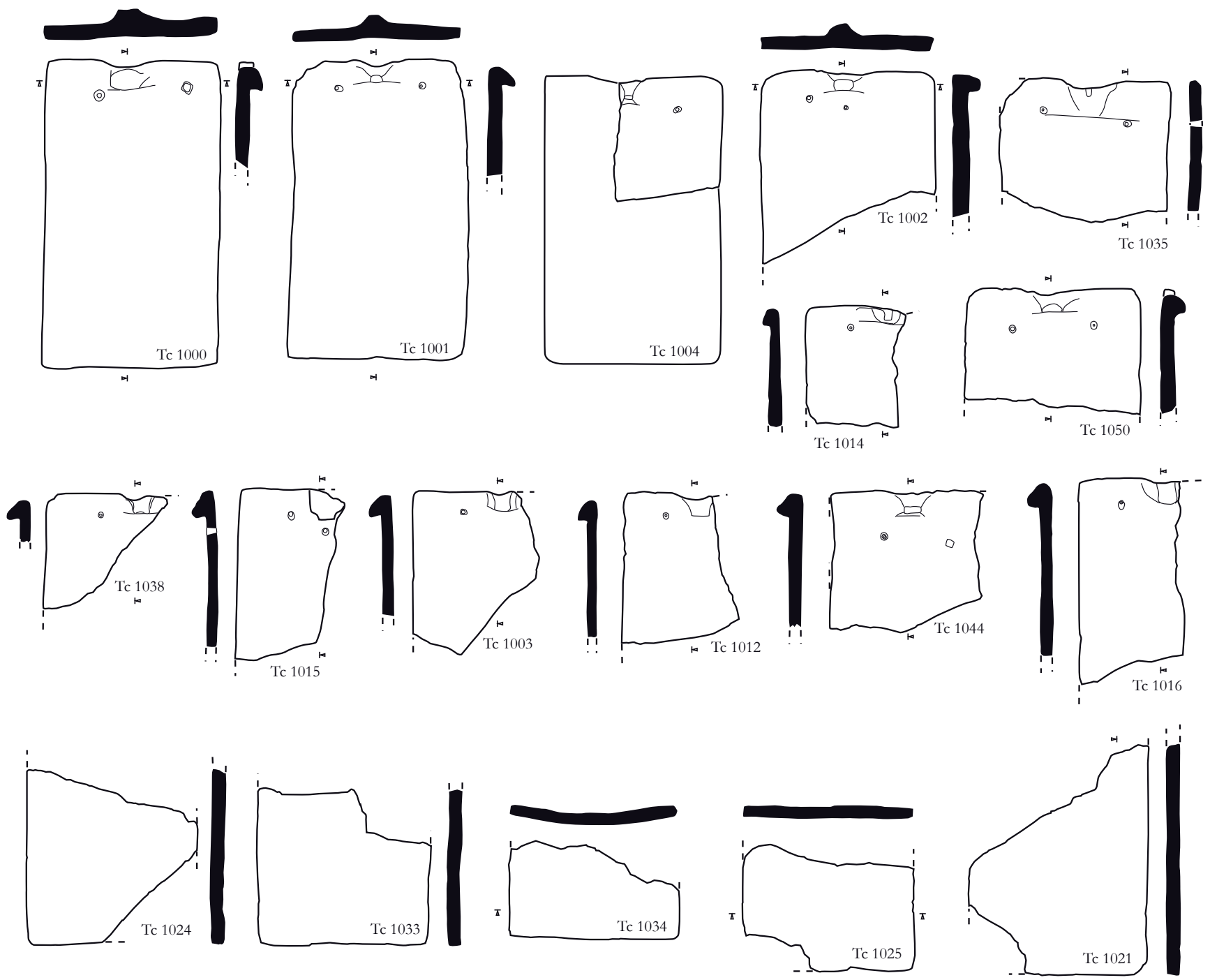

Saint-Corneille (Sarthe), "La Chapelle"

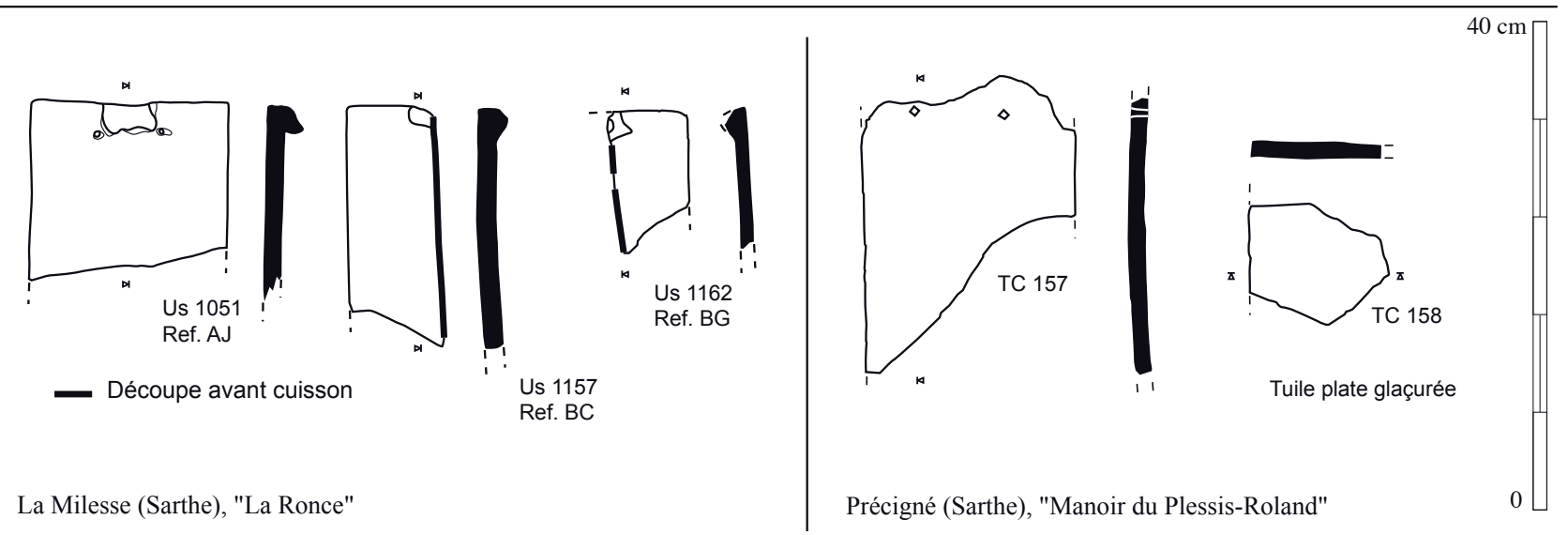

Figure 11 : Corpus de tuiles plates (J.-F. Nauleau, Inrap).

Figure 11: Corpus of flat tiles (J.-F. Nauleau, Inrap). 


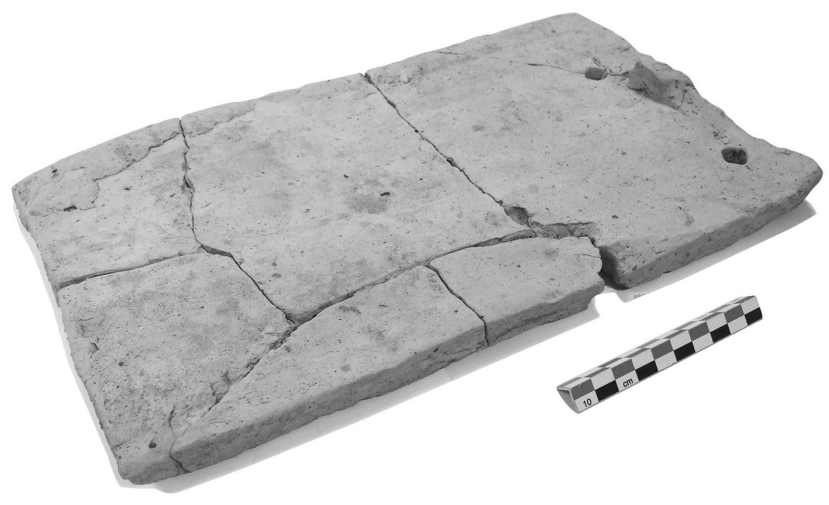

Figure 12 : (Voir planche couleur XXX) Tuile plate (SaintCorneille, Sarthe) (Cliché J.-F. Nauleau, Inrap).

Figure 12: (Voir planche couleur XXX) Flat tile (Saint-Corneille, Sarthe) (Photo J.-F. Nauleau, Inrap).

Figure 13 : Couverture de tuiles plates : restitution et caractéristiques techniques (J.-F. Nauleau, Inrap).

Figure 13: Covering of flat tiles: restitution and technical characteristics (J.-F. Nauleau, Inrap).
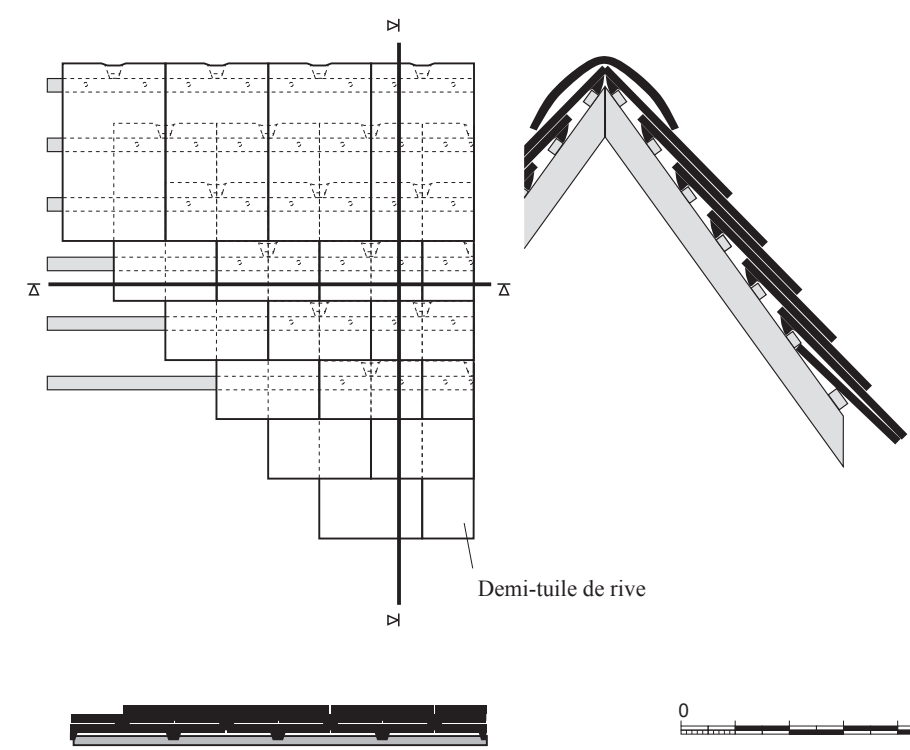

0 $50 \mathrm{~cm}$
60 à $80 \mathrm{~kg} / \mathrm{m}^{2}$

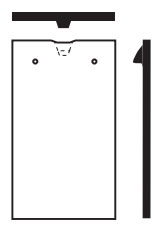

$330 \times 190 \mathrm{~mm}$

40 à 80 tuiles $/ \mathrm{m}^{2}$
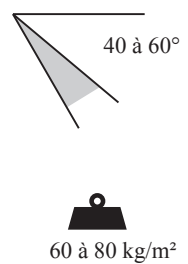

\section{Cartographie des sites de consommation et données chronologiques}

Malgré la faiblesse numérique des données (effectif d'environ 1400 restes représentant 85 individus), qui rend difficile l'appréciation de la diffusion réelle de cette tuile, son aire d'utilisation s'avère relativement restreinte, correspondant approximativement au département de la Sarthe ${ }^{19}$ (fig. 14).

La superposition de ces données à celles de la carte de répartition actuelle des matériaux de couverture révèle que cette aire ne semble pas avoir varié dans les grandes lignes au moins, jusqu’à nos jours.

Les premières occurrences de ce matériau sont signalées dans la région dans le courant du XIII ${ }^{e}$ siècle. C'est le cas notamment sur le site de La Chapelle à Saint-Corneille.

19. Une occurrence est signalée sur un manoir en Vendée, à SaintHilaire-le-Vouhis, mais très à l'écart de l'aire de diffusion de la tuile plate connue actuellement. Il est difficile d'en mesurer la représentativité (Delaval, 2011, p. 276).

\section{Données concernant les tuiles plates}

Bien que l'origine de cette tuile plate reste mal connue, il s'agit d'un matériau clairement médiéval qui ne puise pas son origine dans une tradition technique antique.

Il est frappant de constater que son format et ses techniques d'assemblage sont de même nature que ceux des bardeaux de bois : format quadrangulaire avec perforations hautes et pose avec recouvrement important. Il existe peut-être une filiation entre ces deux matériaux. Le passage à la terre cuite aurait alors été un moyen d'améliorer la résistance et la durabilité du matériau. Il est également possible qu'on ait souhaité imiter un autre matériau plus onéreux, l'ardoise. Il est vrai que les dates d'apparition des deux matériaux sont assez proches (l'ardoise étant apparue dans la région vers le $\mathrm{XI}^{\mathrm{e}}$ ou le $\mathrm{XII}^{\mathrm{e}}$ siècle mais ne s'étant réellement diffusée que vers le $\mathrm{XIII}^{\mathrm{e}}$ siècle). D'ailleurs, des cas de substitution volontaire pour cause de coût élevé et de non disponibilité d'une main-d'œuvre qualifiée sont connus (Lebouteux, 2001, p. 184). 


\begin{tabular}{|c|c|c|c|c|c|c|}
\hline Site & $\mathbf{N}^{\circ}$ Individu & $\begin{array}{l}\text { Longueur } \\
(\mathrm{mm})\end{array}$ & $\begin{array}{l}\text { Longueur } \\
\text { Conservée } \\
\quad(\mathrm{mm})\end{array}$ & $\begin{array}{c}\text { Largeur } \\
(\mathrm{mm})\end{array}$ & Epaisseur (mm) & $\begin{array}{l}\text { Nombre de } \\
\text { perforations }\end{array}$ \\
\hline \multirow{14}{*}{$\begin{array}{l}\text { Saint-Corneille } \\
\text { (Sarthe) } \\
\text { « La Chapelle » }\end{array}$} & Tc 1000 & 339 & & 195 & 16 & 2 \\
\hline & Tc 1001 & $326-329$ & & 193-194 & 16 & 2 \\
\hline & Tc 1002 & & 203 & 191 & 15 & 2 (1 axiale) \\
\hline & Tc 1003 & & 175 & & 14 & - \\
\hline & Tc 1004 & 318 & & 196 & 15 & - \\
\hline & Tc 1006 & & 310 & 189 & 15 & - \\
\hline & Tc 1021 & & 250 & 196 & 15 & - \\
\hline & Tc 1024 & & 190 & 189 & 14 & - \\
\hline & Tc 1025 & & 120 & 189 & 14 & - \\
\hline & Tc 1033 & & 170 & 187-191 & 15 & - \\
\hline & Tc 1034 & & 105 & 185 & 15 & - \\
\hline & Tc 1035 & & 145 & 185 & 13 & 2 \\
\hline & Tc 1039 & & 140 & 185 & 14 & - \\
\hline & Tc 1050 & & 135 & 192 & 13 & 2 \\
\hline \multirow{3}{*}{$\begin{array}{c}\text { Le Mans (Sarthe) } \\
\text { «Place du Jet } \\
\text { d'eau » }\end{array}$} & Tc 1219 & & 140 & 196 & $13 / 16$ & 1 \\
\hline & Tc 1221 & & 270 & 196 & $16 / 18$ & - \\
\hline & & & & 170 & & \\
\hline $\begin{array}{c}\text { Le Mans (Sarthe) } \\
\text { «Ecole Claude } \\
\text { Chappe }\end{array}$ & & 314 & & 190 & 14 & 2 \\
\hline \multirow{4}{*}{$\begin{array}{l}\text { La Milesse } \\
\text { (Sarthe) } \\
\text { « La Ronce » }\end{array}$} & Ref. $=\mathrm{AJ}$ & & & 161 & $13 / 15$ & 2 \\
\hline & Ref. $=A Z$ & & & 145 & 15 & 0 \\
\hline & Ref. $=U$ & & & 152 & & 0 \\
\hline & Ref. $=$ BC & & & $71 / 75$ & & 0 \\
\hline $\begin{array}{c}\text { Précigné (Sarthe) } \\
\text { « Le Plessis- } \\
\text { Rolland » }\end{array}$ & Tc 157 & & 230 & 175 & $16 / 17$ & 2 \\
\hline
\end{tabular}

Tableau 2 : Format des tuiles plates composant le lot étudié. Table 2: Format of flat tiles in the studied lot.

Ces tuiles plates apparaissent à Paris, vers la fin du XII ou vers le début du XIII ${ }^{\mathrm{e}}$ siècle (Brut, 2009). Les plus anciennes, dépourvues de crochet de fixation, n'auraient été maintenues que par des chevilles de bois sur des pentes plus faibles (Ravoire, 2009; Jeannin, Bonvalot, 2009). Le type à crochet et perforations, plus tardif, apparaittrait en Bourgogne vers le $\mathrm{Xv}^{\mathrm{e}}$ siècle (Aumard, Cailleaux, et al., 2009) mais serait en usage dès la fin du XIII ${ }^{\mathrm{e}}$ siècle à Paris. Une tendance à la diminution de la taille des tuiles au cours du temps semble ressortir des différentes études, mais avec la coexistence de plusieurs gabarits jusqu'aux Époques moderne et contemporaine, nommés " petit moule » et "grand moule».

\section{Les matériaux spécifiques}

Quelques sites ont fourni des matériaux qui n'entrent pas dans les catégories déjà évoquées. Il s'agit de tuiles de faîtage, d'arêtiers et de quelques éléments dont la nature reste à déterminer (fig. 15).
Le site de Domagné en Ille-et-Vilaine ${ }^{20}$ a livré de grandes quantités de tuiles faîtières glaçurées, associées à une couverture en ardoise verte. Cette toiture couvrait un bâtiment de ferme dont les parties basses au moins étaient maçonnées; il semble avoir été édifié aux alentours des $\mathrm{XIV}^{\mathrm{e}}$-XV ${ }^{\mathrm{e}}$ siècles et abandonné vers le XVII siècle.

Une tuile a pu être reconstituée. Elle est longue de $330 \mathrm{~mm}$, large de $240 \mathrm{~mm}$, sa hauteur d'ouverture étant de $115 \mathrm{~mm}$. Les tuiles sont couvertes d'une glaçure verte mais une minorité en est néanmoins dépourvue.

À Saint-Corneille, une tuile du même type, mais non glaçurée, a été identifiée. Elle coiffait une toiture de tuile plate, son gabarit étant légèrement plus grand avec une longueur supérieure à $350 \mathrm{~mm}$ et une largeur estimée à $250 \mathrm{~mm}$.

Sur ce même site, plusieurs fragments de tuiles d'un autre type ont également été découverts. Ces tuiles paraissent

20. Ce site ne figure pas dans le périmètre de la zone d'étude, mais s'y trouve d'un point de vue «culturel " (fouille F. Le Boulanger, Inrap, étude en cours). 
Figure 14 : Localisation des sites ayant livré des tuiles plates (J.-F. Nauleau, Inrap).

Figure 14: Location of sites on which flat tiles have been found (J.-F. Nauleau, Inrap).

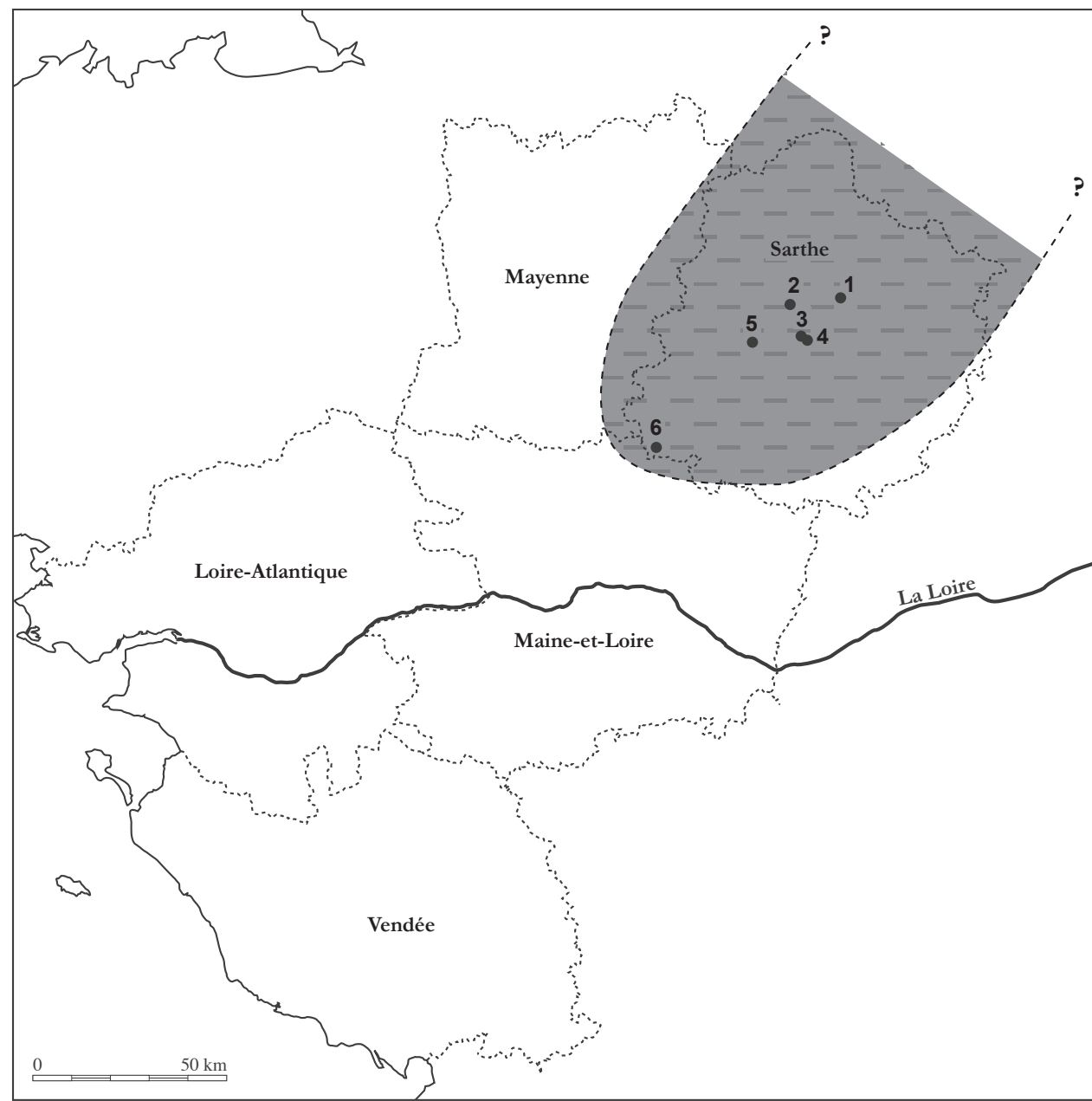

Aire de diffusion estimée de la tuile plate

1 : Saint-Corneille ; 2 : La Milesse ; 3 : Le Mans ; 4 : Yvré-l’Evêque ; 5 : Coulans-sur-Gée ; 6 : Précigné.

être de forme tronconique, au moins dans leur partie haute, et pourraient être d'assez grande taille (Tc 1005 est large de $190 \mathrm{~mm}$ ). L'une d'elles est perforée axialement, elles évoquent des matériaux morphologiquement très proches décrits en Franche-Comté (Jeannin, Bonvalot, 2009), dans des contextes plus tardifs du XVII ${ }^{\mathrm{e}}$ au XIX ${ }^{\mathrm{e}}$ siècle, ainsi qu'en Bourgogne à Soirans-Fouffrans pour les XVI ${ }^{e}-\mathrm{XVII}^{\mathrm{e}}$ siècles (Charlier, 1994). Il s'agit de tuiles de forme tronconique très marquée, mises en œuvre sur des arêtes de toitures à croupes.

Signalons enfin des fragments non identifiés qui évoquent des tuiles plates à rebords (?), mais de très petit gabarit et en contexte du second Moyen Âge. À Juigné-sur-Sarthe, quelques fragments ont été trouvés, associés à des tuiles canal à crochet, ce qui ne manque pas de surprendre. À Nantes, sur la fouille du plateau du Bouffay (Nauleau, 2014c), des fragments évoquent quant à eux les chatières romaines (tuiles de ventilation), mais avec des caractéristiques claire- ment médiévales (pâte blanche fine bien cuite et épaisseur très réduite). Ces quelques occurrences sont pour l'heure trop rares pour qu'il soit possible d'en comprendre la portée.

\section{Couverture en tuiles : synthèse des données et mise en perspectives (fig. 16)}

La période d'apparition des tuiles canal est située aux environs du $\mathrm{XII}^{\mathrm{e}}$ siècle, avec une diffusion qui devient sensible au XIII ${ }^{\mathrm{e}}$ siècle au sein de deux territoires plus ou moins distincts : un territoire "sarthois " (Sarthe, extrémités nord-est du Maine-et-Loire et est de la Mayenne) et un territoire "vendéen " (Vendée, pays de Retz, Mauges). La disparition des tuiles canal à crochet vers le $\mathrm{XV}^{\mathrm{e}}-\mathrm{XVI}^{\mathrm{e}}$ siècle semble coïncider avec l'essor de la tuile canal simple ${ }^{21}$. La seconde

21. Des observations identiques ont été faites en Lorraine, avec passage de l'une à l'autre entre le $\mathrm{XV}^{\mathrm{e}}$ et le XvII ${ }^{\mathrm{e}}$ siècle (Blaising, 2012). 

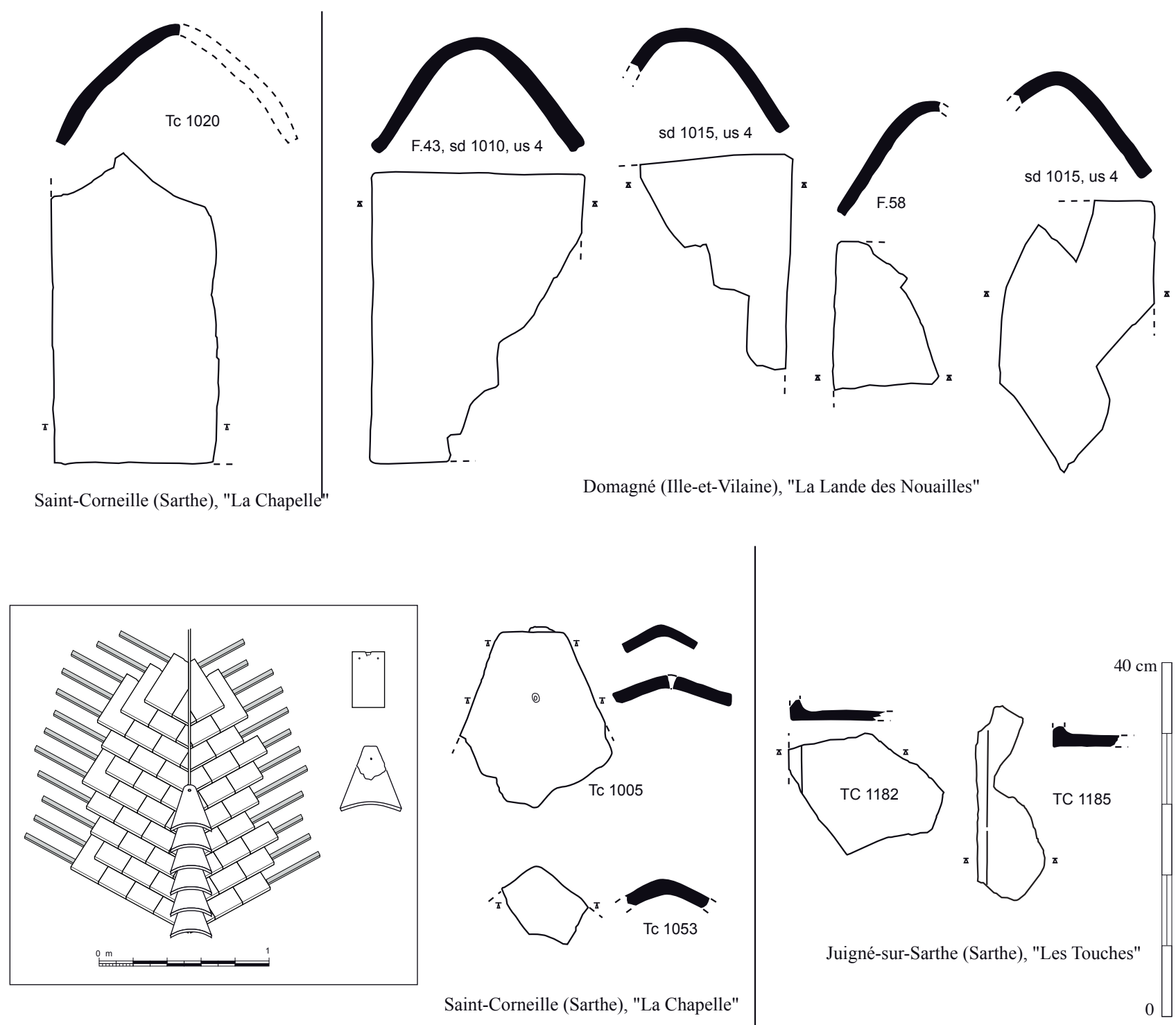

Figure 15: Matériaux spécifiques associés aux tuiles plates : tuiles faîtières et tuiles d'arêtier (J.-F. Nauleau, Inrap).

Figure 15: Specific materials associated to flat tiles: roof ridge tiles and angle tiles (J.-F. Nauleau, Inrap).

aurait donc fait disparaître la première. Par ailleurs, la tuile canal simple est absente du Maine, alors que la tuile à crochet y était très présente. L'abandon du crochet aurait donc accompagné la restriction de l'aire d'usage de la tuile canal, jusqu'à sa disparition au nord de la Loire.

En ce qui concerne les tuiles plates, elles apparaissent elles aussi vers le XIII ${ }^{\mathrm{e}}$ siècle, mais uniquement au sein du territoire sarthois. Tous les points d'occurrence archéologique sont situés dans l'aire actuelle d'usage de ce matériau qui ne semble donc avoir connu aucune modification notable depuis le XIII ${ }^{\mathrm{e}}$ siècle.

Au Mans, si les tuiles canal et plates sont utilisées durant les XIII ${ }^{\mathrm{e}}$-XIV ${ }^{\mathrm{e}}$ siècles, seules les tuiles plates continuent d'être employées à partir du $\mathrm{Xv}^{\mathrm{e}}$ siècle. Cette tendance est confirmée sur deux autres sites au moins. Les tuiles plates provenant toujours de contextes plus récents, du XviI ${ }^{e}$ siècle à Précigné et de l'Époque moderne à Coulans-sur-Gée. Ces exemples illustrent bien ce phénomène de mutation qui voit le passage d'un type à l'autre, les tuiles canal étant abandonnées au profit des tuiles plates aux alentours des $\mathrm{XV}^{\mathrm{e}}$ $\mathrm{XVI}{ }^{\mathrm{e}}$ siècles.

Le schéma d'ensemble semble donc être le suivant : essor simultané des tuiles canal et plates vers le XiII ${ }^{\mathrm{e}}$ siècle au sein des deux territoires sarthois et vendéen, les tuiles plates n'étant présentes que dans le cœur du premier. Vers les $\mathrm{XV}^{\mathrm{e}}-\mathrm{XVI}^{\mathrm{e}}$ siècles, l'aire de diffusion des tuiles canal se rétracte pour se limiter 

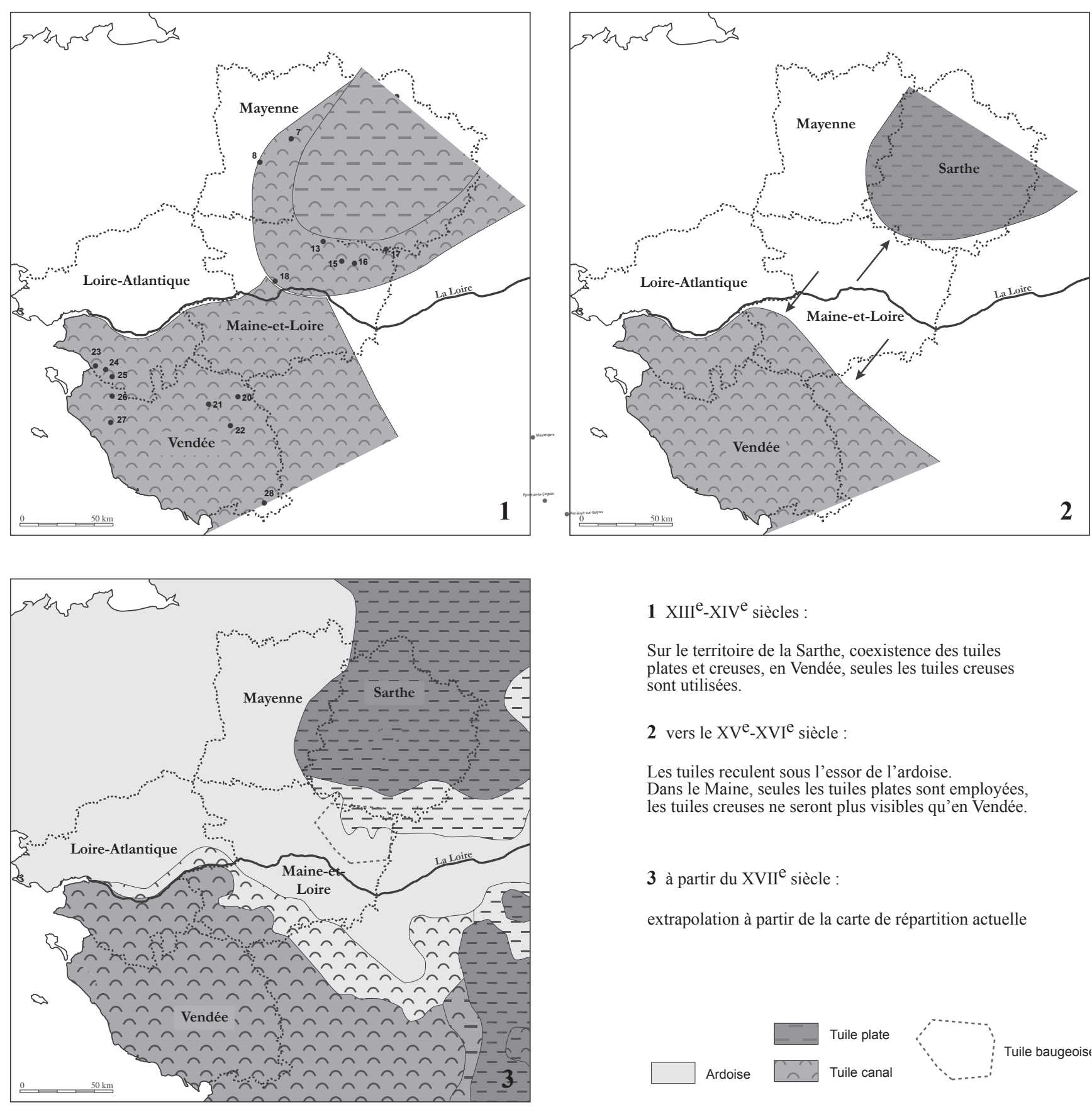

$1 \mathrm{XIII}^{\mathrm{e}}-\mathrm{XIV}^{\mathrm{e}}$ siècles :

Sur le territoire de la Sarthe, coexistence des tuiles plates et creuses, en Vendée, seules les tuiles creuses sont utilisées.

2 vers le $\mathrm{XV}^{\mathrm{e}}-\mathrm{XVI}^{\mathrm{e}}$ siècle :

Les tuiles reculent sous l'essor de l'ardoise.

Dans le Maine, seules les tuiles plates sont employées, les tuiles creuses ne seront plus visibles qu'en Vendée.

3 à partir du XVII ${ }^{\mathrm{e}}$ siècle :

extrapolation à partir de la carte de répartition actuelle

Figure 16 : Proposition d'évolution des aires d'utilisation des tuiles plates et canal depuis le XıII ${ }^{\mathrm{e}}$ siècle (J.-F. Nauleau, Inrap).

Figure 16: Proposition of evolution of the areas where different roof tiles used since the $13^{\text {th }}$ century (J.-F. Nauleau, Inrap).

désormais au seul secteur vendéen. En Sarthe, les tuiles plates occupent désormais seules le créneau des terres cuites de couverture, cette situation n'évoluant plus jusqu’à nos jours.

Comment expliquer le passage des tuiles canal aux tuiles plates en Sarthe? Plusieurs hypothèses peuvent être émises. Le handicap principal des couvertures à tuiles canal à crochet réside dans la nécessité de disposer de deux types de tuiles différents, ce qui complique nettement la question de l'entretien avec une possibilité de procéder à des remaniements limitée. Par ailleurs, la pose tiercée des tuiles plates, si elle génère un poids nettement supérieur $(75$ contre $45 \mathrm{~kg} /$ $\mathrm{m}^{2}$ environ), assure en revanche un maintien bien supérieur des tuiles sur la charpente et une moins grande vulnérabilité face au vent.

Les observations réalisées en Alsace, montrent un schéma d'évolution très proche de celui décrit ici. En effet, jusqu'au 
milieu du XVI ${ }^{\mathrm{e}}$ siècle, tuiles plates et tuiles canal cohabitent avant que les premières ne supplantent définitivement les secondes (Burnouf et al., 1986). Dans l'Est de la France plus globalement, l'aire de la tuile creuse s'est réduite considérablement (Charlier, 1994). Il apparaît donc que les observations faites dans les Pays de la Loire s'insèrent dans un mouvement plus global, mais dont il est difficile de comprendre la genèse et les causes.

\section{Le cas des tuiles baugeoises}

Dans un large périmètre autour de la commune de Baugé, dans le nord-est du Maine-et-Loire, se rencontrent actuellement des toitures singulières (Lebouteux, 2001, p. 172; Chaumont, 1991; Giraud-Labalte, 1984). Elles se composent de tuiles de courant à crochet mais dépourvues de l'habituelle tuile de couvrant qui est remplacée par un large joint de mortier appelé " crétis ", qui assure l'étanchéité entre les files de tuiles de courant. Le crochet permet la pose sur des charpentes à pente plus forte que pour les tuiles canal ordinaires.

Lorsqu'on souhaite aérer des combles, dans le cas d'activités agricoles ou artisanales spécifiques, le crétis est absent. Des halles de séchage de tuileries-briqueteries utilisent ainsi ce type de couverture dans le département du Maine-etLoire, aux Rairies et à Echémiré par exemple (fig. 17).

Ce type de couverture est spécifique à une aire géographique restreinte d'environ mille kilomètres carrés qui figure dans l'aire d'extension des couvertures en tuiles canal à crochet présentes dans la région $\mathrm{du} \mathrm{XIII}^{\mathrm{e}} \mathrm{au} \mathrm{XVI} \mathrm{X}^{\mathrm{e}}$ siècle. Après cette période, les tuiles perdent leur crochet et ne se

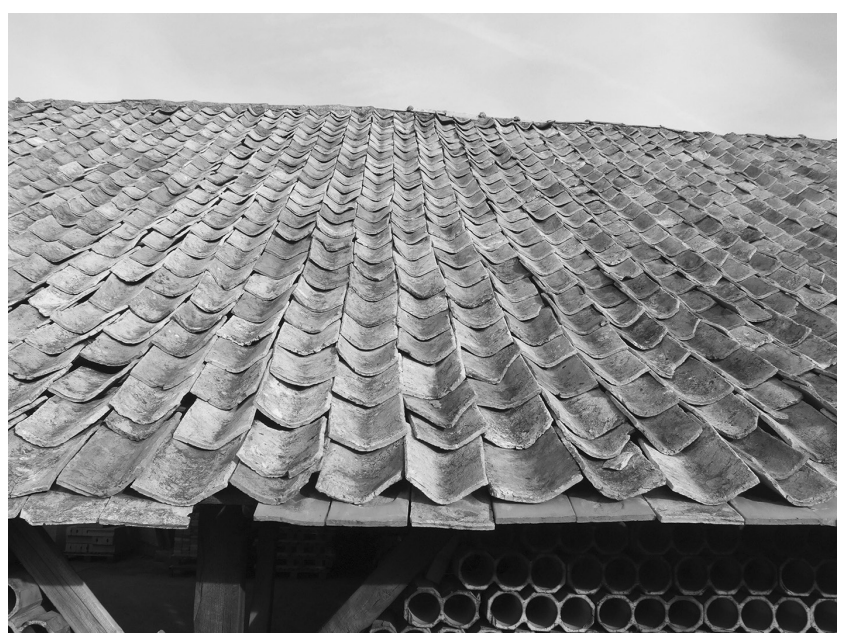

Figure 17 : (Voir planche couleur XXX) Toiture baugeoise sur une grange : halle de séchage de carreaux de sol (Les Rairies, Maineet-Loire) (Cliché J.-F. Nauleau, Inrap).

Figure 17: (See colour plate XXX) Baugeoise roof on a barn : floor tiles from the drying barn (Les Rairies, Maine-et-Loire) (Photo J.-F. Nauleau, Inrap). rencontrent plus que dans une aire vendéenne. Ces tuiles baugeoises sont-elles le témoin de leur perduration, sous une forme légèrement différente, au sein de cette aire géographique? Les données manquent encore pour répondre à cette question.

\section{LA TUILE FACE AUX AUTRES MATÉRIAUX DE COUVERTURE}

"Pourquoi la tuile? " pourrait être le sous-titre de cette partie; en effet, son usage n'est pas exclusif pendant le Moyen Âge, celui de l'ardoise et des matériaux périssables étant également largement répandu. Puisque les limites de répartition entre ces différents matériaux se dessinent clairement $^{22}$, il est intéressant d'essayer d'en comprendre la genèse.

En premier lieu, on peut s'interroger sur l'existence d'un déterminisme géologique et géographique : l'abondance relative des ressources en argile explique-t-elle la répartition de la tuile sur le territoire étudié? Les données climatiques peuvent être aussi convoquées, en particulier en termes d'influence sur les formes de comble. Le rôle des autorités ne sera pas oublié. Il tient à l'évidence une place de choix dans cette réflexion, au moins en contexte urbain pour des raisons de sécurité. Enfin, on devra évoquer l'influence des phénomènes de mode qui ont parcouru l'histoire de l'architecture, les tuiles étant évidemment actrices de cette histoire.

\section{Un possible déterminisme géologique et géographique}

\section{Les argiles}

La localisation et l'abondance des argiles au sein du territoire étudié constituent des données essentielles. Les récentes études menées par le BRGM sur la question de "l'aléa retrait-gonflement des sols argileux " pour l'ensemble des départements français constituent des documents précieux concernant la cartographie de ces ensembles lithologiques ${ }^{23}$. L'examen de ces différentes études montre que la région est riche en gisement (fig. 18 et 19), avec des différences assez sensibles entre départements. Ceux avec les ressources les moins importantes sont la Mayenne (68 \% du territoire est constitué de formations susceptibles de contenir des argiles), la Loire-Atlantique (73 \%), le Maine-et-Loire (74\%). La Vendée (81\%) et encore davantage la Sarthe (89,5\%), sont les départements les plus riches. Dans les territoires proches,

22. Néanmoins, les usages combinés et synchrones de tuiles et d'ardoise sur des corps de bâtiments différents est avérée sur de nombreux sites.

23. Par exemple, Le Guern, Coulon, 2009 pour le département de la Loire-Atlantique. 


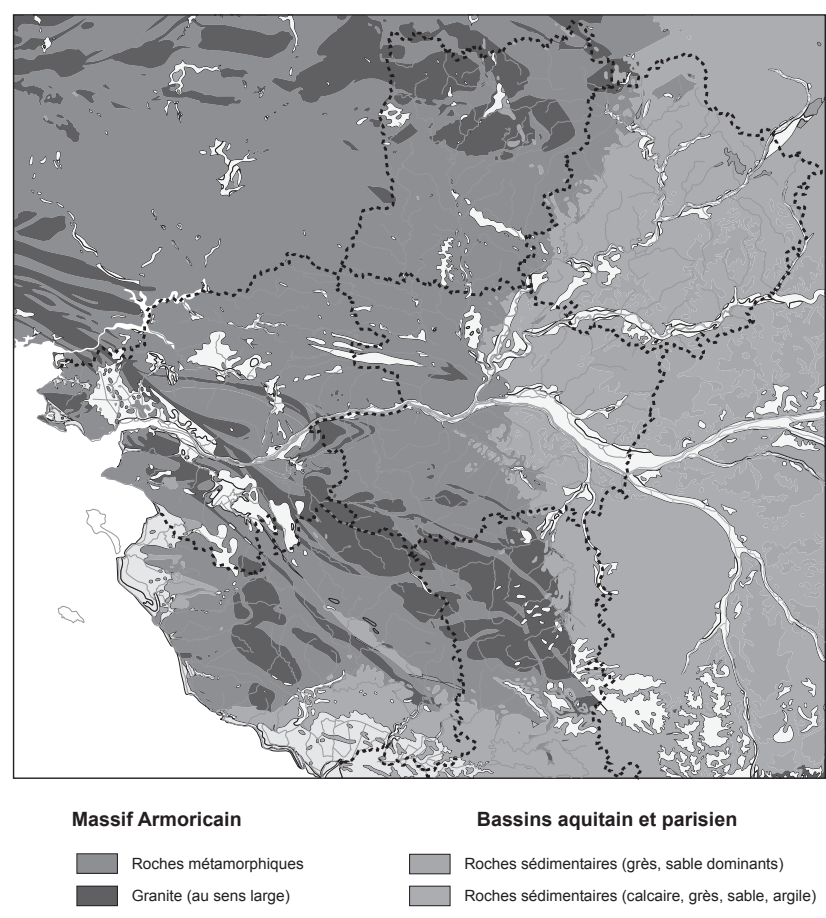

Figure 18 : (Voir planche couleur XXXI) Carte géologique simplifiée de la zone d'étude (à partir de la carte géologique BRGM au 1/1000 000) (J.-F. Nauleau, Inrap).

Figure 18: (See colour plate XXXI) Simplified geological map of the study area (from the BRGM geological map 1/1000000) (J.-F. Nauleau, Inrap).

l'Ille-et-Vilaine ne contient que $53 \%$ de formations argileuses, le Morbihan $46 \%$ et les Deux-Sèvres $52 \%$.

La superposition de ces données à la carte d'usage des toitures en terre cuite permet les observations suivantes : les départements dans lesquels les tuiles sont actuellement les plus présentes sont également ceux au sein desquels les ressources en argile sont les plus abondantes. En revanche, en Mayenne, et hors région, en Ille-et-Vilaine et dans le Morbihan, ces départements pauvres en tuiles sont aussi les moins riches en argile. La situation est plus contrastée pour la Loire-Atlantique et le Maine-et-Loire : ces deux départements, mixtes du point de vue des matériaux de couverture, sont situés en position intermédiaire en termes de richesse de gisements.

Il semble donc, d'après ces données, qu'un lien existe entre type de matériau de couverture dominant et abondance des gisements d'argile. Cependant, cette observation doit être nuancée car le département des Deux-Sèvres, pourtant largement à dominante de tuiles apparaît pauvre en argile. Par ailleurs, l'observation plus fine de la cartographie des gisements argileux en Loire-Atlantique ne laisse percevoir aucune différence majeure de densité entre ses parties nord et sud, alors même que ces deux zones sont bien dissemblables en termes de types de matériaux de couverture.
Il est possible d'affiner la lecture et de distinguer au sein des gisements d'argile deux grandes familles : des argiles de décantation, formées dans les bassins sédimentaires mésozoïques (Bassin parisien en Sarthe et Bassin aquitain dans le sud-Vendée), et des argiles altéritiques qui se sont formées sur le massif Armoricain au détriment des séries métamorphiques (schistes, gneiss, amphibolites...) et des roches plutoniques (granite essentiellement).

La superposition d'une carte géologique simplifiée (limites des bassins sédimentaires) et de la carte de répartition des matériaux de couverture montre ainsi que deux situations apparaissent : dans le cas des tuiles canal, l'aire de répartition couvre indifféremment les argiles altéritiques du massif Armoricain et celles, sédimentaires, du Bassin aquitain. En revanche, pour les tuiles plates, l'aire épouse la limite ouest du Bassin parisien, avec une pénétration d'une vingtaine de kilomètres dans le massif Armoricain. Que conclure de ces observations? La production de la tuile plate s'accommodet-elle uniquement d'une argile sédimentaire fine? La tuile creuse peut-elle se contenter d'une argile moins affinée?

Dans ce cas, l'influence des gisements argileux serait non seulement quantitative comme on l'a déjà évoqué, mais également qualitative, le degré de finesse permettant ou non la production de certains matériaux.

\section{Les gisements ardoisiers}

Les schistes ardoisiers sont surtout localisés autour de la ville d'Angers. Les gisements bretons n'exercent eux, qu'une faible influence dans la région; quant aux gisements mayennais, ils ne semblent exploités que plus tardivement, vers le $\mathrm{Xv}^{\mathrm{e}}$ siècle, c'est le cas notamment du bassin de CongrierRenazé (Meuret, 1998, p. 142). Pourtant, la place du matériau sur les toitures à l'heure actuelle est très importante, tandis que les données cartographiques montrent l'importance de la Loire ${ }^{24}$ dans cet essor. L'aire d'usage de l'ardoise interrompt clairement celle de la tuile plate. Il semble donc y avoir concurrence directe entre les deux modes de couverture, qui offrent il est vrai des caractéristiques de pente de toit et de poids au mètre carré assez similaires.

Donc, si le déterminisme géologique est en réalité de faible importance (les gisements sont limités spatialement et l'ardoise angevine n'aurait pas dû diffuser au-delà d'un rayon local), c'est clairement l'association avec la Loire, qui a permis un essor si précoce et si important.

24. Dès le début de la Période moderne, la batellerie de Loire, très dynamique, va permettre la diffusion de ce matériau de la Normandie à l'Île-de-France, jusqu'en Bourgogne (Cayla, 2003). Des trains de bateaux sont alors utilisés, permettant le transport de très importants tonnages d'ardoise. 


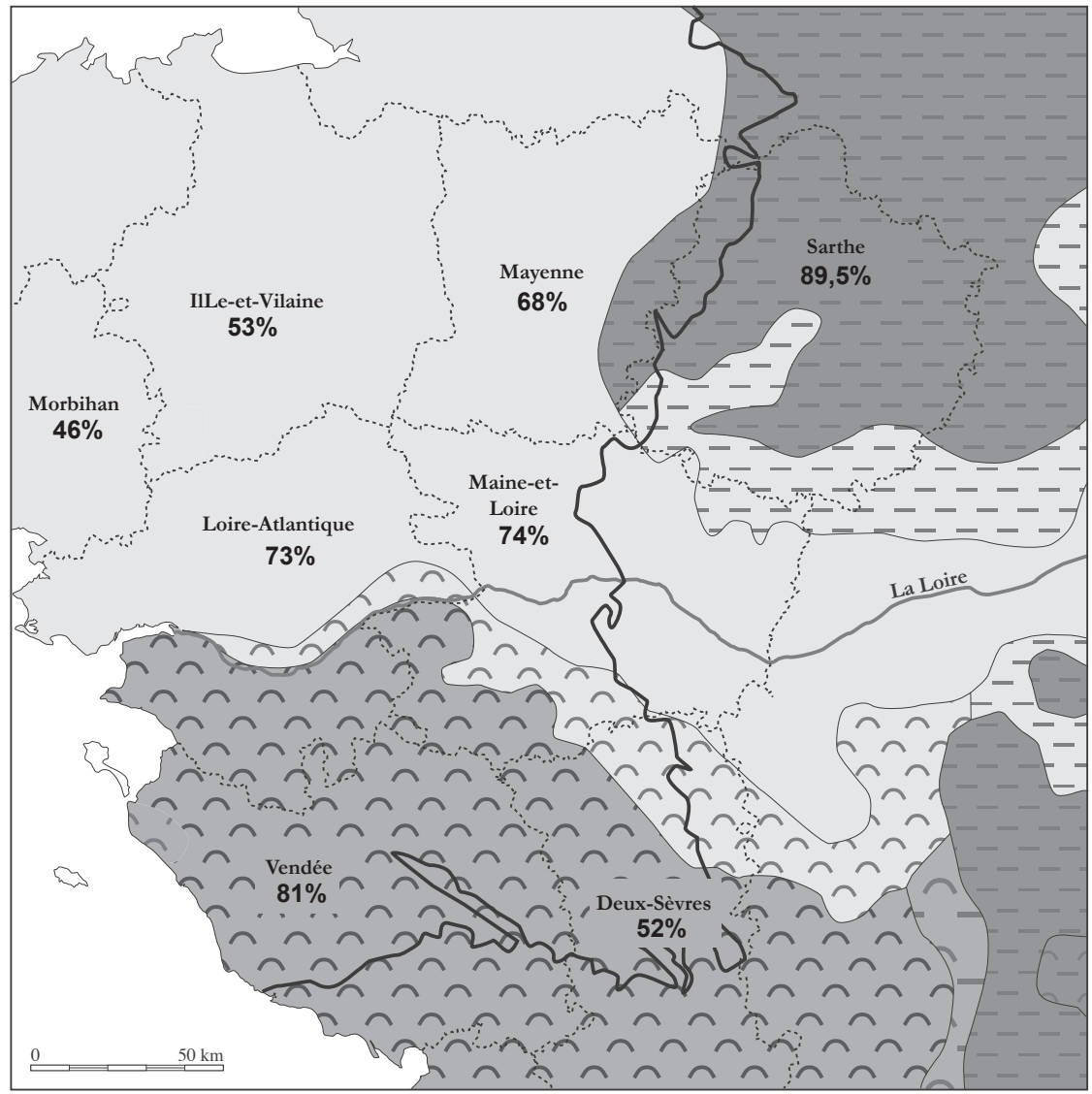

Tuile plate

Tuile canal

Ardoise
Limite est et sud du massif Armoricain $\mathbf{7 3} \%$ Surface des formations

géologiques à dominante argileuse
Figure 19 : Abondance relative des argiles confrontée à la carte de répartition des matériaux de couverture (J.-F. Nauleau, Inrap). Figure 19: Relative abundance of clays compared to the distribution map of roof materials (J.-F. Nauleau, Inrap).

\section{Le climat}

L'influence du climat peut-elle être invoquée dans la forme des combles et le type de matériau mis en œuvre?

Dans les limites d'un même département, les situations peuvent être assez contrastées, mais globalement, les plus fortes précipitations sont mesurées en Vendée $(880 \mathrm{~mm}$ à La Roche-sur-Yon ${ }^{25}$ ) et en Loire-Atlantique $(790 \mathrm{~mm}$ à Nantes). À l'inverse, les départements les moins pluvieux sont, dans l'ordre, le Maine-et-Loire (670 mm à Angers), la Sarthe $(685 \mathrm{~mm}$ au Mans) et la Mayenne $(740 \mathrm{~mm})$.

La cartographie des matériaux telle qu'elle est constatée, avec une répartition schématiquement sud-ouest/nord-est ne peut s'expliquer par le gradient pluviométrique orienté lui, ouest-est. Le département de la Loire-Atlantique est de ce fait significatif : les précipitations sont de même type au nord comme au sud, alors que les matériaux rencontrés y sont très différents.

25. Source : météo-France, moyenne des précipitations sur la période 1971-2000.
En définitive, la présence des tuiles canal en sud-Vendée ne découle pas de l'influence des conditions climatiques. Si celles-ci sont à l'évidence un facteur important dans la répartition des matériaux de couverture à l'échelle du territoire français, ce n'est pas le cas à l'échelle de notre aire d'étude restreinte. Pour la période romaine, il est frappant de constater qu'aucun déterminisme ni géologique ni climatique, n'est rentré en compte dans la diffusion de la tegula puisqu'elle a été adoptée uniformément dans toute la Gaule.

\section{Les autres facteurs}

Le lien entre la forme des combles et le type de matériau de couverture est bien avéré. La restriction de l'aire de la tuile creuse sans crochet peut être corrélée avec l'abaissement général des combles sur son secteur de repli, en Vendée, dans le pays de Retz, et dans les Mauges (Boissière, Delaval, 1995). Autrement dit, le crochet aurait été abandonné parce qu'il n'était plus indispensable dans la nouvelle aire réduite 
de la tuile ${ }^{26}$. Mais il est bien difficile de distinguer cause(s) et conséquence(s) : les tuiles canal ont-elles perdu leur crochet parce qu'il était devenu inutile sur les toits peu pentus du sud-Loire? ou a-t-on, à l'inverse, adapté la pente des toits à ce matériau plus facile à fabriquer et à mettre en œuvre?

L'identité et le statut social du maître d'ouvrage sont des facteurs importants dans le type de choix opéré. Les élites urbaines, qu'elles soient commerçantes ou religieuses, veulent, au travers de l'architecture, affirmer leur statut. Dans cette optique, au-delà du choix architectural, les matériaux eux-mêmes peuvent tenir une place importante. Mais la question est complexe en ce qui concerne le Moyen Âge, car les représentations mentales et symboliques médiévales ne sont pas les nôtres et on ne doit pas se limiter à une lecture strictement technique des matériaux. Il apparaît par exemple, que les matériaux périssables étaient d'un usage répandu, y compris sur des bâtiments d'un certain prestige, notamment pour des raisons symboliques (Pastoureau, 2004, p. 93).

L'interventionnisme des autorités a pu lui aussi jouer un rôle non négligeable. L'essor du fait urbain et la densification de l'habitat qui en découle au cours du Moyen Âge engendrent rapidement des problèmes du point de vue de la sécurité. Les maisons étant bâties majoritairement en pans de bois et couvertes en chaume ou en bardeaux, la menace d'incendie est donc très grande. Les autorités administratives ou communales émettent ainsi dès le début du XIII ${ }^{\mathrm{e}}$ siècle, des ordonnances pour tenter de réglementer l'usage de ces matériaux périssables (Épaud, 2007, p. 122; De Waha, 1986, p. 56; Hoffsummer, 2011, p. 321). Malgré cela, leur usage reste très large durant tout le Moyen Âge et même l'Époque moderne et les incendies de grande envergure sont alors fréquents.

Le coût est évidemment un des facteurs qui influe le plus sur le choix des matériaux. Pour ceux de construction en général, le coût reste en grande partie imputable au transport, qui, compte tenu de la faible qualité des réseaux et des péages successifs, est très important pendant tout le Moyen Âge et au cours de l'Époque moderne. Parmi les matériaux de couverture, l'ardoise est probablement celui qui pâtit le plus de cette situation. En effet, contrairement aux autres matériaux, la ressource est très localisée et l'exportation de ce matériau est nécessairement coûteuse. Le transport entre pour plus de $50 \%$ dans le coût total du matériau, ce qui limite grandement sa diffusion (Lebouteux, 2001, p. 54).

Du point de vue de leur abondance, les matières végétales sont évidemment les mieux placées, les coûts de récolte étant

26. Bien plus tard, l'introduction de la tuile mécanique sur les territoires habituels de la tuile plate ou de l'ardoise va engendrer une baisse des pentes dans toutes ces régions (Lebouteux, 2001, p. 8). très modérés, puisque dans la plupart des cas, les matériaux sont des sous-produits de la culture des céréales.

Pour les tuiles, comme on a pu le constater, dans la mesure où les ressources ne manquent pas non plus, étant également réparties sur le territoire, leur coût de transport devait être assez faible. Néanmoins, le façonnage requiert une maind'œuvre assez abondante tandis que le combustible nécessaire à la cuisson devait représenter une part importante du coût final. Cette situation change radicalement avec la mise au point de la tuile mécanique (brevet Gilardoni), au milieu du XIX ${ }^{e}$ siècle : son apparition induit, grâce au système d'emboîtement, la baisse du nombre de tuiles au mètre carré, soit une réduction des temps de pose et une baisse du coût global des couvertures en tuiles qui vont lui permettre de concurrencer l'ardoise sur les pentes moyennes.

\section{LES BRIQUES}

\section{Les briques avant le XIII ${ }^{\mathrm{e}}$ siècle}

\section{Le cas des briques moulées ornementales}

À l'exception d'un seul site de découverte récent (Rémy, 2014), l'archéologie préventive n'a pas apporté d'éléments nouveaux au corpus existant; ces briques seront donc rapidement évoquées.

Une remarquable série de briques moulées, rassemblée au musée Dobrée à Nantes, a été constituée, principalement au cours du XIX $x^{e}$ siècle, à partir des premiers édifices chrétiens de la région nantaise, principalement l'église abbatiale Saint-Martin de Vertou, l'église Saint-Similien à Nantes, la chapelle Saint-Martin à Couëron et le site de la chapelle Saint-Lupien à Rezé. Ces briques à décors historiés ou à motifs géométriques ne sont pas réellement des briques de maçonnerie mais plutôt des briques de placage ornementales. Elles relèvent de plusieurs types : briques-claveaux trapézoïdales, briques barlongues ou carrées composant probablement des frises, ou encore briques de corniche et modillons (fig. 20). Les motifs sont assez variés : chrisme, palmettes, scènes avec lièvres et lévriers, ou bien encore animaux marins, réels ou imaginaires, se rapportant aux légendes de l'Antiquité. La scène d'Adam et Ėve autour de l'arbre de la Tentation est la plus célèbre. Ces productions peuvent être datées des $\mathrm{VI}^{\mathrm{e}}$-VII ${ }^{\mathrm{e}}$ siècles, bien qu'elles aient toujours été trouvées en position secondaire.

D'autres éléments ont été découverts à Angers, et dernièrement, à Juigné-sur-Loire (Maine-et-Loire), où une fouille a mis au jour un lot de briques sensiblement différentes, remployées dans le soubassement d'un mur daté des $\mathrm{VI}^{\mathrm{e}}$ VII ${ }^{\mathrm{e}}$ siècles (Rémy, 2014). 

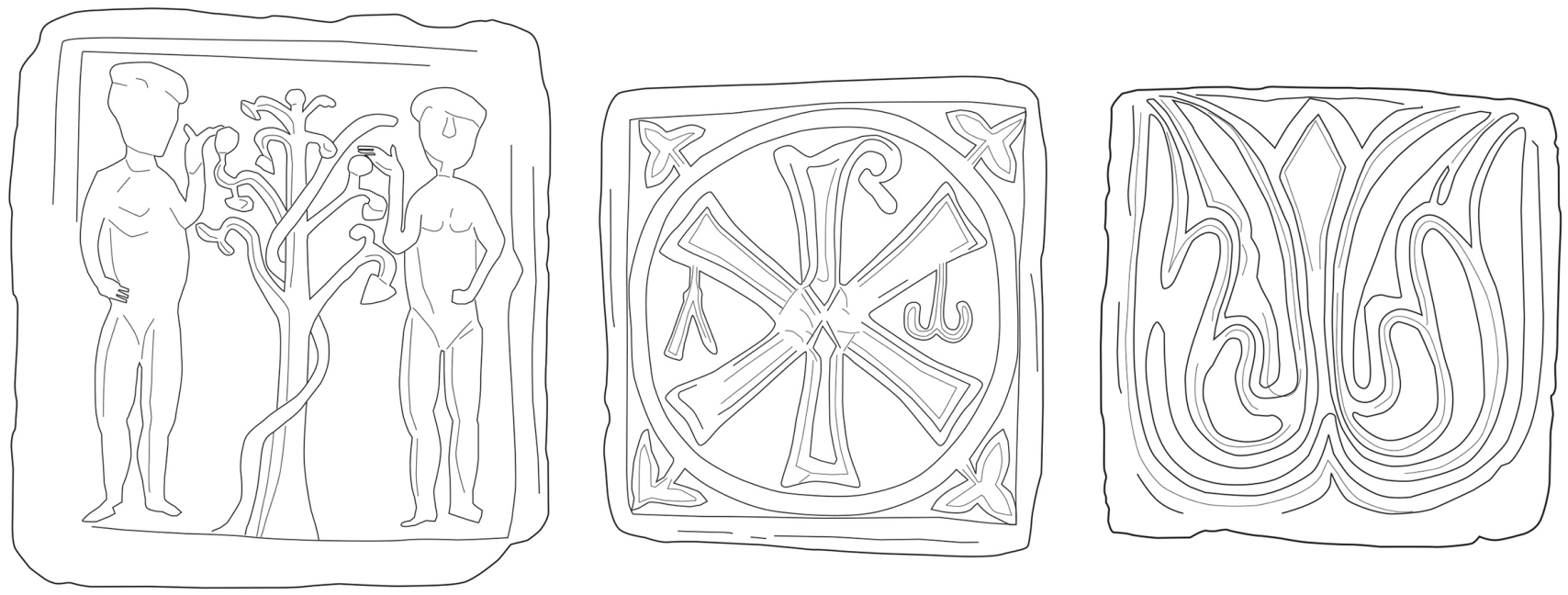

Figure 20 : Exemples de briques ornementales mérovingiennes (Vertou, Loire-Atlantique, Église Saint-Martin. Collections Musée Dobrée, Nantes; de gauche à droite : 850.29.1, 903.469, 876.4.11) (J.-F. Nauleau, Inrap).

Figure 20: Examples of merovingien ornemental bricks (Vertou, Loire-Atlantique, Église Saint-Martin. Collections Musée Dobrée, Nantes; from left to right: 850.29 .1 , 903.469, 876.4.11) (J.-F. Nauleau, Inrap).

Des éléments similaires ont été également trouvés dans la région parisienne (Périn, 1986) et en Normandie. Plus loin, les premières découvertes ont été faites en Espagne et surtout en Afrique du Nord (Tunisie notamment, Duval et al., 1991), ce qui a conduit les chercheurs à y voir une influence directe sur les productions de la basse-Loire. En réalité, les répertoires de motifs et de symboles sont communs à l'ensemble de ces communautés chrétiennes, tandis que les supports d'expression eux, varient selon les régions.

Peu d'études ont concerné les lots régionaux depuis l'inventaire de D. Costa en 1964 (Costa, 1964). Citons par exemple le travail de M.-C. Maufus (Maufus, 1983). Compte tenu du meilleur état des connaissances concernant les matériaux en terre cuite durant le haut Moyen Âge (Jesset, 2014 par exemple), un réexamen de l'ensemble des collections régionales paraît à présent nécessaire.

\section{Les briques de maçonnerie}

La brique romaine est relativement bien présente dans la région au cours des $\mathrm{I}^{\mathrm{er}}$ et $\mathrm{II}^{\mathrm{e}}$ siècles, puis décline rapidement ensuite durant l'Antiquité tardive ${ }^{27}$. Son emploi dans les enceintes des chefs-lieux de cité vers la fin du III $^{\mathrm{e}}$ siècle pouvant résulter, au moins en partie, de pratiques de remploi. L'importance des quantités de matériaux (blocs architectoniques par exemple) prélevés sur les édifices publiques

27. Notons tout de même à Neuville-sur-Sarthe (Sarthe), sur la fouille du site du "Chapeau " (Guillier, 2013), un caveau daté de la fin du III ${ }^{e}$ ou du début du Iv $v^{e}$ siècle construit en briques très homogènes de format 320 $\times 260 \mathrm{~mm}$ qui semblent témoigner d'une production et non d'un remploi. urbains des $\mathrm{I}^{\mathrm{er}}$ et $\mathrm{II}^{\mathrm{e}}$ siècles et remployés dans les fondations de ces enceintes n'est plus à démontrer.

Pour la période du haut Moyen Âge, aucune brique n'a été recensée dans l'aire d'étude. Ainsi, au-delà d'un probable biais dû au peu de données disponibles, il est avéré qu'elles sont rarissimes à cette époque. Cette absence ne peut être attribuée à une perte de savoir-faire puisque, dans le même temps, des briques ornementales de grande qualité sont produites (cf. supra) et que par ailleurs, la production de briques est avérée en région Centre (Jesset, 2014).

Elles réapparaissent ensuite sur un certain nombre d'édifices carolingiens, principalement religieux mais pas exclusivement ${ }^{28}$, qui restent toutefois limités quantitativement à l'échelle de la région. On les trouve alors fréquemment en arases horizontales au sein d'un appareil mixte qui évoque l'opus mixtum romain, mais souvent disposées avec une moindre régularité; des tegulae peuvent même avoir été utilisées. La brique est aussi employée en claveau d'arc de baie, le plus souvent en alternance avec la pierre de taille, et en bandeau(x) à l'extrados de l'arc. On les trouve enfin, mais plus rarement, en opus spicatum (appareil en arêtes de poisson), comme sur les églises de Savennières (Maine-etLoire), ou dans le contrecœur de l'aula de Doué-la-Fontaine (Maine-et-Loire).

Par ailleurs, la région abrite également un certain nombre d'édifices dans lesquels la brique est présente. Par exemple en Loire-Atlantique, l'abbatiale de Saint-Philbert de Grand-

28. Citons par exemple l'aula de Doué-la-Fontaine (Maine-et-Loire), l'enceinte de Champtoceaux (Maine-et-Loire) et le château de Mayenne (Mayenne). 
Lieu, l'église Saint-Médard de Doulon à Nantes (démolie en 1971, Lotton, Pirault, 2007), enfin l'église Saint-Martin de Vertou (démolie à la Révolution ${ }^{29}$ ). En Maine-et-Loire, la collégiale Saint-Martin d'Angers, et les églises SaintSymphorien d'Andard, et Saint-Pierre et Saint-Romain de Savennières (fig. 21 et 22).

L'étude de la mise en œuvre des briques autour de l'an mil rencontre plusieurs difficultés. D'une part, la datation des édifices eux-mêmes pose problème, tant les indices stylistiques, les modes constructifs et les éventuelles datations absolues $\left({ }^{14} \mathrm{C}\right)$ peuvent être contradictoires. Longtemps, on s'est appuyé sur la présence de l'opus mixtum pour attribuer aux édifices concernés une datation proche ou antérieure à l'an mil. L'état actuel de la recherche montre cependant la complexité de la question que le recours à des méthodes de datation croisées a permis de reconsidérer (Baylé, 1997; Guibert et al., 2007; Guibert et al., 2014).

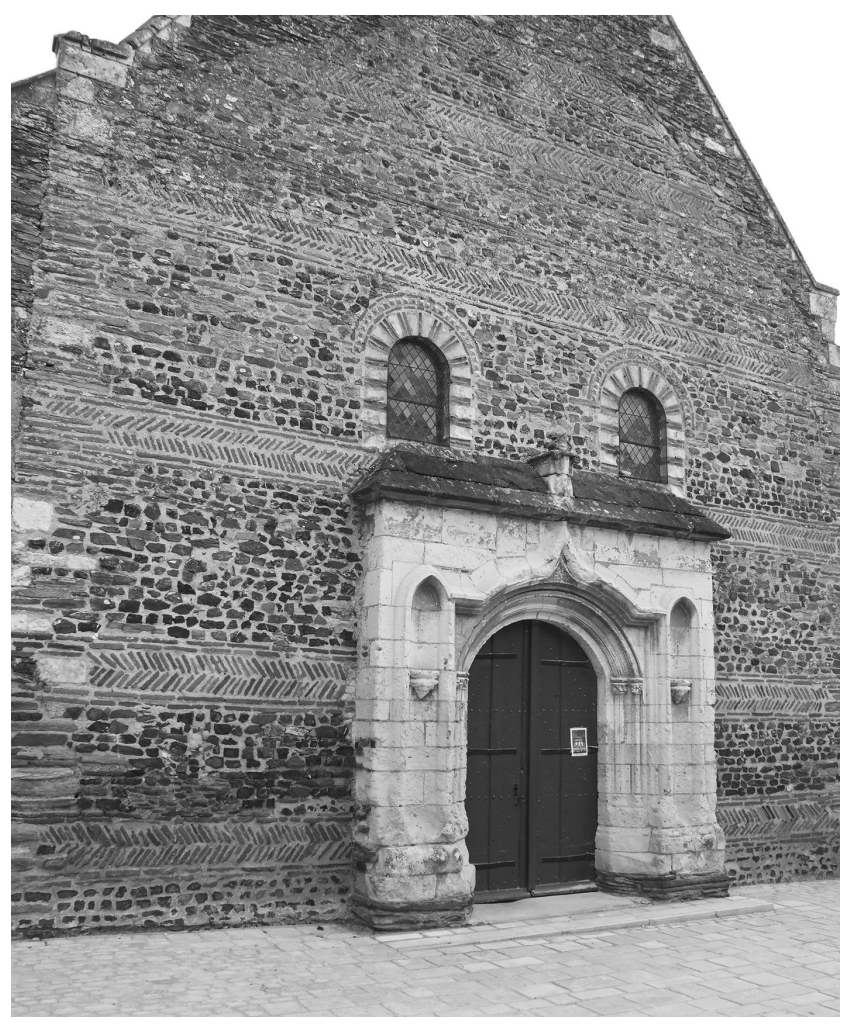

Figure 21 : (Voir planche couleur XXXII) Façade de l'église SaintPierre et Saint-Romain de Savennières (Maine-et-Loire) (Cliché J.-F. Nauleau, Inrap).

Figure 21: (See colour plate XXXII) Facade of the Saint-Pierre and Saint-Romain church in Savennieres (Maine-et-Loire) (Photo J.-F. Nauleau, Inrap).

29. Un croquis a été réalisé par le curé de la paroisse avant sa démolition et montre un appareil de briques en opus spicatum sur la façade (communication orale L. Pirault, Inrap).

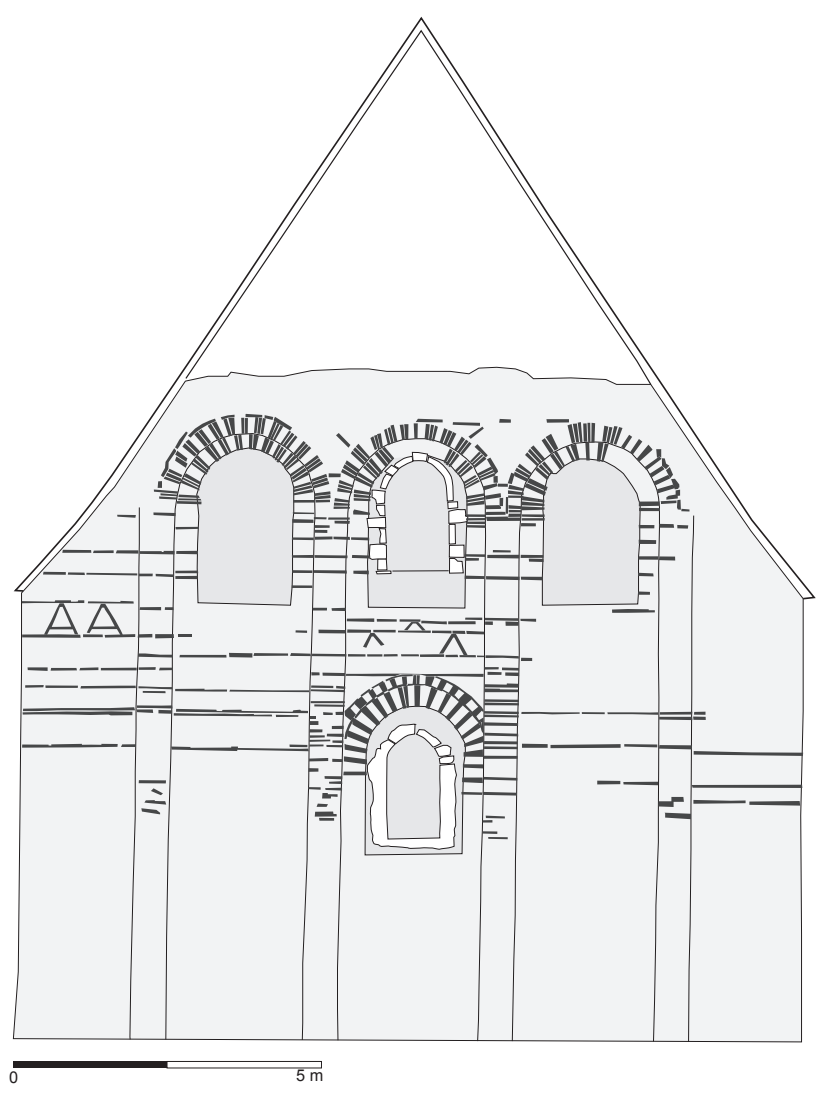

Figure 22 : Chevet de l'église Saint-Médard de Doulon (Nantes, Loire-Atlantique) (L. Pirault, Inrap, à partir des relevés de G. Ferronnière et P. Lebouteux).

Figure 22: Apse of the Saint-Médard church at Doulon (Nantes, LoireAtlantique) (L. Pirault, Inrap, from the drawings of G. Ferronnière and P. Lebouteux).

Concernant les matériaux eux-mêmes, il a semblé longtemps évident qu'il ne s'agissait que de remplois antiques, tant on pensait les techniques de productions perdues (Baylé, 1997). Par ailleurs, des cas de remplois sont manifestes $^{30}$ et même bien au-delà de la période carolingienne. C'est le cas par exemple au Mans, à proximité de la cathédrale, où des briques, probablement prélevées sur l'enceinte gallo-romaine, sont employées dans l'âtre d'une cheminée de la fin du XIII ${ }^{\mathrm{e}}$ ou du début du XIV ${ }^{\mathrm{e}}$ siècle (fouille de la place du Jet-d'Eau, cf. supra). Quant à l'opus spicatum, il est présenté en général comme un appareil décoratif. Pourtant, il est avéré qu'il répond surtout à la médiocre qualité des matériaux (Valais, 1998, p. 60) à mettre en ouvre ${ }^{31}$ et qu’il est, à ce titre, révélateur de pratiques de remploi.

30. Citons par exemple le cas de remploi de bessales romaines dans un spectaculaire pavage polychrome à l'abbaye de Landevennec au $\mathrm{x}^{\mathrm{e}}$ siècle (Finistère).

31. Durant l'Antiquité, à Toulouse, cet appareil a été employé pour répondre à l'hétérogénéité du format des briques de remplois disponibles (De Filippo, 2004, p. 114). 
Pour autant, des situations de productions réelles de briques sont avérées par l'archéologie comme dans le cas de Notre-Dame-sous-Terre, au Mont-Saint-Michel, dans la seconde moitié du x ${ }^{e}$ siècle (Guibert et al., 2007), ou bien mentionnées dans les textes comme à Fécamp à la même période (Renoux, 1991, p. 433-455).

Le recours aux études métrologiques sur les édifices permet d'apporter des éléments d'analyse souvent décisifs et, le cas échéant, de mettre en évidence des productions médiévales. Dans la région par exemple, le format des briques romaines est à présent assez bien connu (Le Bohec, 1983; Goulpeau, 1988; Nauleau, 2013a). Même si leur gabarit semble évoluer dans le temps dans le sens d'une diminution généralisée, il semble possible de discriminer matériaux romains remployés et matériaux médiévaux.

Quelques observations ont été faites sur les briques de l'abbatiale de Saint-Philbert de Grand-Lieu (LoireAtlantique) et sur celles de l'église Saint-Pierre et SaintRomain de Savennières (Maine-et-Loire). À Saint-Philbert, des mesures réalisées sur une série de briques permettent de proposer un gabarit moyen situé aux alentours de $340 \times 210$ $\times 35 / 40 \mathrm{~mm}$. En revanche, à Savennières, le format moyen est de $385 \times 285 \times 40 \mathrm{~mm}$, très proche de celui des briques romaines décrites à Angers et Rezé (Nauleau, 2013a). L'hypothèse d'un remploi massif de matériaux romains peut donc être envisagée, provenant de bâtiments romains situés à proximité immédiate ou même, pourquoi pas, à partir de l'enceinte romaine d'Angers. De très importantes quantités de matériaux ont été prélevées sur ces édifices antiques mais force est de constater que l'on en trouve bien peu de traces sur les sites médiévaux, en tout cas sur les sites ruraux (Valais, 2012b) sur lesquels l'emploi de la pierre est très peu fréquent pendant toute la période.

En Normandie (Baylé, 1997), deux séries de briques ont été repérées sur plusieurs monuments : des briques longues de $410 \mathrm{~mm}$ dans les parties basses des édifices et d'autres comprises entre 250 et $280 \mathrm{~mm}$, observées dans les parties hautes. La première série peut être considérée comme résultant d'une campagne de récupération de matériaux romains, tandis que l'autre serait le témoignage d'une production des environs de l'an mil.

Le format des briques n'étant pas le seul critère sur lequel s'appuyer, on peut aussi travailler sur l'étude macroscopique des pâtes, comme dans le cas des tegulae alto-médiévales, déjà évoqué. Les pâtes médiévales homogènes contiennent une forte proportion d'inclusions siliceuses, tandis que les pâtes romaines ont une fraction non plastique très réduite, mais contiennent de nombreux et caractéristiques nodules d'argilite ocre. L'exemple de Saint-Philbert illustre bien cette constatation (fig. 23). Les stigmates de façonnage tels que le sablage, la rectification des tranches ainsi que les traces de

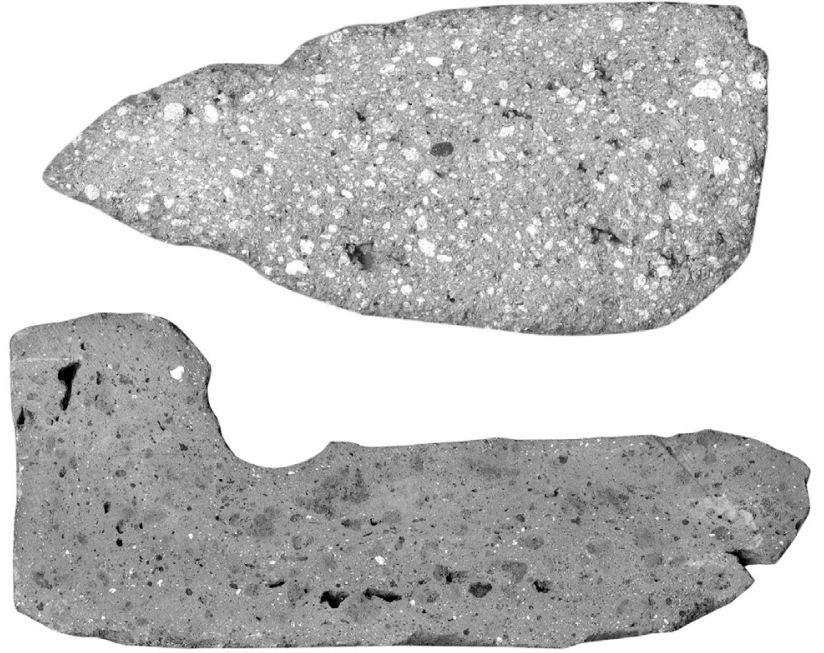

Figure 23 : (Voir planche couleur XXXII) Briques romaines et briques médiévales : les types de pâtes comme marqueur (J.-F. Nauleau, Inrap).

Figure 23: (See colour plate XXXII) Roman and Medieval bricks: paste types as markers (J.-F. Nauleau, Inrap).

décompte (marques digitées et incisions sur tranches) sont également des éléments à prendre en compte.

Au sujet de la production réelle de briques aux alentours du x siècle, il est donc difficile de généraliser à l'ensemble de la région, chaque édifice étant à considérer individuellement. De plus, l'histoire de ces édifices étant souvent complexe, seules des campagnes d'étude et de datations rigoureuses sur les maçonneries $\left({ }^{14} \mathrm{C}\right)$ et sur les terres cuites (archéomagnétisme et thermoluminescence), seraient à même de préciser les périodes d'édification des édifices et de production des matériaux en terre cuite mis en œuvre dans leur architecture.

\section{La renaissance de la brique au XIII ${ }^{\mathrm{e}}$ siècle}

À partir du XIII ${ }^{\mathrm{e}}$ siècle s'opère un relatif essor de la brique. Cantonnée jusqu'alors à des édifices prestigieux, elle commence à pénétrer la société et à s'implanter sur des sites ruraux. Quelques sites du second Moyen Âge ont ainsi livré de la brique, souvent en quantité limitée.

\section{Les sites}

En milieu rural, le site de Juigné-sur-Sarthe a livré quelques fragments homogènes (Nauleau, 2013c), provenant d'un bâtiment non maçonné, situé au cœur d'un enclos fossoyé de faible envergure.

Le manoir de La Milesse (Sarthe) a, quant à lui, fourni un lot de petites briques daté de la fin du Xvi siècle jusqu’à l'époque contemporaine. À Nantes, dans le quartier SaintJoseph-de-Porterie, le diagnostic d'un ensemble bâti daté 
Tableau 3 : Format des briques composant le lot étudié.

Table 3: Brick formats from the studied lot.

\begin{tabular}{|c|c|c|c|c|c|c|}
\hline Site & $\begin{array}{c}\text { Type de mise en } \\
\text { ouvre }\end{array}$ & Ref. lot & $\begin{array}{l}\text { Longueur } \\
(\mathrm{mm})\end{array}$ & $\begin{array}{l}\text { Largeur } \\
(\mathrm{mm})\end{array}$ & $\begin{array}{c}\text { Epaisseur } \\
(\mathrm{mm})\end{array}$ & Datation proposée \\
\hline \multirow{2}{*}{$\begin{array}{l}\text { Saint-Georges -sur-Loire } \\
\text { (Maine-et-Loire) } \\
\text { « Réfectoire des Moines » }\end{array}$} & Conduit de cheminée & $\begin{array}{l}\text { moyenne de } 40 \\
\text { ind. }\end{array}$ & 155 & 95 & $21 / 23$ & Fin XVle s. \\
\hline & Sol & & 217 & 108 & 24 & $\mathrm{XVIII}{ }^{\mathrm{e}}$ s.? \\
\hline \begin{tabular}{|c|} 
Brissac-Quincé (Maine-et- \\
Loire) « Place de l'église »
\end{tabular} & $\begin{array}{l}\text { Paroi de moule à } \\
\text { cloche }\end{array}$ & $\begin{array}{l}\text { moyenne de } 10 \\
\text { ind. }\end{array}$ & $180 / 185$ & $95 / 100$ & $20 / 23$ & \begin{tabular}{|c|} 
première moitié $\mathrm{XVI}$ \\
$\mathrm{s}$.
\end{tabular} \\
\hline $\begin{array}{l}\text { Laval (Mayenne) « Ilot } \\
\text { Saint-Tugal » }\end{array}$ & $\begin{array}{l}\text { Paroi de moule à } \\
\text { cloche }\end{array}$ & $\begin{array}{l}\text { moyenne de } 10 \\
\text { ind. }\end{array}$ & 185 & $95 / 100$ & $?$ & $\begin{array}{c}\text { première moitié } \mathrm{XVI} \\
\mathrm{s} .\end{array}$ \\
\hline $\begin{array}{c}\text { Nantes (Loire-Atlantique) } \\
\text { «Manoir de Bouvet » }\end{array}$ & Murs porteurs & $\begin{array}{l}\text { Observations } \\
\text { dans maçonnerie }\end{array}$ & $210 / 250$ & $110 / 130$ & $20 / 40$ & vers 1760 \\
\hline \multirow{4}{*}{$\begin{array}{c}\text { Nantes (Loire-Atlantique) } \\
\text { «Zac Erdre-Porterie » }\end{array}$} & & & 220 & 108 & 35 & \multirow{4}{*}{$\mathrm{XV}^{\mathrm{e}}$ s. probable } \\
\hline & & & 175 & 75 & 42 & \\
\hline & & & 215 & 102 & 25 & \\
\hline & & & & 125 & & \\
\hline \multirow{2}{*}{$\begin{array}{c}\text { Le Mans (Sarthe) «Place } \\
\text { du Jet d'eau » }\end{array}$} & Âtre de cheminée & & 207 & 105 & $15 / 17$ & \multirow{2}{*}{$\mathrm{XIV}$ s. probable } \\
\hline & & & & 115 & $15 / 18$ & \\
\hline \multirow{3}{*}{$\begin{array}{c}\text { La Milesse (Sarthe) « La } \\
\text { Ronce» }\end{array}$} & Maçonnerie & $\begin{array}{c}\text { moyenne de } 25 \\
\text { ind. }\end{array}$ & 195 & 80 & 27 & \multirow{3}{*}{$>\mathrm{XVl} \mathrm{I}^{\mathrm{s}}$} \\
\hline & & & & 102 & & \\
\hline & & & & 108 & & \\
\hline \multirow{13}{*}{$\begin{array}{c}\text { Nantes (Loire-Atlantique) } \\
\text { «Plateau du Bouffay } ~\end{array}$} & & 1120 & & 115 & 35 & $\mathrm{XIV}^{\mathrm{e}} \mathrm{s}$ ? ? \\
\hline & & & & 99 & & Avant $1480 \mathrm{~s}$ \\
\hline & & 1086 & & 105 & 39 & prob. $X V I^{e} s$. \\
\hline & & 1109 & & 110 & $35 / 36$ & \multirow{3}{*}{ prob. $X V I^{e} s$} \\
\hline & & 1110 & & 108 & $37 / 38$ & \\
\hline & & & & 107 & & \\
\hline & & 1114 & & 90 & $23 / 29$ & \multirow{5}{*}{$X V I I I^{e}-X V I I I I^{e} s$} \\
\hline & & 1115 & & 99 & 24 & \\
\hline & & 1116 & & 111 & 34 & \\
\hline & & & & 102 & & \\
\hline & & & & 112 & & \\
\hline & & & & 102 & & \multirow{2}{*}{$X V I I I^{e}-X I X^{e} s}$. \\
\hline & & & & 107 & & \\
\hline \multirow{5}{*}{$\begin{array}{c}\text { Juigné-sur-Sarthe (Sarthe) } \\
\text { « Les Touches » }\end{array}$} & \multirow{5}{*}{$\begin{array}{l}\text { Âtre ou conduit de } \\
\text { cheminée (?) }\end{array}$} & 1180 & & 103 & 15 & \multirow{5}{*}{ milieu XIII' $-X^{e} V^{e} s$} \\
\hline & & 1176 & & 107 & $15 / 16$ & \\
\hline & & 1179 & & 110 & 16 & \\
\hline & & 1178 & & 120 & $20 / 21$ & \\
\hline & & 1177 & & 122 & 19 & \\
\hline
\end{tabular}

des alentours $\mathrm{du} \mathrm{Xv}^{\mathrm{e}}$ siècle a permis de recueillir un lot de matériaux assez varié (Nauleau, 2009b, p. 79-80).

En milieu urbain, la fouille du quartier du Bouffay à Nantes a également permis de constituer un lot situé entre le XIV et le XIX ${ }^{e}$ siècle (Nauleau, 2014c).

Quoique les études de bâti se soient jusqu’à présent peu intéressées au cas de la brique, celle-ci est donc pourtant bien présente et commence à être considérée, comme par exemple à Nantes, sur le manoir moderne et contemporain de la Fontaine de Hérédie (étude en cours, direction du Patrimoine et de l'Archéologie, ville de Nantes).

\section{La morphologie des briques}

À Juigné-sur-Sarthe (Sarthe), cinq briques présentent une largeur intacte qui s'échelonne entre 103 et $122 \mathrm{~mm}$, pour des épaisseurs comprises entre 15 et $21 \mathrm{~mm}$. Leur façonnage est assez grossier et des traces de lissage aux doigts dessinant de petites gorges en face supérieure de certains éléments. Le lot est daté de la fin du XIII ${ }^{\mathrm{e}}$ jusqu'à la seconde moitié du $\mathrm{XIV}^{\mathrm{e}}$ siècle.

À Nantes, on dénombre une trentaine de fragments. Les largeurs relevées s'échelonnent entre 90 et $115 \mathrm{~mm}$ avec des épaisseurs très variables de 24 à près de $40 \mathrm{~mm}$. La brique la 
plus large $(115 \mathrm{~mm})$ est aussi celle qui provient du contexte le plus ancien (XIV siècle).

À La Milesse, le format très majoritaire est de $195 \times 80 \times$ $27 \mathrm{~mm}$; seules deux briques sont larges de 102 et $108 \mathrm{~mm}$. Elles semblent apparaître assez tardivement dans le bâtiment, vers la fin du Xvi ${ }^{\mathrm{e}}$ siècle.

À Saint-Joseph-de-Porterie (Nantes), les dimensions sont très variables, au même titre que les pâtes, ce qui témoigne de probables phases de remaniement du bâtiment au-delà du $\mathrm{XV}^{\mathrm{e}}$ siècle : les dimensions relevées sont $220 \times 108 \times 35 \mathrm{~mm}$, $175 \times 75 \times 42 \mathrm{~mm}, 215 \times 102 \times 25 \mathrm{~mm}$ par exemple.

Enfin, au Mans, sur la fouille de la place du Jet-d'Eau, une brique de format $207 \times 105 \times 15 / 17 \mathrm{~mm}$ était employée dans l'âtre d'une cheminée.
L'effectif du corpus de briques est numériquement trop faible et insuffisamment daté pour qu'il ne soit possible d'engager une étude réelle de l'évolution de leur format à l'échelle de la région. Notons tout de même qu'il semble que la brique adopte, dès le XIII ${ }^{\mathrm{e}}$ siècle, un petit gabarit inférieur à $220 \mathrm{~mm}$ de long, de 75 à $125 \mathrm{~mm}$ de largeur et de 20 à $30 \mathrm{~mm}$ d'épaisseur. Cette observation corrobore nombre d'autres études qui mettent en évidence la naissance d'une brique médiévale allongée, différente de la brique romaine (Jeremic, 1997). Ce gabarit est également assez proche de celui de la brique industrielle $(220 \times 105 \mathrm{~mm})$, qui semble donc se dessiner dès cette époque (fig. 24). Seule l'épaisseur diffère, elle est en, général, de 45 à $55 \mathrm{~mm}$ à partir du $\mathrm{XIX}^{\mathrm{e}}$ siècle.

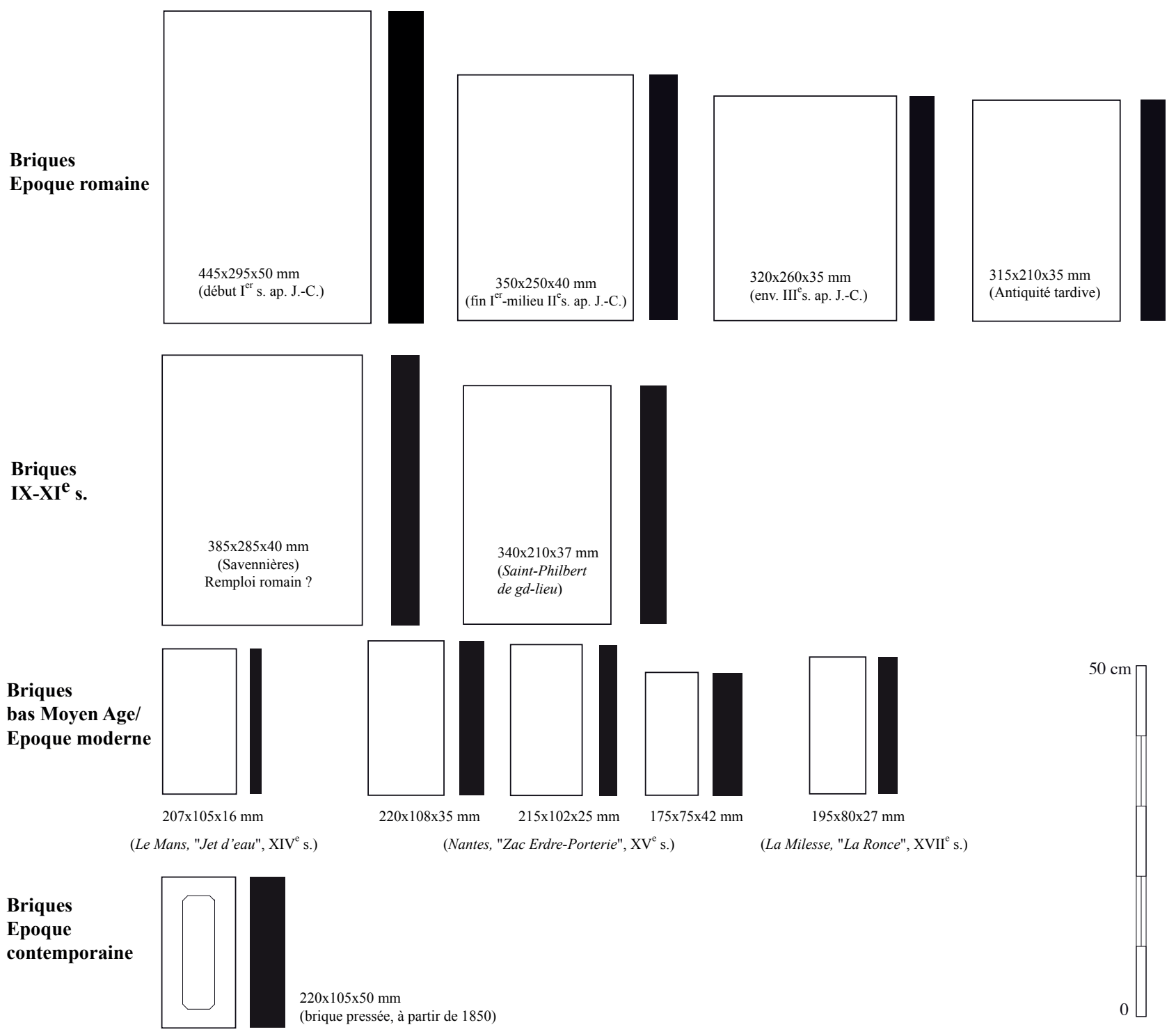

Figure 24 : Formats des briques médiévales et modernes comparés aux formats romains (J.-F. Nauleau, Inrap).

Figure 24: Medieval and modern brick formats compared to Roman formats (J.-F. Nauleau, Inrap). 
À l'échelle du territoire français, on sait que les briques font leur apparition massive en France à partir de deux pôles de diffusion, l'un dans la région Nord, la Belgique et les Pays-Bas et l'autre dans le Midi toulousain, aux alentours des $\mathrm{XI}^{\mathrm{e}}-\mathrm{XII}^{\mathrm{e}}$ siècles. Le format des briques rencontrées à cette période est plutôt grand : $280 \times 140 \times 80 \mathrm{~mm}$ dans le nord et $360 \times 250 \times 40 / 50 \mathrm{~mm}$ dans le Midi toulousain pour les briques dites "foraines " (De Montjoye, 2003; Chapelot, 2004). Dans notre zone d'étude, les valeurs sont bien moindres et si l'on tente de se raccrocher à ces grandes aires culturelles de la brique, les dimensions et le format allongé se rapporteraient plutôt aux matériaux de l'aire septentrionale. Il reste encore à comprendre les modalités de la diffusion des briques médiévales et de la constitution de ces deux entités spatiales sur le territoire français.

\section{L'étude des pâtes : un marqueur de diffusion}

Une étude macroscopique après découpe des matériaux sur une table de sciage, assortie d'une numérisation à haute définition, permet, dans un premier temps, une description et une catégorisation satisfaisante ${ }^{32}$. Sur le site du plateau du Bouffay, à Nantes, ce travail a été mené sur les briques et les carreaux de sol. Plusieurs groupes techniques de pâte ont ainsi pu être isolés au sein du lot de matériaux; l'importance et la nature des éléments de la fraction non plastique ainsi que les caractéristiques de celle plastique sont très variables et permettent d'effectuer des distinctions.

La tentative de corrélation entre type de pâte et type de matériau n'a pas été probante, il apparaît que les différents groupes techniques se rencontrent dans plusieurs catégories de matériaux. En revanche, la corrélation avec les contextes chronologiques est bonne (fig. 25). Ainsi le groupe 1, pâte hétérogène à nombreuses inclusions siliceuses (argile altéritique du massif Armoricain d'origine locale) ne concerne que des matériaux trouvés dans des contextes médiévaux. De même, la pâte du groupe technique 3, pâte " marbrée " blanche à crème avec nodules ocre, très caractéristique, ne concerne que des matériaux apparaissant dans les niveaux du XVII ${ }^{e}$-XVIII ${ }^{e}$ siècles. Ces pâtes marbrées sont par ailleurs systématiquement rencontrées sur les sites sarthois et plus largement sur toute l'aire géographique de la région concernée par le Bassin parisien. Un travail auprès du centre tuilier des Rairies ${ }^{33}$ (Durtal, Maine-et-Loire), a permis de faire des rapprochements entre certaines des productions médiévales et modernes et les argiles encore employées sur place. Il est

32. En revanche, lorsqu'on veut répondre à des questions précises de caractérisation de groupes techniques ou de provenance, le recours à des analyses chimiques ou minéralogiques s'avère indispensable dans un second temps.

33. Collaboration en particulier avec Didier Cailleaux aux Rairies (Maine-et-Loire).
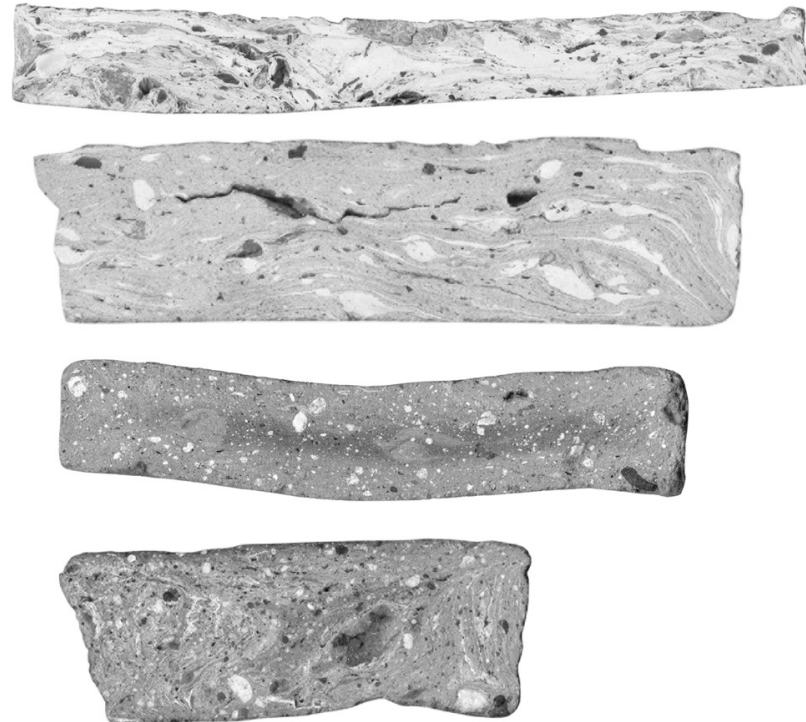

Figure 25 : (Voir planche couleur XXXIII) Pâtes locales (en bas) (argiles altéritiques) et pâtes importées (en haut) (argiles de bassin sédimentaire) (J.-F. Nauleau, Inrap).

Figure 25: (See colour plate XXXIII) Local pastes (down) (alteritic clays) and imported pastes (up) (clays from the sedimentary basin) (J.-F. Nauleau, Inrap).

avéré que les pâtes d'aspect marbré et contenant des nodules non plastiques blanc à ocre sont liées à des gisements argileux sédimentaires du Bassin parisien. Néanmoins, en l'absence d'un travail de grande ampleur centré sur le recensement des gisements argileux, d'une part, et d'une analyse d'un corpus de matériaux d'autre part, il est prématuré d'établir des corrélations plus précises.

Ce constat permet néanmoins d'établir qu'à partir d'une époque située aux environs du XvII siècle, mais qui reste à préciser, les matériaux fabriqués dans des ateliers exploitant des argiles du Bassin parisien (Maine-et-Loire, Sarthe, Indre-et-Loire, etc.) ont été importés et diffusés dans l'ouest de la région. Il faut probablement y voir le résultat d'une préférence qualitative, les argiles sédimentaires, plus fines, s'adaptant mieux à la production de certains éléments et notamment à celle des carreaux de sol ${ }^{34}$. On peut se demander si ces productions n'ont pas accompagné vers l'ouest le tuffeau massivement importé durant l'Époque moderne grâce à la batellerie de Loire et de ses affluents. Une enquête au sein des sources archivistiques permettrait probablement de préciser cette question. Il est également possible de faire un lien avec les importations observées dans le domaine du mobilier céramique : on constate en effet que vers le

34. Encore actuellement, les unités de production exploitant des argiles altéritiques du massif Armoricain (Vendée, Maine-et-Loire), importent des argiles sédimentaires plus plastiques (brie flandrien côtier ou argiles mésozoïques) pour la production de carreaux de sol. 
$\mathrm{XVII}^{\mathrm{e}}$ siècle, les grès du Berry affluent dans la région ${ }^{35}$, ce qui semblerait confirmer l'importance de routes commerciales entre ces territoires.

\section{Contexte architectural des briques}

Régionalement, la place des briques dans l'architecture médiévale et moderne est délicate à apprécier, faute de témoignages matériels suffisamment abondants et d'études réelles. Dans le cas d'un bâtiment à ossature bois, plusieurs hypothèses peuvent être proposées. Il peut s'agir de matériaux mis en œuvre dans des maçonneries de type solin ou mur-bahut destinées à supporter les sablières basses de l'ossature bois et éviter un contact avec le sol. Il peut s'agir de briques utilisées en hourdis, c'est-à-dire en remplissage entre les pans de bois. Enfin, on peut aussi envisager leur emploi dans tout ce qui concerne la cheminée : âtre, contrecœur, conduit ou souche de cheminée sur la toiture.

Si les deux premières hypothèses sont bien attestées dans les terres d'élection de la brique (Midi toulousain et Nord de la France), elles le sont peu dans la région. Les remplissages de pans de bois en briques y sont assez peu répandus et n’apparaissent pas avant le début du XvI ${ }^{\mathrm{e}}$ siècle (Alix, Epaud, 2013).

En revanche, la dernière hypothèse est attestée archéologiquement, notamment au Mans, sur le site de la place du Jet-d'Eau : l'âtre de la cheminée d'un bâtiment du quartier canonial est réalisé à partir de tuiles plates, de carreaux de sol et de briques posées de chant, constituant un sol réfractaire. Des observations similaires ont été faites en Normandie, à Louviers (Eure, Calderoni et al.).

De plus, les observations archéologiques montrent le développement important des conduits en brique à partir du XVI ${ }^{e}$ siècle (fig. 26), sachant que les données sont plus difficiles à rassembler pour les périodes antérieures. La faible largeur de la brique est à l'évidence un atout car elle permet de ménager un conduit assez large, même dans un mur d'épaisseur limitée. Plus généralement, des études récentes sur l'histoire de la cheminée en Pays de la Loire (Meuret, 2012) ont montré le développement de la cheminée adossée et sa diffusion dans la société au cours des $\mathrm{XII}^{\mathrm{e}}$-XIII ${ }^{\mathrm{e}}$ siècles. Compte tenu de ces données, il n'est pas interdit de penser que la brique doit sa réapparition, au moins dans un premier temps, à sa parfaite adéquation technique avec la cheminée.

\section{Bilan de L'ÉTUde}

Par bien des aspects, cette étude ne constitue qu'un début de recensement et d'étude des différents matériaux en terre

35. Merci à Christian Le Boulaire (direction du Patrimoine et de l'Archéologie de la ville de Nantes) pour ces informations.

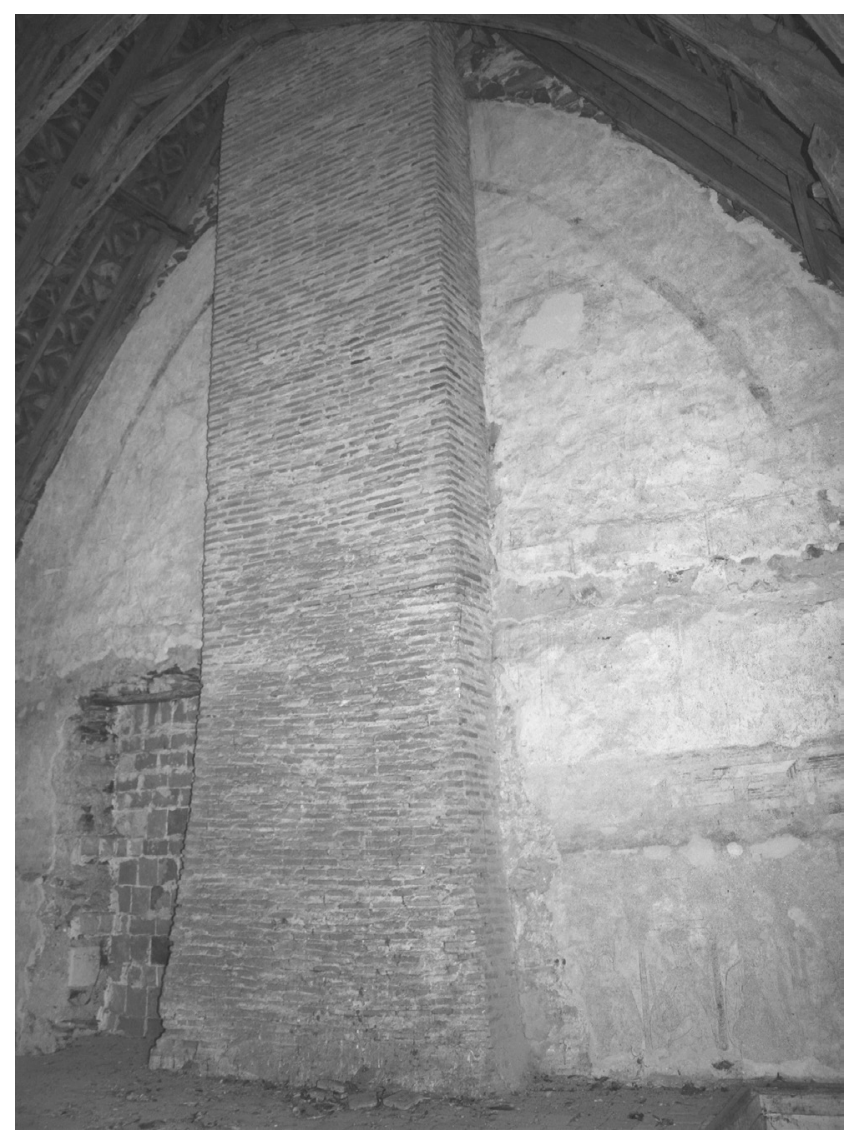

Figure 26 : (Voir planche couleur XXXIII) Conduit en briques, "Réfectoire des Moines », Saint-Georges-sur-Loire, Maine-et-Loire (date probable : 1573) (Cliché J.-F. Nauleau, Inrap).

Figure 26: (See colour plate XXXIII) Brick duct, "Réfectoire des Moines", Saint-Georges-sur-Loire, Maine-et-Loire (probable date: 1573) (Photo J.-F. Nauleau, Inrap).

cuite. Elle a permit cependant d'éclairer un certain nombre de points particuliers.

Ainsi, le travail sur les tegulae de l'époque du haut Moyen Âge fournit des moyens d'identification permettant de les discriminer par rapport à celles de l'époque romaine. Pour le second Moyen Âge, l'étude des tuiles améliore notre connaissance des gabarits et des aires d'extension respectives des deux types (creuse et plate). L'évolution de ces aires permet même d'esquisser une histoire de ce matériau pour la fin du Moyen Âge et l'Époque moderne.

En ce qui concerne les briques, elles semblent quasiment absentes pendant tout le premier Moyen Âge, à l'exception des briques ornementales. Il faut attendre le XIII ${ }^{e}$ siècle pour qu'elles réapparaissent sous un petit format, en lien probable avec l'essor d'un nouveau dispositif d'agrément dans l'habitat : la cheminée. L'étude des pâtes révèle qu'à partir du XVII ${ }^{e}$ ou du XVIII ${ }^{e}$ siècle, un apport massif de matériaux en provenance du Bassin parisien (ouest de la région ou plus 
vraisemblablement Berry ou Touraine) supplante les productions locales associées aux argiles altéritiques du massif Armoricain, surtout dans le domaine des carreaux de sol non glaçurés.

Quoi qu'il en soit, des points pour lesquels les données rassemblées ici sont trop peu abondantes restent à développer. La question de l'emploi de la brique au cours du premier Moyen Âge est au nombre de ceux-ci. Un réexamen des lots de briques ornementales parait nécessaire de même que des campagnes de mesures sur les édifices carolingiens, de façon à contribuer à l'identification des remplois de briques romaines.

De façon plus surprenante, l'Époque moderne est également mal renseignée et les données issues d'études de bâti trop rares. Il faudrait tenter de préciser les usages de la brique à la fin du Moyen Âge afin de savoir si la brique attend réellement le début du XIX ${ }^{e}$ siècle pour se généraliser.

Malgré ces limites, un catalogue typologique permettant d'identifier les matériaux commence à se construire, et une grille d'évolution typo-chronologique voit le jour pour certains d'entre eux. Au travers de ces données, c'est une véritable histoire régionale de ces matériaux qui commence à se dessiner sur le temps long. Cette histoire complexe mêle des questions strictement techniques à des considérations culturelles, sociales et économiques. Objets d'étude à part entière, ces matériaux montrent comment l'histoire des techniques architecturales est intimement liée à celles, plus larges, de l'économie et des sociétés.

\section{Remerciements}

Merci à toutes les personnes qui ont, d'une façon ou d'une autre, collaborées à ce projet : L. Barthet, C. Québriac, $N$. Lemoine (musée départemental T. Dobrée, Nantes), M. Laurens-Berge, C. Le Boulaire, F. Mercier (direction de l'Archéologie et des Patrimoines, ville de Nantes), A. Valais, E. Peytremann, S. Augry, L. Pirault, F. Guérin, P. Forré, F. Le Roux, E. Mare, E. Coffineau, S. Thébaud, V. Poinsignon (Inrap), A. Rémy (service archéologique départemental du Maine-et-Loire) et H. Meunier (Capra).

\section{Bibliographie}

Alix C. et Epaud F. (dir.), 2013 - La construction en pan de bois au Moyen Âge et à la Renaissance, Tours/Rennes, PUFR/PUR, $450 \mathrm{p}$.

Aumard S., Cailleaux D., Durnecker L., Leriche A. et Weber A., 2009 - «Tuiles glaçurées et toitures ornées des édifices gothiques du Nord de la Bourgogne. Premiers résultats des enquêtes sur les couvertures anciennes des cathédrales de Sens et Auxerre (Yonne) ", in Chapelot J. et al., Terres cuites architecturales médiévales et modernes, Caen, CRAHM, p. 325-338.

Bauchet J.-P. et Naveau J., 1991 - « Mobilier et matériaux de construction provenant des fouilles d'Entrammes ", in Les thermes romains d'Entrammes, La Mayenne : Archéologie, Histoire, supplément $n^{\circ} 1$, p. 151-160.

BAYLÉ M., 1997 - « La brique dans l'architecture préromane et romane de Normandie ", in Material culture in Medieval Europe, Papers of the Medieval Europe Brugge 1997 Conference, Vol. 7, p. 445-450.

Blaising J.-M., 2012 - " Tuiles à crochet, ancêtres gothiques des tuiles canal?", Archeologia Mosellana, 8, p. 81-84.

Boissière J. et Delaval A., 1995 - "L'évolution des types de charpente en Bas-Poitou ", in Le bois dans l'architecture, coll. "Entretiens du Patrimoine; 14 ", p. 81-88.

Brodeur J., Chevet P., Daudin L., Mastrolorenzo J., Morera I. et Mortreau M., 1997 - Angers (Maine-et-Loire) Château d'Angers. Fouille des jardins du quadrilatère et de la terrasse du Logis Royal. Volume 2 : l'occupation des origines à l'arrivée des comtes d'Anjou, Rapport de fouille archéologique, Afan GO, $129 \mathrm{p}$.

Brut C., 2009 - "Les tuiles médiévales parisiennes ", in Chapelot J. et al., Terres cuites architecturales médiévales et modernes, Caen, CRAHM, p. 407-416.

Burnouf J., Maire J., Rieb J.-P., Schellmanns R. et Seiler M., 1986 - « Les matériaux de construction en terre cuite en Alsace au Moyen Âge : tuiles, briques, carreaux, poterie de poêle ", in Terres cuites architecturales au Moyen Âge, Mémoires de la commission départementale d'Histoire et d'Archéologie du Pas-de-Calais, tome XXII, Arras, p. 94-107.

Calderoni P., Guillot B. et Le Cain B. - «Aspects techniques de la construction en pans de bois (fin XIII ${ }^{\mathrm{e}}$ siècle $/ \mathrm{XV}^{\mathrm{e}}$ siècle) d'après plusieurs découvertes archéologiques en milieu urbain (Rouen, Harfleur, Louviers, Évreux) ". Histoire/dossiers, La construction en pans de bois. Société d'Études Diverses de Louviers et de sa région. http://sedlouviers.pagespersoorange.fr/histoire/dossiers/pcalderoni/pcaldero.htm [consulté le 2 février 2013.]

Cayla P., 2003 - «La marine de l'ardoise ", La Loire, 303, Arts, Recherches et Création, n75, Nantes, p. 66-73.

Chapelot O., 2004 - « La terre cuite architecturale dans le bâtiment médiéval ", in BEsSAC et al., La construction : les matériaux durs : pierre et terre cuite, éd. augm., Paris, Errance, (Archéologiques), p. 149-167.

Chapelot J., Chapelot O. et Rieth B. (dir.), 2009 - Terres cuites architecturales médiévales et modernes, Caen, CRAHM, $454 \mathrm{p}$.

Charlier F., 1994 - « Soirans-Fouffrans, la Tuilerie (Côte-d'Or) : un atelier de terre cuite, $\mathrm{XV}^{\mathrm{e}}-\mathrm{XVII}^{\mathrm{e}}$ siècles ", Archéologie médiévale, Tome XXIV, p. 301-366. 
Chaumont R., 1991 - «Une particularité architecturale : la toiture en tuiles du Baugeois (Maine-et-Loire) ", Les Cahiers du Baugeois, $\mathrm{n}^{\circ}$ 9, p. 51-61.

Chauveau C., 2012 - La Garnache - Butte Cavalière et Château, Fouille programmée triannuelle 2011-2013, rapport intermédiaire 2011, SRA Pays de la Loire.

Costa D., 1964 - Art mérovingien, Musée T. Dobrée Nantes, Paris, (Inv. coll. publ. françaises, 10).

DAVY C., 1995 - «Un cas de tuile baugeoise à Saint-Jean-Baptiste de Château-Gontier au XI ${ }^{\mathrm{e}}$ siècle ", La Mayenne, Archéologie, Histoire, 18, p. 117-125.

De Filippo R., 2004 - «La brique et les matériaux de construction en terre cuite à l'époque romaine ", in BESSAC J.-C. et al., La construction, Les matériaux durs : pierre et terre cuite, Paris, Errance, p. 97-116.

De Montjoye A., 2003 - «La maison médiévale en brique (XII $\mathrm{XIV}^{\mathrm{e}}$ siècles) en France méridionale ", Société archéologique du midi de la France, p. 109-128.

De Waha M., 1986 - "Aux origines de l'architecture de briques en Hainaut ", in Terres cuites architecturales au Moyen Âge, Mémoires de la Commission départementale d'Histoire et d'Archéologie du Pas-de-Calais, tome XXII, Arras, p. 52-59.

Delaval A., 2011 - "Les charpentes en Pays de Loire. ", in Hoffsummer P. (dir.), Les charpentes $d u \mathrm{XI}^{\mathrm{e}}$ au $\mathrm{XIX}^{\mathrm{e}}$ siècle Grand Ouest de la France, Architectura Medii Aevi (5), p. 269277.

Demandrille P. et Cambou G., 2008 - Traité de couverture, Paris, Charles Massin (éd.), 522 p.

Duval N., Picard J.-C., Fontaine J., Février P.-A. et Barruol G., 1991 - Naissance des arts chrétiens, La Documentation française, $434 \mathrm{p}$.

EPAud F., 2007 - De la charpente romane à la charpente gothique en Normandie, Caen, Publications du CRAHM, 609 p.

Forré P. et Jolin N., 2006 - «Données complémentaires sur les couvertures en tuiles à ergot ", Feuillets mensuels de la Société nantaise de préhistoire, $\mathrm{n}^{\circ} 438,50^{\mathrm{e}}$ année, p. 38-41.

Giraud-Labalte C., 1984 - Matériaux de couverture en pays bangeois, Étude commandée par la direction du Patrimoine, Nantes, 57 p.

Goulpeau L., 1988 - «Introduction à une étude métrologique des tuiles et briques gallo-romaines ", Revue Archéologique de l'Ouest, 5, p. 97-107.

Goutal M., 1996 - «Tuiles creuses sur fortes pentes en Lorraine », Bulletin monumental, Tome 15, p. 16-17.

GuérIn F., 2001 - Saint-Fulgent "La Petite Valinière " (Vendée), Rapport de fouille archéologique, Cesson-Sévigné, Afan GO, $109 \mathrm{p}$.

Guibert P., Sapin C., Blain S., Baylé M., Lanos P. et al., 2007 - Les terres cuites architecturales comme sources d'information chronologique et technique des édifices avant l'an mil, Premier colloque francophone sur l'histoire de la construction, Paris, France. Ed. Picard, p. 421-428.

Guibert P., 2014, avec la coll. de Bailiff I., BaYlé M., Blain S., Bouvier A., Büttner S., Chauvin A., Dufresne P., Gueli A., Lanos P., Martini M., Prigent D., Sapin C., Sibilia E. et Troja O. - « L'apport des méthodes de datation physique à la caractérisation et à la datation de matériaux de construction et de structures architecturales : un bilan et des perspectives ", in Bolle C., Coura G. et Léotard J.-M., (dir.), L'archéologie des bâtiments en question. Un outil pour les connaître, les conserver et les restaurer, actes du colloque ICOMOS de Liège, 9-10 novembre 2010, p. 115-123.

Guillier G., 2013 - Neuville-sur-Sarthe (Sarthe), Le Chapeau : le sanctuaire gaulois et gallo-romain du Chapeau à Neuville-surSarthe, Rapport de fouille archéologique, Cesson-Sévigné, Inrap GO, 430 p.

Hoffsummer P., 2011 - Les charpentes du $\mathrm{XI}^{\mathrm{e}}$ au $\mathrm{XIX}^{\mathrm{e}}$ siècle - Grand Ouest de la France, Architectura Medii Aevi (5), 385 p.

Hunot J.-Y., 2011 - « La couverture d'ardoise en Anjou, quelques témoignages archéologiques ", in Hoffsummer P. (dir.), Les charpentes $d u \mathrm{XI}^{\mathrm{e}}$ au $\mathrm{XIX}^{\mathrm{e}}$ siècle - Grand Ouest de la France, Architectura Medii Aevi (5), p. 219-232.

Hunot J.-Y. Ет Gú́RIN J., 2007 - « Couverture de tuiles creuses du XII ${ }^{\mathrm{e}}$ siècle et charpentes médiévales en Anjou ", Bulletin monumental, t. 165-3, p. 235-248.

JEAN S., 1981 - L'architecture rurale française, Poitou, pays charentais, Musée national des arts et traditions populaires, Paris.

JEANNIN Y. et Bonvalot N., 2009 - «Terres cuites architecturales en Franche-Comté : un aperçu de la question ", in CHApelot J. et al., Terres cuites architecturales médiévales et modernes, Caen, CRAHM, p. 351-384.

Jeremic M., 1997 - « L'évolution du format des briques sur le territoire de la Serbie, de l'Antiquité au Moyen Âge ", Mélanges de l'École française de Rome. Moyen Âge, Temps modernes, T. 109, $\mathrm{n}^{\circ} 1 . \mathrm{p} .7-20$.

Jesset S., 2014 - «La production de terre cuite architecturale durant le haut Moyen Âge à Saran (Loiret) : entre tradition et modernité ", SFECAG, Actes du Congrès de Chartres, p. 177196.

Le Bohec Y., 1983 - "Les marques sur briques de Jublains. Recherches de chronologie relative sur le complexe fortifié ", in Armée romaine et province, III, p. 88-94.

Le Guern C. et Coulon A., 2009 - Cartographie de l'aléa retrait gonflement des sols argileux dans le département de LoireAtlantique. Rapport BRGM/RP-56818-FR. BRGM, 131 p.

Lebouteux P., 200 I - Traité de couverture traditionnelle, H. Vial éd, $320 \mathrm{p}$.

LEVESQUe R., I995 - Fenêtre sur combles, catalogue de l'exposition "Fenêtre sur combles ", présentée au logis de la Chabotterie, à Saint-Sulpice-le-Verdon (commissaire de l'exposition et auteur du catalogue), Conseil général de Vendée, 76 p. 
Lotton A.-M. et Pirault L., 2007 - « L'ancienne église SaintMédard de Doulon ", Bulletin de la Société Archéologique et historique de Nantes et de la Loire-Atlantique, Vol. 142, p. 99-113.

Martineau J. avec la coll. de Bellanger P. et Cornec J., 2007 Château de Châteaubriant, Chapelle castrale (Loire-Atlantique), Rapport de fouille archéologique, Cesson-Sévigné, Inrap GO, 120 p.

Maufus M.-C., 1983 - « Le décor architectural en terre cuite dans la région nantaise, pendant l'Antiquité tardive ", in BARRAL I Altet X. et al., Artistes, artisans et production artistique en Bretagne au Moyen Âge, Rennes, p. 173-177.

Meunier H., 2014 - Le logis abbatial de l'abbaye de L'Épau, Yvrél'Évêque (72), Nantes, DRAC Pays de la Loire.

Meuret J.-C., 1998 - "Construction et habitat aux confins Anjou-Bretagne du XI ${ }^{\mathrm{e}}$ au $\mathrm{Xv}^{\mathrm{e}}$. Des textes au terrain ", in Prigent D. et Tonnerre N.-Y., La construction en Anjou au Moyen Âge. Actes de la table ronde d'Angers des 29 et 30 mars 1996, Angers, Presse de l'Université d'Angers, p. 141-176.

Meuret J.-C., 2012 - « Les premières cheminées dans les Pays de la Loire ", Histoires de cheminées, 303, n 124, p. 16-31.

Nauleau J.-F., 2009 - "Les matériaux de couverture en terre cuite ", in Valais A., Précigné (Sarthe) Manoir du PlessisRoland, Rapport de diagnostic archéologique, Cesson-Sévigné, Inrap GO, p. 33-42.

Nauleau J.-F., 2009b - Nantes (Loire-Atlantique), ZAC ErdrePorterie, Tranche 2, Rapport de diagnostic, Cesson-Sévigné, Inrap GO, 163 p.

NAUleau J.-F., 2012 - «Les matériaux de couverture antiques et médiévaux ", in Valais A., Carquefou, Loire-Atlantique ZAC de la Haute Forêt, tranche II, Rapport de fouille archéologique, Cesson-Sévigné, Inrap GO, p. 244-249.

Nauleau J.-F., 2013a - "Les matériaux de construction en terre cuite d'époque romaine dans l'ouest des Pays de la Loire. Premier bilan ", Revue Archéologique de l'Ouest, 30, p. 223-259.

Nauleau J.-F., 2013b - "Étude des terres cuites architecturales ", in Le Guevellou R., Beaupréau, Parc d'activités Anjou-Actiparc Centre Mauges, tranche 2, Maine-et-Loire, Rapport de diagnostic archéologique, Cesson-Sévigné, Inrap GO, p. 53-60.

Nauleau J.-F., 2013c - "Les matériaux de construction en terre cuite ", in Valais A., Juigné-sur-Sarthe (Sarthe) Les Touches, Rapport de fouille archéologique, Cesson-Sévigné, Inrap GO, p. 116-131.

Nauleau J.-F., 2013d - Saint-Viaud, Loire-Atlantique, ZAC Multisites La Miraudais - Le Petit Bois, Rapport de diagnostic, Cesson-Sévigné, Inrap GO, 91 p.

Nauleau J.-F., 2013e - " Les terres cuites architecturales ", in GuÉrin F., Saint-Corneille, "La Chapelle », Sarthe, Rapport de fouille archéologique, Cesson-Sévigné, Inrap GO, p. 139-149.

Nauleau J.-F., 2013f - " Les matériaux de construction en terre cuite ", in Le Roux F., La Milesse (Sarthe), La Ronce, LGVBPL section 17, Rapport de fouille archéologique, Cesson-Sévigné, Inrap GO, p. 211-223.

Nauleau J.-F., 2014a - "Les terres cuites architecturales ", in Brodeur J. et al., Angers (Maine-et-Loire) Clinique Saint-Louis, Rapport de fouille archéologique, Inrap GO, Cesson-Sévigné, Volume II : Les études, p. 315-352.

Nauleau J.-F., 2014b - « Le mobilier en terre cuite », in Mare E., Coulans-sur-Gée, Les Nouis, Rapport de fouille archéologique, Cesson-Sévigné, Inrap GO, 175 p. 92-96.

Nauleau J.-F., 2014c - « Les matériaux de construction en terre cuite ", in Augry S. et al., Nantes (Loire-Atlantique) NeptuneBouffay. Evolution du front sud de la ville historique entre Loire et espace urbain. Rapport de fouille archéologique. CessonSévigné : Inrap GO, tome 3, études spécialisées, p. 133-146.

Nauleau J.-F., 2015 - «Les matériaux de construction en terre cuite ", in Dubillot X. et al., Ancenis, Le Pâtis 1 : une ferme mérovingienne et des aménagements agraires de la fin du Moyen Âge, Inrap GO, Cesson-Sévigné.

Nauleau J.-F., 2016 - " Les matériaux de construction en terre cuite et les ardoises de couverture ", in Augry S. et al., Le Mans, fouille de la Place du jet d'eau, Inrap GO, Cesson-Sévigné.

Nauleau J.-F., 2016 - « Beaupréau (49), "La Tufferie” : Un atelier de tuilier-briquetier médiéval dans les Mauges ", RAO, $\mathrm{n}^{\circ} 33$, p. 245-278.

NAVEAU J., 1984 - « La céramique à œil de perdrix et la production de La Hardelière à Laval (Mayenne) ", Archéologie médiévale, Tome XIV, p. 169-219.

Pascal J., Bonnin N. et Leblanc P., 2007 - Château des ducs de Bretagne, cour du château (Loire-Atlantique), Rapport de fouille archéologique, Cesson-Sévigné, Inrap GO, 391 p.

Pastoureau M., 2004 - Une histoire symbolique du Moyen Âge occidental, La librairie du Xxi ${ }^{\mathrm{e}}$ siècle, Seuil, $450 \mathrm{p}$.

Perin P., 1986 - « Terres cuites architecturales du haut Moyen Âge trouvées à Paris ", in Terres cuites architecturales au Moyen Âge, Mémoires de la Commission départementale d'Histoire et d'Archéologie du Pas-de-Calais, tome XXII, Arras, p. 9-16.

Pirault L., 2002 - La Tannière, Rezé (Loire-Atlantique), Rapport de fouille programmée, Cesson-Sévigné, Inrap GO, 45 p.

Pirault L., 2004 - Saint-Jean-de-Linières, La Forêterie, La Boisnière, Maine-et-Loire, Rapport de diagnostic, CessonSévigné, Inrap GO, n. p.

Ravoire F., 2009 - «Études de quelques lots de tuiles médiévales et modernes provenant de Paris, Blandy-les-Tours (Seine-etMarne) et Roissy-en-France (Val d'Oise) ", in Chapelot J. et al., Terres cuites architecturales médiévales et modernes, Caen, CRAHM, p. 393-405.

Rémy A., 2014 - Juigné-sur-Loire, Saint-Melaine-sur-Aubance, Maine-et-Loire, Le Beyen, la Conroye, rapport de fouille archéologique préventive, Service de l'archéologie du conseil général de Maine-et-Loire, 254 p. + annexes. 
Renoux A., 1991 - Fécamp, du palais ducal au palais de Dieu, Paris, éditions du CNRS, p. 453-455.

Valais A., 1998 - «Les premiers édifices romans du nord de l'Anjou : techniques de construction et éléments de chronologie. ", in Prigent D. et Tonnerre N.-Y., La construction en Anjou au Moyen Âge. Actes de la table ronde d'Angers des 29 et 30 mars 1996, Presse de l'Université d'Angers, p. 55-75.
Valais A., 2006 - Courgains, La Colinière (Sarthe), Rapport de diagnostic, Cesson-Sévigné, Inrap GO, 28 p.

VAlAis A., 2012 - L'habitat rural au Moyen Âge dans le nord-ouest de la France. Tome 2 : Les notices, Rennes, PUR, 462 p.

VIau Y., 2006 - Golf de Baugé, Pontigné - Les Bordes (Maine-etLoire), Rapport de diagnostic, Cesson-Sévigné, Inrap GO, $73 \mathrm{p}$.

Zusammenfassung: Die Ziegel und Backsteine des Mittelalters in der Region Pays de la Loire : Bemerkungen zum aktuellen Forschungsstand - Die Baumaterialen aus gebranntem Ton sind in der Region Pays de la Loire während des Mittelalters und der Neuzeit gut vertreten. Gleich ob es sich um Dachziegel, Backsteine, Bodenkacheln oder andere wichtige Bauelemente handelt, besaßen Werksteine aus gebranntem Ton große Bedeutung, insbesondere seit dem 12.-13. Jahrhundert n. Chr. Die ausführliche Untersuchung dieser Baumaterialen gestattet es, sie näher anzusprechen und zu charakterisieren, sowie ihren Platz und ihre Verwendung in den Bauten näher zu untersuchen. Für einige dieser Baumaterialien kann anhand ihrer morphologischen Entwicklung eine Typochronologie aufgestellt werden, die für die archäologische Forschung große Bedeutung besitzt. Insgesamt betrachtet ermöglicht diese Studie, die einen langen Zeitraum umfasst, Phasen der intensiven Nutzung dieser Baumaterialien und Phasen ihres Rückgangs herauszustellen, die anschließend interpretiert und verstanden werden müssen.

Im Rahmen eines umfassenden Verständnisses müssen dabei natürliche, wirtschaftliche, soziale und kulturelle Faktoren berücksichtigt werden, die bei der Wahl und der Nutzung von Baumaterialien aus gebranntem Ton eine Rolle gespielt haben und die ihre Bevorzugung gegenüber anderen in der Region reich vertretenen Baumaterialien wie Granit, Tuffstein und Schiefer erklären.

Schlüsselwörter: Mittelalter, Baumaterial, Architektur, Ziegel, Backstein, Geologie, Ton, Klima. 